INSTITUTO DE PESQUISAS ENERGÉTICAS E NUCLEARES

Autarquia associada à Universidade de São Paulo

\title{
AVALIAÇÃO DOSIMÉTRICA DA SOLUÇÃO FRICKE GEL USANDO A TÉCNICA DE ESPECTROFOTOMETRIA PARA APLICAÇÃO NA DOSIMETRIA DE ELÉTRONS E NÊUTRONS
}

Thyago Fressatti Mangueira

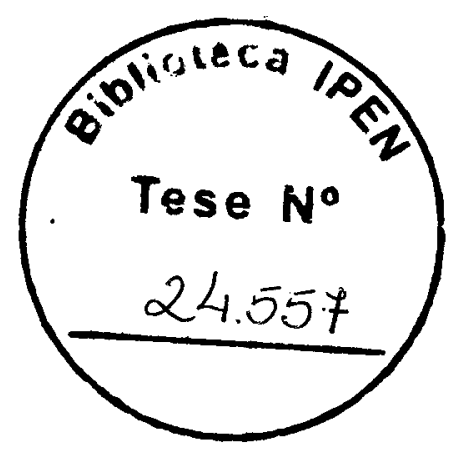

\begin{abstract}
Dissertação apresentada como parte dos requisitos para obtenção do Grau de Mestre em Ciências na Área de Tecnologia Nuclear - Aplicações.
\end{abstract}

Orientadora:

Dra. Letícia L. C. Rodrigues 
Aos meus pais, Edna e Ivaldo, que mesmo longe foram fundamentais em cada passo da minha vida acadêmica. 


\section{AGRADECIMENTOS}

À minha orientadora, Dra. Letícia L. C. Rodrigues, pela confiança, credibilidade, paciência, amizade e por todas as oportunidades de crescimento que me proporcionou durante a orientação do mestrado.

Ao IPEN, na pessoa do Sr. Superintendente, Dr. Nilson Dias Vieira Junior, pela oportunidade de executar este trabalho.

À Comissão Nacional de Energia Nuclear (CNEN), Fundação de Amparo à Pesquisa do Estado de São Paulo (FAPESP), Conselho Nacional do Desenvolvimento Científico e Tecnológico (CNPq) e à Coordenação de Aperfeiçoamento de Pessoal de Nivel Superior (CAPES) pelo auxílio financeiro que permitiu minha total dedicação ao trabalho de pesquisa.

À minha namorada Juliana Rosada Dias, que além do amor e companheirismo demonstrado foi uma grande fonte de esclarecimentos $e$ referências sobre as lacunas da dosimetria em radioterapia e discussões sobre as possíveis aplicações deste trabalho na rotina de um hospital.

À Dra. Linda V. E. Caldas, sempre muito compreensiva e prestativa.

Ao Dr. Paulo Rogério Pinto Coelho, pela disponibilidade, interesse, colaboração e atenção durante irradiações no $\mathrm{BH \# 3}$ do Reator de Pesquisa do IPEN e discussões a respeito dos resultados obtidos.

À Dra. Laura Natal Rodrigues, ao físico Marcelo Ribeiro Piciolli, à Dra. Maria Esmeralda Ramos Poli e aos demais aprimorandos e funcionários da Divisão de Oncologia do Instituto de Radiologia (InRad) do Hospital das Clínicas (HC) da Faculdade de Medicina da Universidade de São Paulo (FM-USP), pela disponibilidade não apenas dos equipamentos mas também de seu precioso tempo acompanhando cada irradiação, pelo auxilio em todas as dúvidas e principalmente pela amizade. 
Ao fisico Homero Lavieri Martins, à física Karina Waiswol Boccaletti, aos demais físicos, aprimorandos e funcionários do setor de Radioterapia do Hospital A. C. Camargo, pelo tempo e pelos equipamentos disponibilizados.

À Sra Donata Celicea de O. Zanin, pela amizade, companheirismo e auxílio em cada passo burocrático.

Ao Eng. Carlos G. da Silveira è̀ Eng. Elizabeth S.R. Somessari, do Centro de Tecnologia das Radiações (CTR), pelo auxilio durante as irradiações, pelo tempo disponibilizado, por todos os esclarecimentos e amizade.

A todos os alunos e funcionários do GMR, que de maneira direta ou indireta contribuiram para a realização deste trabalho.

Aos meus mais que amigos, meus "irmãos" de orientação, Maira, pela amizade construída, pelas inúmeras caronas, lições e correções de inglês; Eduardo que ainda falta acertar a escola de samba a qual me chama no lugar do nome; e Cléber que compartilhou de quase todos os experimentos apresentados nesta dissertação e acabou se tornando não apenas um grande companheiro de trabalho, mas também um grande amigo.

À Dra. Adelaide de Almeida, ao Dr. Lucas Nonato de Oliveira e ao M.Sc. Marcos Vasques Moreira, não apenas por minha iniciação na vida acadêmica, mas também pelo apoio e amizade.

A toda a minha família, em especial minhas tias Bete e Elaine e minha avó Maria e aos meus sogros Valter e Maria Inês, cujo apoio sempre foi fundamental na minha carreira acadêmica e em minha vida.

A todos os amigos, pela paciência, compreensão e apoio, em especial ao Kleber Bessa que por afinidade considero um irmão de sangue e ao Eric e à Maira Tiemi, grandes amigos e companheiros de estudos desde quando eu era ainda um graduando. 


\title{
AVALIAÇÃO DOSIMÉTRICA DA SOLUÇÃO FRICKE GEL USANDO A TÉCNICA DE ESPECTROFOTOMETRIA PARA APLICAÇÃO NA DOSIMETRIA DE ELÉTRONS E NÊUTRONS
}

\author{
Thyago Fressatti Mangueira
}

\section{RESUMO}

Neste trabalho as principais características dosímetricas da solução Fricke Xilenol Gel ( $F X G$ ) foram estabelecidas para futura aplicação clínica na dosimetria de elétrons. As curvas de dose resposta para feixes de nêutrons térmicos para pesquisa em Terapia por Captura de Nêutrons (BNCT) e feixes elétrons de aplicação industrial também foram determinadas. A técnica padrão de leitura utilizada foi espectrofotometria. Para o feixe clínico as reprodutibilidades intra e inter-lotes da solução FXG são melhores que $1,4 \%$ e $5,1 \%$ respectivamente, o comportamento da resposta para o intervalo de dose entre 0,2 e 40 Gy é linear e independente da energia e da taxa de dose para o intervalo estudado. Devido aos efeitos da oxidação natural do FXG o tempo ótimo entre o preparo e a irradiação é de $24 \mathrm{~h}$ e o comportamento da curva de dose resposta não se altera no período estudado para a variação da absorvância líquida do dosímetro. Para o estudo com o campo de nêutrons as curvas de dose resposta do FXG apresentaram comportamento linear em todo intervalo de dose estudado, e para campos industriais de elétrons o comportamento é exponencial decrescente. De acordo com os resultados obtidos para os feixes de radiação estudados, não houve alteração na posição das bandas características do espectro de absorção do FXG. Como testes adicionais, foi determinada a viabilidade do uso do método de leitura do FXG por imagens fotográficas digitais e aplicação do FXG na dosimetria para braquiterapia intracavitária. O bom desempenho do dosímetro FXG nos testes realizados indica que este pode ser utilizado na avaliação tridimensional da dose em tratamento radioterápicos. 


\title{
DOSIMETRIC EVALUATION OF THE FRICKE GEL DOSIMETER USING THE SPECTROPHOTOMETRIC TECHNIQUE FOR APPLICATION IN ELECTRON AND NEUTRON DOSIMETRY
}

\section{Thyago Fressatti Mangueira}

\begin{abstract}
In this work the main dosimetric characteristics of the Fricke Xylenol Gel (FXG) solution were established for further application in the measurement of dose distribution of clinical electron fields. The dose-response curves of the FXG in a neutron field were also evaluated for the research in Boron Neutron Capture Therapy (BNCT) and industrial electron fields. The standard reading technique was the spectrophotometric. For the clinical field, the intra and inter-batch reproducibility are better than $1.4 \%$ and $5.1 \%$, respectively, the response presents a linear behavior for doses ranging from 0.2 to $40 \mathrm{~Gy}$ independently of the energy and the dose rate in the studied ranges. Due to the effects of the FXG natural oxidation, the optimum elapsed time between FXG preparation and irradiation was established as $24 \mathrm{~h}$ period and the behavior of the dose-response curve of the FXG using the variation in the absorbance relative to the non-irradiated dosimeter as a basis during the whole studied period were not altered. The dose-response to the industrial electron beam presented an exponential decreasing behavior and the neutron beam for research in BNCT presented a linear behavior for the complete studied dose range. According to the obtained results for the different types of radiation studied for the FXG, there was no change in the position of the characteristic bands of the absorption spectrum due to the interaction of these radiation types. Additional tests were performed to determine the digital photographic imaging of FXG analyses viability and the application of FXG dosimetry on intracavitary brachytherapy. The good performance of the FXG dosimeter in the tests that were carried out indicates that this dosimeter may be applied to the tri-dimensional dose evaluation in radiotherapic treatments using electrons and neutron beams.
\end{abstract}




\section{SUMÁRIO}

Página

AGRADECIMENTOS

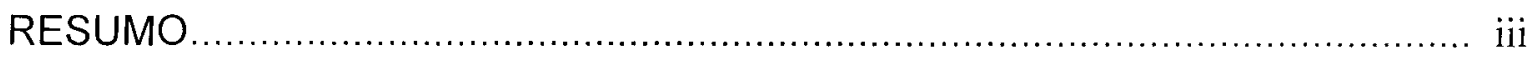

ABSTRACT

1. INTRODUÇÃO

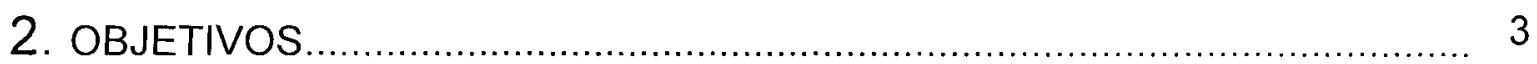

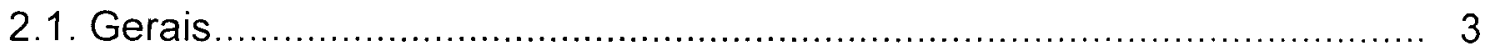

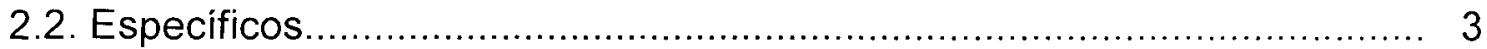

3. FUNDAMENTOS TEÓRICOS............................................................... 4

3.1. Grandezas e parâmetros dosimétricos ............................................... 4

3.1.1. Código de práticas para dosimetria de feixes de fótons e elétrons

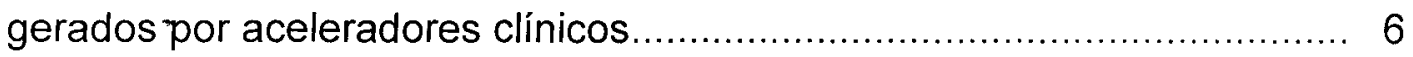

3.2. Fonte de elétrons de megavoltagem ................................................. 7

3.2.1. Aceleradores lineares clínicos........................................................ 7

3.2.2. Aceleradores lineares industriais............................................... 8

3.2.3. Interação do feixe de elétrons de megavoltagem com a matéria.... 9

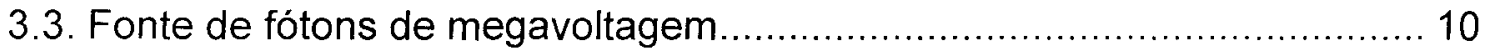

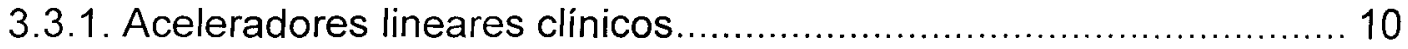

3.3.2. Fonte de radiação gama tipo Gammacell.................................. 11

3.3.3. Interação do feixe de fótons com a matéria................................... 12

3.4. Fonte de nêutrons para pesquisa em BNCT ....................................... 12

3.4.1. Interação dos nêutrons com a matéria.......................................... 13

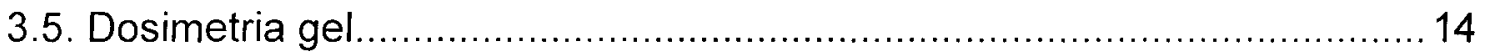

3.5.1. Dosímetro Fricke Xilenol Gel (FXG) ....................................... 15 


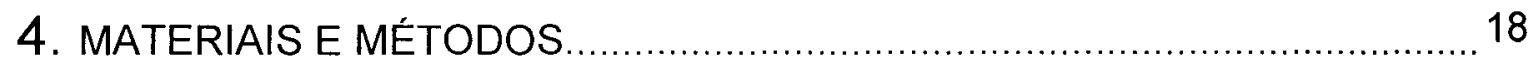

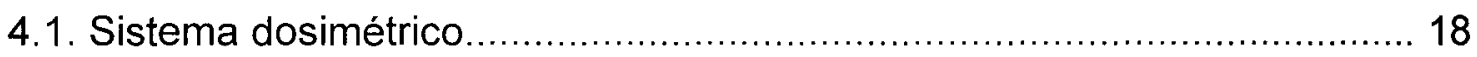

4.1.1. Preparo, manuseio e transporte do dosímetro FXG ....................... 18

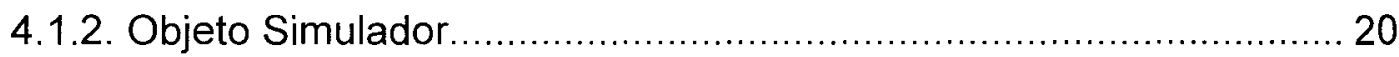

4.1.3. Sistema de leitura e análise dos dados ..................................... 22

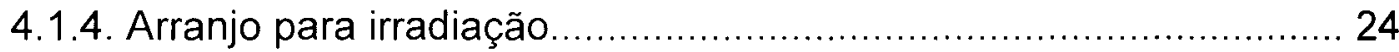

4.2. Fontes de radiação ionizante e arranjo experimental................................24

4.2.1. Acelerador linear Varian Clinac 2100-C ................................... 24

4.2.2. Acelerador de elétrons Dynamitron Job 188................................25

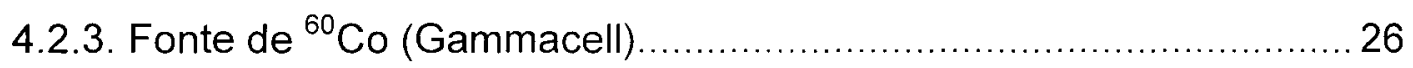

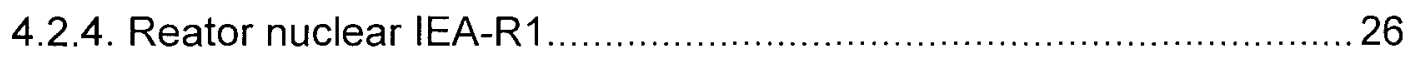

4.3. Testes de desempenho do dosímetro FXG................................... 28

4.3.1. Espectro de absorção ótica do FXG irradiado com feixes clínicos de elétrons e nêutrons e feixe industrial de elétrons................................28

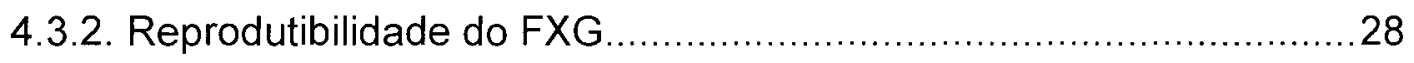

4.3.3. Curvas de dose resposta 28

4.3.3.1. Curvas de dose resposta para acelerador

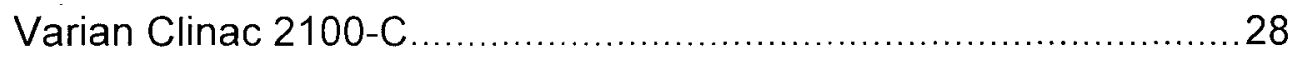

4.3.3.2. Curvas de dose resposta para acelerador

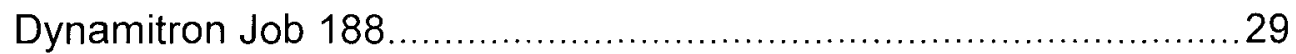

4.3.3.3. Curvas de dose resposta para reator nuclear

IEA-R1

4.3.4. Limite inferior e superior de detecção para feixes clínicos de elétrons.

4.3.5. Dependência energética da resposta para feixes clínicos de elétrons.

4.3.6. Dependência da resposta com a taxa de dose para feixes clínicos de elétrons. 30

4.3.7. Variação da absorvância em função do tempo (estabilidade).......... 30

4.4. Sistema alternativo de leitura.

4.5. Aplicação do dosimetro $F X G$ em dosimetria 3D para Braquiterapia de alta taxa de dose 


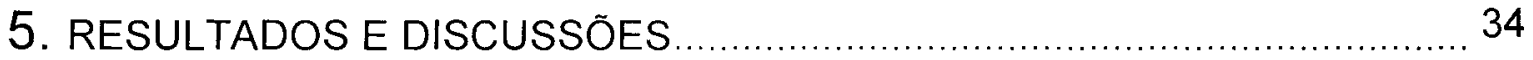

5.1. Espectro de absorção ótica do FXG irradiado com feixes clinicos de 34 elétrons e nêutrons e feixe industrial de elétrons.

5.2. Reprodutibilidade do FXG..................................................

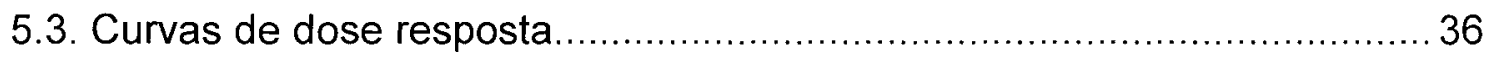

5.3.1. Curvas de dose resposta para feixes de fótons e elétrons do

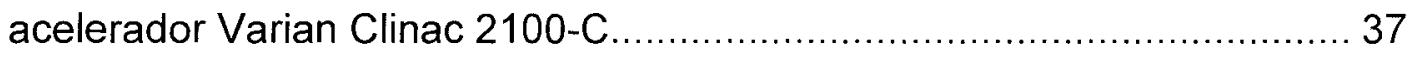

5.3.2. Curvas de dose resposta para acelerador Dynamitron Job 188 _......39

5.3.3. Curvas de dose resposta para reator nuclear IEA-R1 .................... 41

5.4. Limite inferior e superior de detecção do FXG para feixes clinicos de elétrons.

5.5. Dependência energética da resposta do dosímetro FXG para feixes clínicos de elétrons.

5.6. Dependência da resposta do dosímetro FXG com a taxa de dose para feixes clínicos de elétrons. 45

5.7. Variação da absrovância em função do tempo (estabilidade).................... 46

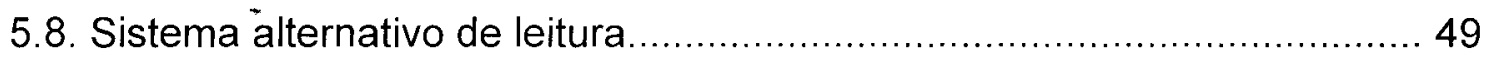

5.9. Aplicação do dosímetro $F X G$ em dosimetria 3D para Braquiterapia de alta taxa de dose .52

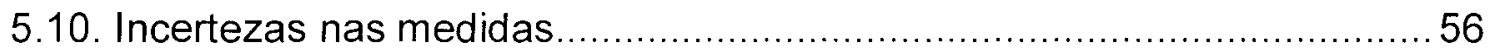

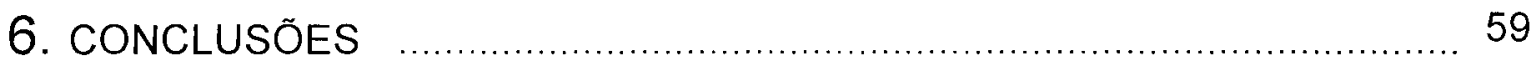

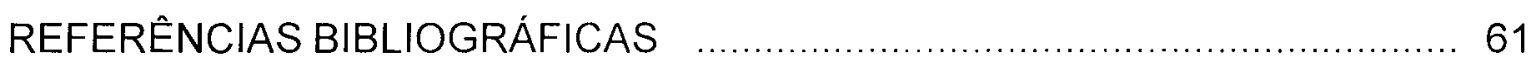




\section{LISTA DE TABELAS}

Página

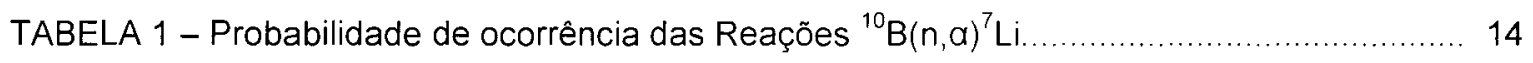

TABELA 2 - Composição química do dosimetro FXG desenvolvido no IPEN ......................... 19

TABELA 3 - Parâmetros de medida do espectrofotômetro Shimadzu UV-2101 PC …............... 23

TABELA 4 - Profundidade de dose máxima $R_{100}$, espessura de água sólida sobre o suporte e energia nominal dos feixes gerados pelos Clinac 2100-C para um campo $10 \times 10 \mathrm{~cm}^{2}$.

TABELA 5 - Coeficientes do ajuste linear da curva de dose resposta para fótons e elétrons de 6 e $15 \mathrm{MeV}$

TABELA 6 - Variação porcentual para a leitura do dosimetro FXG para uma mesma dose entre as curvas de dose resposta do FXG para fótons e elétrons.

TABELA 7 - Coeficiente angular, LID e LSD para feixes clínicos de elétrons em função da energia nominal

TABELA 8 - Coeficientes do ajuste linear da curva de dose resposta do FXG para irradiações com elétrons mensurada em diferentes tempos após a irradiação.

TABELA 9 - Coeficientes do ajuste linear da curva de dose resposta do FXG para irradiações com elétrons em diferentes tempos após o preparo. 


\section{LISTA DE FIGURAS}

\section{Página}

FIGURA 1 - Gráfico indicando as regiões de "build up", EPC e redução da dose com a profundidade a partir de um valor de dose máxima, características de de um feixe de radiação incidente em um meio material (Adaptado de: Thermoluminescent Dosimetry, JR Cameron).

FIGURA 2 - Esboço de uma curva de porcentagem de dose profunda para um feixe de elétrons mostrando os pontos de referencia mais importantes. (Adaptado de: Physics of Electron Beam Therapy, SC Klevenhagen)

FIGURA 3 - Acelerador de elétrons Dynamitron Job 188 pertencente ao Centro de Tecnologia das Radiações/IPEN (disponibilizada pelo Engenheiro Carlos G. da Silveira).

FIGURA 4 - Esquema de um Acelerador Linear com os dispositivos modificadores de feixe selecionados para a produção de fótons. (Adaptado de: Folheto de propaganda de aceleradores Varian).

FIGURA 5 - Curva de dose resposta do dosímetro FXG para um feixe clínico de elétrons de $9 \mathrm{MeV}$.

FIGURA 6 - Alteração de cor no dosímetro FXG - da esquerda para direita doses de 0 a 30 Gy em grupos de 3 cubetas.

FIGURA 7 - Cubeta espectrofotométrica padrão (mostrando as dimensões externas). 18

FIGURA 8 - Caixa de isopor com dosimetros FXG acondicionados.

FIGURA 9 - Suporte acrílico com sistema de gaveta, para troca de cubetas sem alterar o arranjo experimental

FIGURA 10 - Objeto simulador utilizado para o posicionamento do suporte entre as placas de água sólida.

FIGURA 11 - Espectro de absorção do dosímetro FXG relativo ao dosimetro não irradiado, para doses de 0,5 a 45 Gy

FIGURA 12 - Objeto simulador mostrando o arranjo experimental.

FIGURA 13 - Arranjo experimental para irradiação na Gammacell pertencente ao CTR.

FIGURA 14 - Esquema em corte horizontal do BH\#3 com o suporte (amostra) completamente inserido.

FIGURA 15 - Aplicador útero-vaginal para braquiterapia intra-cavitária inserido no pote sem o FXG, mostrando os dois ovóides (projetados para o fundo do pote) e a sonda intra-uterina (projetada para a abertura do pote).

FIGURA 16 - Espectro de absorvância do FXG irradiado com feixes clínicos de elétrons para diferentes doses

FIGURA 17 - Absorvância líquida relativa das cubetas não irradiadas de um mesmo lote. 
FIGURA 18 - Absorvância líquida relativa das cubetas não irradiadas para 5 lotes.

FIGURA 19 - Curva de dose resposta do FXG mostrando a aproximação linear qualitativa para várias energias.

FIGURA 20 - Curva de dose resposta do FXG para feixes clínicos de fótons e elétrons.

FIGURA 21 - Curva de dose resposta do FXG para elétrons de 1,499 MeV com largura de feixe de $112 \mathrm{~cm}$, taxa de dose $1,10 \mathrm{kGy} / \mathrm{s}(0,31 \mathrm{~mA})$ e velocidade de bandeja $6,72 \mathrm{~m} / \mathrm{min}$.

FIGURA 22 - Alteração de cor no dosímetro FXG devido a irradiação com feixes industriais de elétrons - da esquerda para direita doses de 1,2,5,10 Gy sendo as 2 primeiras com a mesma dose.

FIGURA 23 - Detalhe das bolhas formadas pela irradiação com feixes industriais de elétrons para doses acima de $5 \mathrm{kGy}$..

FIGURA 24 - Gradiente de cor dentro da cubeta indicando o gradiente de dose previsto pela energia do feixe de elétrons.

FIGURA 25 - Curva de dose resposta do FXG com e sem adição ${ }^{10} \mathrm{~B}$ para ${ }^{60} \mathrm{Co}$.

FIGURA 26 - Curva de dose resposta do FXG com adição ${ }^{10} \mathrm{~B}$ para o feixe misto gamma/nêutron.

FIGURA 27 - Curva de dose resposta do FXG com adição ${ }^{10} \mathrm{~B}$ para nêutrons.

FIGURA 28 - Curva de dose resposta do FXG para determinação do LID e do LSD para feixes padrão de elétrons.

FIGURA 29 - Absorvância liquida relativa para doses absorvidas de 5, 20 e 40 Gy em função da energia nominal do feixe.

FIGURA 30 - Absorvância liquida relativa para um único lote de FXG em função da taxa de dose com campo padrão de elétrons.

FIGURA 31 - Absorvância liquida relativa para 5 lotes de FXG em função da taxa de dose com campo padrão de elétrons.

FIGURA 32 - Variação da média do sinal de dosímetros não irradiados, para um único lote de FXG

FIGURA 33 - Curvas de dose reposta de dosimetros FXG que foi mensurada em diferentes tempos após a irradiação.

FIGURA 34 - Curvas de dose reposta de dosimetros FXG irradiados em diferentes tempos após o preparo.

FIGURA 35 - Dependência da resposta do dosímetro FXG, irradiado com 60Co, em função do tempo após o preparo. 
FIGURA 36 - Imagem fotográfica do dosímetro FXG e Alanina Gel utilizada para análise em rotina computacional, acrescida de uma barra de cores para FXG

FIGURA 37 - Curvas de dose reposta de dosímetros FXG irradiados com elétrons de 9 MeV e doses de 1 a 40 Gy para leitura com CCD.

FIGURA 38 - Comparação entre as intensidades das leituras do dosímetro FXG para os dois sistemas de leitura. As doses analisadas foram 1, 5, 10, 20, 30 e 40 Gy apresentadas no Gráfico em ordem crescente de sinal.

FIGURA 39 - Curvas de isosode geradas pelo software Brachyvision a partir de duas radiografias ortogonais do objeto simulador e da determinação das posições e tempo das paradas da fonte.

FIGURA 40 - Imagem fotográfica do objeto simulador desmontado (sem o pote plástico) após ser posicionado em frente a um negatoscópio.

FIGURA 41 - Imagem fotográfica de um corte do FXG na região próxima ao fim da sonda intra-uterina sendo possivel observar o orifício gerado pela retirada da sonda e também o gradiente de cor no gel gerado pela irradiação.

FIGURA 42 - Imagem fotográfica de um corte do FXG na região que compreende os ovódies sendo possivel observar os três orificios gerados pela retirada do aplicador e também o gradiente de cor no gel gerado pela irradiação.

FIGURA 43 - Composição entre a imagem por RMN e as curvas de isodose calculadas pelo software Brachyvision.

FIGURA 44 - Gráfico gerado no software MATLAB de um corte axial a $1 \mathrm{~mm}$ do final da sonda intra-uterina nas imagens por RMN devido a variação na intensidade do valor dos voxels. 


\section{INTRODUÇÃO}

A aplicação da radiação ionizante na medicina esta amplamente difundida, tanto para diagnóstico (radiodiagnóstico) quanto para terapia (radioterapia). Dependendo do tipo e da energia, a radiação ionizante interage de uma maneira diferente com $\circ$ meio que atravessa, sempre formando pares de íns e conseqüentemente transferindo energia para o meio (Khan, 1994).

Em radioterapia este depósito de energia (dose absorvida) é utilizado para tratar uma série de enfermidades, principalmente cânceres, pois as células cancerosas são mais sensiveis à radiação ionizante (radiossensíveis) do que as células saudáveis. Mesmo com esta diferença na radiossensibilidade deve-se irradiar a menor quantidade de tecido saudável possivel, ao mesmo tempo em que se procura aplicar a dose prescrita pelo médico ao tumor (CNEN, 1990).

Para reduzir a dose absorvida em tecidos saudáveis pode-se utilizar do contato direto das fontes de radiação com a região a ser tratada (braquiterapia) ou 0 uso de diferentes energias e tipos de radiações ionizantes. Para isto novas tecnologias e métodos de tratamento vêm sendo elaborados. Um grande salto nesta evolução da radioterapia foi a utilização de colimadores de feixe do tipo multi-lâminas e a popularização de aceleradores lineares clínicos com várias energias de fótons e elétrons.

Os feixes radioterápicos de elétrons podem, em muitos casos, substituir terapias com Raios-X de quilovoltagem e até mesmo a braquiterapia por moldagens, que continuam sendo utilizadas em alguns serviços de Radioterapia (INCA, 2008). Os tratamentos mais indicados para terapia com feixes de elétrons são lesões com baixo poder de disseminação como: linfomas, tumor de mucosa geniana, vestíbulo nasal, tumores orbitários, tumores de pálpebra, lábio e vulva, além do tratamento adjuvante do plastrão torácico pós-mastectomia, carcinomas epidermóides, meduloblastomas, retinoblastomas, e tumores pediátricos (INCA, 2008; Karzmark, 1993).

Novas modalidades de radioterapia utilizando outras partículas como nêutrons, prótons e íns pesados de energia alta vêm se tornando cada vez mais viáveis com a criação de aceleradores de íons pesados e reatores nucleares de 
pequeno porte voltados para aplicação clínica (Burn 2004; Gambarini, 1997; Nelms, 2008).

A procura por tratamentos com prótons e outros ions é devido ao Pico de Bragg que faz a curva de porcentagem de dose profunda (PDP) ser muito favorável ao tratamento de regiões próximas a órgãos de risco (Kahn,1994; Nelms, 2008).

A terapia com nêutrons, usualmente chamada de BNCT (do inglês Boron Neutron Capture Therapy), faz uso de fármacos $\operatorname{com}{ }^{10} \mathrm{~B}$ que tendem a se concentrar na região de interesse. Como o feixe é colimado, o gradiente de dose depositada sobre o local de tratamento é muito alto, salvaguardando os tecidos saudáveis que estão próximos ou diretamente sobre o feixe de nêutrons. O interesse clínico do BNCT esta no tratamento de tumores de alto risco como gliomas, metástases cerebrais e melanomas primários além de cânceres de figado e "cabeça e pescoço" (Barth, 2005).

Com o uso freqüente destes recursos no tratamento oncológico faz-se necessário o desenvolvimento de técnicas dosimétricas que facilitem a determinação da distribuição de dose de feixes de radiação ionizante com bordas atipicas ou 'aplicados sobre superficies irregulares (Calcina, 2007; Gambarini, 2000; Barth, 2005; Nelms, 2008). A Dosimetria Gel permite estas medições da dose absorvida em três dimensões (3D) em objetos simuladores antropomórficos tecido-equivalentes (Gore, 1984; Day, 1990; MacDougall, 2002; Maryanski, 1993).

$\mathrm{Na}$ correta seleção e utilização de um sistema dosimétrico para uma determinada medição é fundamental o conhecimento das propriedades dosimétricas do sistema utilizado, como os limites mínimo e máximo de detecção do sistema, intervalo de linearidade da resposta com a dose, dependência energética e com a taxa de dose, tempo ótimo para utilização e permanência do sinal entre outros. 


\section{OBJETIVOS}

\subsection{GeRAIS}

Avaliação dosimétrica da solução Fricke Xilenol Gel usando a técnica de espectrofotometria para aplicação clínica na dosimetria de elétrons e nêutrons.

\subsection{ESPECÍFICOS}

- Padronizar o método de obtenção da solução Fricke gel e a sua formulação para aplicação na dosimetria de elétrons e nêutrons;

- Estudar os fatores que podem afetar a resposta do dosímetro gel;

- Realizar testes de desempenho do dosimetro gel em feixes de elétrons tais como: sensibilidade, reprodutibilidade, estabilidade da resposta, limites máximo e mínimo de detecção, dependência energética da resposta, resposta em função da dose, dependência da resposta com a taxa de dose, empregando a técnica de espectrofotometria;

- Avaliar a resposta do dosímetro Fricke Gel com e sem adição de boro no dispositivo de feixe $\mathrm{BH} 3$ do reator IEA-R1 do IPEN.

\subsection{COMPLEMENTARES}

- Adaptar a técnica de leitura ótica com câmeras fotográficas digitais para o FXG desenvolvido no IPEN.

- Apresentar possível aplicação da dosimetria FXG em tratamentos radioterápicos com gradiente de dose alto. 


\section{FUNDAMENTOS TEÓRICOS}

\subsection{GRANDEZAS E PARÂMETROS DOSIMÉTRICOS}

A grandeza dosimétrica mais utilizada em radioterapia para medição da radiação é a dose absorvida. Dose absorvida $D$, em um ponto $P$, é a quantidade de energia $d E_{c}$ cedida ao meio, em um volume $d V$, por qualquer radiação ionizante por unidade de massa $\mathrm{dm}$.

$$
D=\frac{d E_{c}}{d m}
$$

dada no sistema internacional de unidades em $1 / \mathrm{kg}$ e referida pelo nome especial Gray (Gy).

No instante em que o feixe de radiação ionizante penetra perpendicularmente em um meio, não há uma relação constante entre o número de partículas carregadas que entra e o que sai em um volume $d V$, ou seja, não há Equilibrio de Partículas Carregadas (EPC). Conforme o feixe incidente penetra, a relação entre o número de cargas que entram e as que saem de um volume $d V$ aumenta até se igualarem (Johns, 1986).

Assim espera-se que a dose absorvida aumente conforme a profundidade no meio, alcançando um valor máximo no ponto em que começa a ocorrer o EPC. Esta distância entre a superfície do meio e o ponto em que começa a ocorrer o EPC é denominado região de "build up". A partir de então a dose diminuirá com o aumento da profudidade uma vez que o meio atenua a radiação incidente (FIG.1) (Cameron, 1968). A essa distribuição de dose com a profundidade dá-se o nome de curva de Porcentagem de Dose Profunda (PDP).

A curva de PDP para elétrons possui caracteristicas que permitem estabelecer pontos de referência possibilitando a determinação da qualidade do feixe a partir destes parâmetros. A profundidade de dose máxima é denominada de $R_{100}$ e a profundidade na qual a dose é metade da dose máxima de $R_{50}$. Também é possivel determinar o alcance prático $R_{p}$ dos elétrons que é obtido pela intersecção da reta tangente a região de maior inflexão da curva de PDP e a prolongação linear da cauda de "Bremsstrahlung". A definição de alcance para 
feixes de elétrons e a existência da cauda de "Bremsstrahlung" estão descritas no item 3.2.3.

Todos os parâmetros citados para a curva de PDP de um feixe de elétrons são mostrados na FIG.2.

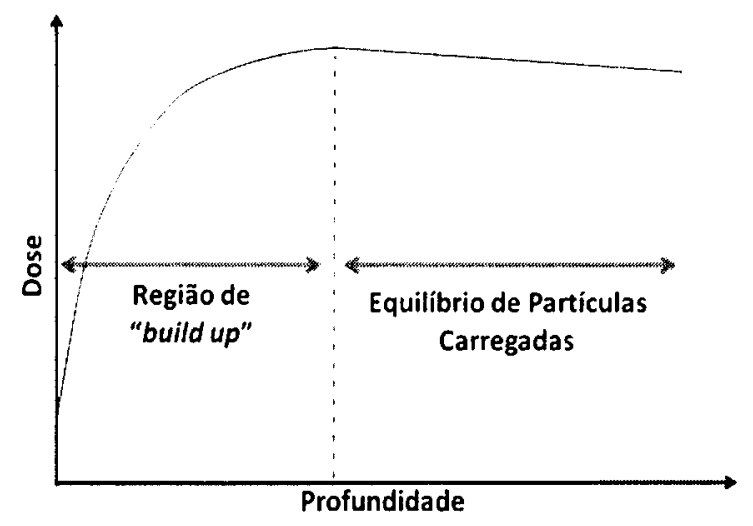

Figura 1 - Gráfico indicando as regiões de "build up", EPC e redução da dose com a profundidade a partir de um valor de dose máxima, caracteristicas de de um feixe de radiação incidente em um meio material (Adaptado de: Thermoluminescent Dosimetry, JR Cameron).

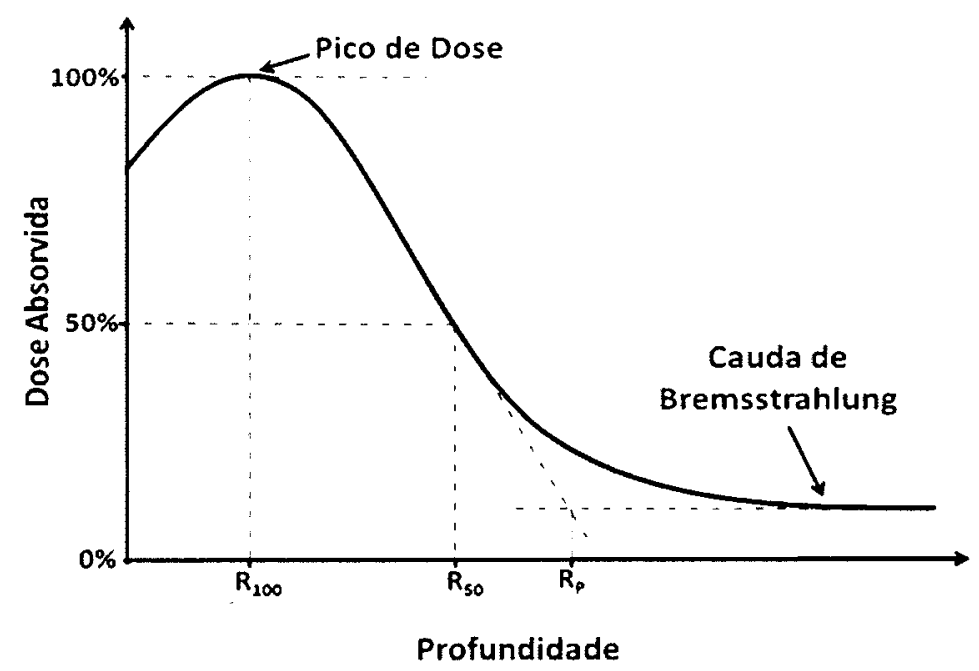

Figura 2 - Esboço de uma curva de porcentagem de dose profunda para um feixe de elétrons mostrando os pontos de referência mais importantes. (Adaptado de: Physics of Electron Beam Therapy, SC Klevenhagen). 


\subsubsection{Código de práticas para dosimetria de feixes de fótons e elétrons gerados por aceleradores clínicos}

A resposta de um sistema dosimétrico depende mais das condições de irradiação do que do tempo de exposição. Por isso, dentre outros documentos técnicos, a Agência Internacional de Energia Atômica (IAEA) publica recomendações para padronizar e aumentar a confiabilidade das dosimetrias relativas em feixes clinicos. O código de práticas atual, Technical Report Series $N^{\circ} 398$ (TRS-398, IAEA, 2000), estabelece algumas condições para o uso de um dosímetro para aplicação na calibração de feixes clínicos.

Apesar deste código de práticas ter por objetivo estabelecer as condições para a calibração de feixes de fótons ou elétrons com dosimetros confiáveis, suas recomendações são pertinentes para a determinação das características de um dosímetro em um feixe conhecido.

O protocolo TRS 398 recomenda o $R_{50}$ como índice da qualidade para feixes de elétrons. Dependendo do valor deste indice, o código de práticas recomenda o material do qual o objeto simulador (OS) deve ser constituído. A água é sempre recomendada para a confecção do OS e o plástico apenas para $R_{\overline{5} 0}<4 \frac{g}{\mathrm{~cm}^{2}}$, ou seja, para feixes de elétrons com menos de $10 \mathrm{MeV}$ aproximadamente. Também são recomendados tamanho de campo de $10 \times 10 \mathrm{~cm}^{2}$, a distância da fonte da radiação ionizante até a superfície do meio irradiado (DFS) de $100 \mathrm{~cm}$ e a profundidade de irradiação para o dosímetro que deve ser a posição de referência $z_{\text {ref }}$ dada pela equação 2.

$$
z_{r e f}=0,6 R_{50}-0,19 / \mathrm{cm}^{2}
$$

com $z_{\text {ref }}$ em $\mathrm{g} / \mathrm{cm}^{2}$.

A profundidade de dose máxima $R_{100}$ possui um valor bem próximo do $Z_{\text {ref }}$ para feixes de elétrons com menos de $10 \mathrm{MeV}$, e para feixes mais energéticos o

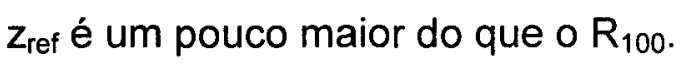




\subsection{Aceleradores lineares de elétrons}

$\mathrm{Na}$ superfície terrestre, apenas aceleradores de partículas conseguem gerar elétrons com energia da ordem de milhões de elétrons-volt (Klevenhagen, 1993).

\subsubsection{Aceleradores lineares clínicos}

Os Aceleradores Lineares $(A L)$ para utilização em procedimentos médicos são as fontes de feixes de fótons ou elétrons de energias altas mais comuns na rotina clínica atualmente. Estes feixes são empregados em uma série de modernos tratamentos radioterápicos, como tratamentos com intensidade modulada feixe (IMRT) (Gauer, 2008), radiocirurgia, radioterapia com arco de elétrons, irradiação total da pele com elétrons (comumente chamada de TBI, do inglês: "Total Body Irradiation") e a radioterapia intra-operatória. (Metcalfe et al, 2007)

AL clínicos são máquinas que utilizam campos de freqüência da ordem das microondas e diferença de potencial elétrico da ordem de milhões de elétrons volts para acelerar elétrons em uma linha reta.

O funcionamento básico de um $\mathrm{AL}$ se da pelo guia de ondas que age como um condutor das microondas e é responsável por grande parte do processo de aceleração dos elétrons. O canhão de elétrons se localiza no orifício de entrada do guia de ondas. Os elétrons são injetados dentro do guia de ondas simultaneamente a emissão do pulso de radiofreqüência fazendo com que estas ondas acelerem os elétrons a velocidades próximas a da luz, e, conseqüentemente, gerando um feixe de elétrons pulsado.

Ao sair do guia de ondas o feixe de elétrons com energia alta possui sua direção de propagação alterada por um magneto fazendo o feixe emergir em direção ao centro de rotação da cabeça do AL (isocentro), com o intuito de facilitar o posicionamento do paciente que será irradiado. Antes do feixe de elétrons emergir do acelerador ele precisa ser espalhado, para abranger áreas maiores de irradiação, para isto folhas espalhadoras são colocadas a frente do feixe logo após ele ter sido direcionado ao isocentro. A colimação do feixe de elétrons se dá 
tanto pelos colimadores da cabeça do AL quanto por aplicadores acoplados na frente da cabeça do $A L$.

As caracteristicas do feixe de elétrons produzido por um AL irá depender dos componentes internos do acelerador. Um Varian Clinac 2100-C pode emitir elétrons de 4 a $15 \mathrm{MeV}$ e com uma taxa de dose de 80 a 400 cGy/min, sendo que estas características podem ser selecionadas pelo usuário.

\subsubsection{Aceleradores lineares industriais}

Existem vários tipos e modelos de aceleradores lineares de elétrons para aplicações industriais. A maioria destas aplicações necessita de feixes de elétrons com energias entre 0,15 e $5 \mathrm{MeV}$ e correntes elétricas que podem gerar uma taxa de dose média em um material irradiado chegar a $10^{6} \mathrm{~Gy} / \mathrm{s}$. Comumente este tipo de equipamento é utilizado para promover a polimerização de plásticos, aumentando sua resistência, e na degradação de residuos químicos pela quebra em componentes menores e menos poluentes (McLaughlin, 1989; Iliev, 2004).

O processo de aceleração dos elétrons nos aceleradores lineares industriais se dá por uma tensão constante aplicada e por uma emissão termoiônica contínua no filamento emissor, resultando em um feixe contínuo de elétrons (Wilton, 1985).

O acelerador de elétrons tipo Dynamitron da Radiation Dynamics gera um feixe fino de elétrons com energia máxima de 1,5 MeV e potência de até $150 \mathrm{~kW}$. O feixe emergente do tubo de aceleração não possui largura suficiente para irradiar de forma homogênea os materiais, por isso um sistema magnético de deflexão do feixe pode é utilizado para realizar uma "varredura" sobre toda a região a ser irradiada. 


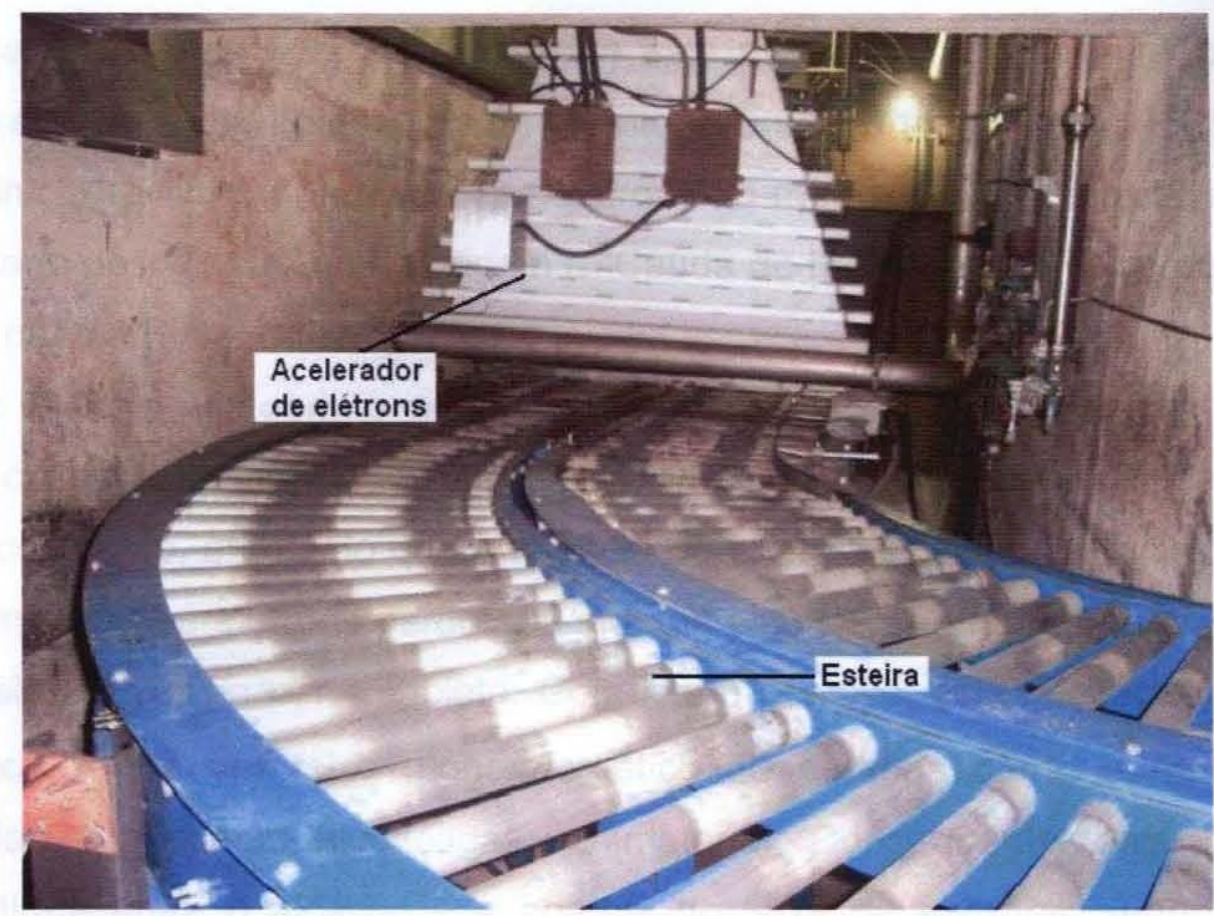

Figura 3 - Acelerador de elétrons Dynamitron Job 188 pertencente ao Centro de Tecnologia das Radiações/IPEN (disponibilizada pelo Engenheiro Carlos G. da Silveira).

\subsubsection{Interação do feixe de elétrons de megavoltagem com a matéria}

Todo feixe de partículas carregadas de energia alta interage diretamente com o campo coulombiano dos átomos do meio em que incide. Estas interações com os prótons e elétrons se dão por colisões elásticas e inelásticas. O depósito de energia no meio ocorre efetivamente pelas colisões inelásticas, com isso a partícula carregada incidente perde energia para o meio conforme se desloca entre os átomos. A perda de energia $d E$ por uma partícula carregada, devido a colisões ao atravessar um comprimento infinitesimal $d x$, é definida como poder de frenagem ou usualmente chamado de stopping power (-dE/dx) (Attix, 1986).

Os elétrons possuem carga negativa e uma massa ínfima quando comparada à massa dos nucleons. Ao incidirem na matéria, os elétrons de um feixe de energia alta colidem com os elétrons orbitais dos átomos (stopping power colisional) ionizando diretamente o meio que atravessam (após este processo, o rearranjo de elétrons orbitais pode gerar raios $X$ característicos). Estes elétrons de energia alta também podem interagir diretamente com o núcleo dos átomos sofrendo desvios e conseqüentemente perdendo energia na forma de fótons de 
raios $X$ (stopping power radiativo), sendo esta radiação indiretamente ionizante gerada é chamada de radiação de freamento (bremsstrahlung) (Attix, 1986). Com isso, do início ao fim do percurso dos elétrons no meio, o feixe é inevitavelmente contaminado por raios $\mathrm{X}$ dando origem a "Cauda de bremsstrahlung" mostrada na curva de pdp na FIG.2 do item 3.1.

Ao interagirem com o meio, os elétrons apenas perdem parte de sua energia, ou seja, a fluência de partículas em um comprimento infinitesimal se mantém constante, enquanto que a fluência de energia se altera (Stanley, 1993). Desta forma o feixe elétrons perde sua energia cinética enquanto penetra o meio até que ela se dissipe por completo. Com isto é possivel estabelecer o conceito de alcance $R$ de um feixe monoenergético de elétrons como a média das profundidades máximas alcançadas no material. Conseqüentemente há uma relação direta entre o alcance e a energia do feixe de elétrons, sendo muitas vezes determinada a energia do feixe de elétrons através de seu alcance em um dado material.

Estabelecer experimentalmente $\circ$ alcance de um feixe de elétrons polienergético não é simples, por isto em radioterapia define-se a energia do feixe emergente dos aceleradores clínicos de elétrons através do alcance prático (Khan, 1994), para isto define-se o termo "Qualidade do Feixe", ou seja, um valor diretamente ligado à energia média dos elétrons que representa aproximadamente a capacidade do feixe de radiação penetrar a matéria.

\subsection{Fonte de fótons de megavoltagem}

Radiações eletromagnéticas (fótons) ionizantes podem ser classificadas quanto a sua origem em Raios $\mathrm{X}$ e Raios gama. Os Raios $\mathrm{X}$ são gerados por transições eletrônicas ou em um processo de frenagem brusca de elétrons rápidos. Os Raios gama são originados em núcleos atômicos instáveis.

\subsubsection{Aceleradores lineares clinicos}

Os $A L$ produzem feixes de fótons de megavoltagem de maneira similar a descrita para feixes de elétrons no item 3.2.1. A grande diferença está em que no processo de produção de Raios $\mathrm{X}$ há a necessidade de posicionar um alvo na 
frente do feixe de elétrons gerado pelo equipamento para a conversão da energia cinética dos elétrons em fótons de Raios $\mathrm{X}$ pelo processo de Bremsstrahlung. Como a energia do feixe de elétrons é muito alta, a emissão dos fótons se dá preferencialmente na mesma direção do feixe de elétrons. Ainda são posicionados outros componentes modificadores de feixe, como o flatness filter, desnecessário na produção do feixe de elétrons. A função do flatness filter é manter a intensidade do feixe de fótons igual em toda a área a ser irradiada.

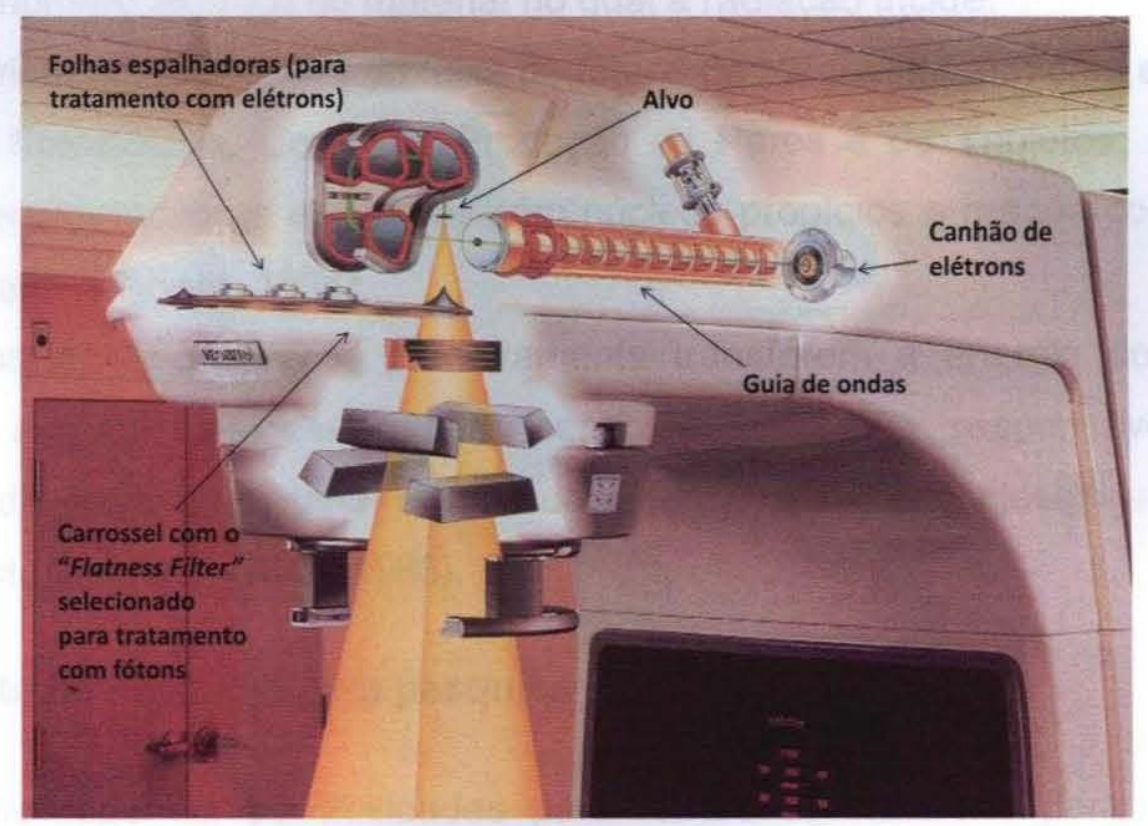

Figura 4 - Esquema de um Acelerador Linear com os dispositivos modificadores de feixe selecionados para a produção de fótons. (Adaptado de: Folheto de propaganda de aceleradores Varian).

\subsubsection{Fonte de radiação gama tipo Gammacell}

A fonte de radiação gama do tipo Gammacell fornece uma dose praticamente homogênea em todo o material simétrico colocado em seu interior.

Um irradiador do tipo Gammacell é uma fonte de radiação gama autoblindada. A fonte de radiação gama deste irradiador consiste de hastes ocas de inox preenchidas com material radioativo (existem modelos com ${ }^{137} \mathrm{Cs} \mathrm{e}{ }^{60} \mathrm{Co}$ ). Estas hastes estão distribuídas em uma superfície cilíndrica de forma a permitir a melhor homogeneidade de dose possível dentro do volume cilíndrico onde as amostras são mecanicamente inseridas. 
Como a meia vida das fontes utilizadas é muito grande (aproximadamente 30 anos pro ${ }^{137} \mathrm{Cs}$ e 5 anos para $\circ{ }^{60} \mathrm{Co}$ ) e a energia de emissão gama e distribuição da dose no material irradiado muito bem conhecidas, é possível utilizar uma fonte deste tipo como padrão para comparação com outras análises.

\subsubsection{Interação do feixe de fótons com a matéria}

Os processos de interação dos fótons dependem da energia dos raios $X$ ou gama e do número atômico do material no qual a radiação incide.

As principais interações do feixe de fótons de megavoltagem com a matéria são: efeito Fotoelétrico, Compton, Produção de Pares e de Tripletos; isto sem levar em consideração as interações com núcleos propícios a reação com fótons de energia alta (Eisberg, 1994).

Todos estes processos primeiramente transferem a energia dos fótons incidentes a partículas carregadas, sendo estas então responsáveis pela deposição da dose no material e por isso os esta radiação é classificada como indiretamente ionizante (Attix, 1986).

\subsection{Fonte de nêutrons para pesquisa em BNCT}

Dentre algumas possibilidades para fontes de nêutrons para pesquisa estão as fontes de fotonêutrons, de fissão espontânea, de reação $(\alpha, n)$, reação por íons acelerados e reatores nucleares (Knoll, 1989). Destes exemplos os reatores e os aceleradores são as fontes de nêutrons com as melhores características para BNCT. Hoje os reatores nucleares construidos especificamente para pesquisa e aplicação clínica são as fontes mais comuns (Burn, 2004).

Para pesquisas em BNCT pode-se adaptar um dispositivo de feixe de reatores nucleares com água leve pressurizada, desenvolvidos para pesquisa. Estes reatores produzem não apenas nêutrons térmicos e epitérmicos (de maior interesse para BNCT), mas também radiação gama com um longo espectro de energia e nêutrons rápidos. Parte dos nêutrons epitérmicos e rápidos são termalizados, ou seja, tem sua energia reduzida a menos de $0,8 \mathrm{eV}$ pela água que envolve o núcleo do reator, o restante terá sua energia reduzida por moderadores 
colocados na entrada do dispositivo de feixe junto as blindagens para redução da contaminação por radiação gama.

Um exemplo desta adaptação é o Reator Nuclear IEA-R1 do IPEN, que possui em um de seus dispositivos de feixe, mais especificamente no Beam Hole número 3 (BH\#3), uma série de materiais modificadores de feixe que reduzem a intensidade do feixe de fótons e termalizam boa parte dos nêutrons epitérmicos e rápidos, permitindo seu uso como uma fonte satisfatória de nêutrons térmicos para pesquisa em BNCT (Cárdenas, 2008; Mangueira, 2008 A).

\subsubsection{Interação dos nêutrons com a matéria}

Os processos de interação dos nêutrons com a matéria dependerão dos constituintes da matéria e da energia do feixe de nêutrons incidente (Tauhata, 2006).

Os nêutrons podem ser classificados conforme sua energia cinética em:

1. Térmicos: possuem energia cinética próxima da quantidade de energia térmica (menos de 0,8 eV). Na temperatura ambiente do laboratório essa energia é aproximadamente $0,025 \mathrm{eV}$. Nêutrons térmicos interagem com a matéria por colisões elásticas com núcleos atômicos e podem provocar reações nucleares induzidas pela absorção dos nêutrons.

2. Epitérmicos, possuem energia cinética entre $0,8 \mathrm{eV}$ e $1 \mathrm{MeV}$. Nêutrons epitérmicos interagem com a matéria por colisões elásticas com núcleos atômicos, que na realidade transferem uma quantidade muito pequena de energia.

3. Rápidos, com energia superior a $1 \mathrm{MeV}$. Nêutrons rápidos perdem uma parte significante de sua energia em uma única interação com os núcleos dos átomos do meio em que incidem, gerando núcleos de recuo que depositam energia no meio.

Em BNCT a interação responsável pelo maior depósito de energia na região de interesse é a absorção de nêutrons térmicos pelos núcleos dos átomos de ${ }^{10} \mathrm{~B}$. No entanto os nêutrons térmicos conseguem penetrar apenas superficialmente no paciente, sendo os nêutrons epitérmicos que atingem maiores profundidades, chegando a região a ser tratada com muito pouca energia (Barth, 2005). 
$A$ reação do ${ }^{10} \mathrm{~B}$ com os nêutrons térmicos $\left({ }^{10} \mathrm{~B}(\mathrm{n}, \alpha){ }^{7} \mathrm{Li}\right)$ possui como produto, átomos de lítio em dois estados: fundamental ( $\mathrm{Li}$ ) e excitado ( $\mathrm{Li}^{*}$ ) (Knoll, 1989). Os valores de energia de emissão gama (chamado usualmente de "valor Q") de cada produto da reação ${ }^{10} \mathrm{~B}(\mathrm{n}, \alpha)^{7} \mathrm{Li}$ com as respectivas probabilidades de ocorrência, estão apresentados na TAB.1:

TABELA 1 - Probabilidade de ocorrência das Reações ${ }^{10} \mathrm{~B}(\mathrm{n}, \alpha)^{7} \mathrm{Li}$

\begin{tabular}{lcc} 
& Q (MeV) & $\begin{array}{c}\text { Probabilidade de } \\
\text { ocorrência (\%) }\end{array}$ \\
\hline${ }_{5}^{10} B+{ }_{0}^{1} n(0,025 \mathrm{eV}) \rightarrow\left\{\begin{array}{llc}{ }_{3}^{7} L i+{ }_{2}^{4} \alpha & 2,792 & 6 \\
\hline{ }_{3}^{7} L i *+{ }_{2}^{4} \alpha & 2,310 & 94\end{array}\right.$
\end{tabular}

O núcleo de ${ }^{7} \mathrm{Li}$ e a partícula $\alpha$ são emitidos em direções opostas, ionizando o pequeno caminho que percorrem (de 5 a $9 \mu \mathrm{m}$ no tecido mole), depositando uma grande quantidade de energia apenas na célula que contém o fármaco $c o m{ }^{10} \mathrm{~B}$, ou seja, o gradiente de dose é muito maior do que nos tratamento com fótons e elétrons, preservando tecidos saudáveis.

\subsection{Dosimetria gel}

Na rotina clinica dosímetros práticos como as câmaras de ionização são os mais utilizados devido à excelente estabilidade, precisão e exatidão da resposta. $\mathrm{O}$ uso de detectores do estado sólido como os dosímetros termoluminescentes e diodos é comum na conferência de dose de entrada e saída da pele, planura de feixe e outras grandezas importantes para a qualidade do tratamento radioterápico. Também são utilizados filmes radiográficos em alguns controles da qualidade de $A L$ e na conferência de tratamentos com Intensidade Modulada de Feixe (IMRT).

Para um correto planejamento radioterápico é necessário conhecer exatamente a distribuição da dose na água devido ao feixe incidente de radiação. O método mais comum para esta determinação é o uso dos chamados "blue phantoms" que consistem de um reservatório de água, motores de passo, uma 
câmara de ionização, um eletrômetro e um sistema computadorizado, integrados de forma a permitir a movimentação da câmara de ionização em todo o volume de interesse enquanto são eletronicamente registrados os valores de dose a cada passo. Durante a análise de um único campo pode ser necessário ligar e desligar o $\mathrm{AL}$ algumas vezes. Este processo realizado em vários campos emitidos pelo acelerador é chamado "Comissionamento" e pode demorar dias para ser realizado, dependendo do número de campos a ser observado.

A maior vantagem da dosimetria gel é a sua aplicação na dosimetria em três dimensões (3D). Com um volume de gel que compreenda toda a região de interesse é possivel avaliar todos os parâmetros físicos de um feixe de radiação ionizante a partir de uma única irradiação.

Existem hoje vários tipos de dosímeros gel, e eles são basicamente divididos em dois tipos: os géis infundidos com uma solução Fricke e os géis poliméricos (Baldock, 2006). Um dosímetro gel ideal deve, entre outras coisas, ser atóxico e descartável em lixo comum, ter sua resposta independente da taxa de dose, da energia e do tipo de feixe incidente, ser tecido equivalente e manter a resposta constante ao longo do tempo.

Os géis poliméricos são estáveis e precisos, mas ou são tóxicos, ou oxidam rapidamente na presença de ar atmosférico ou não são tecido equivalentes. Já os dosimetros Fricke Gel apresentam uma baixa estabilidade para longos períodos de armazenagem, baixa toxicidade, podem ser preparados em atmosfera ambiente e são tecido equivalentes.

\subsubsection{Dosímetro Fricke Xilenol Gel (FXG)}

Dosímetros Fricke são dosímetros químicos que funcionam a partir do principio de oxidação dos íns ferrosos $\left(\mathrm{Fe}^{2+}\right)$ da solução em íons férricos $\left(\mathrm{Fe}^{3+}\right)$ induzida por radiação (Fricke, 1927). Com a adição de Alaranjado de Xilenol à solução Fricke padrão pode-se determinar de maneira indireta a quantidade produzida de íns férricos e ferrosos na solução. Esta inferência possui uma variação linear, diretamente proporcional à dose (Schreiner, 2004) para o intervalo de aproximadamente 0,2 a 40 Gy no comprimento de onda de 585 nm (FIG.5). 


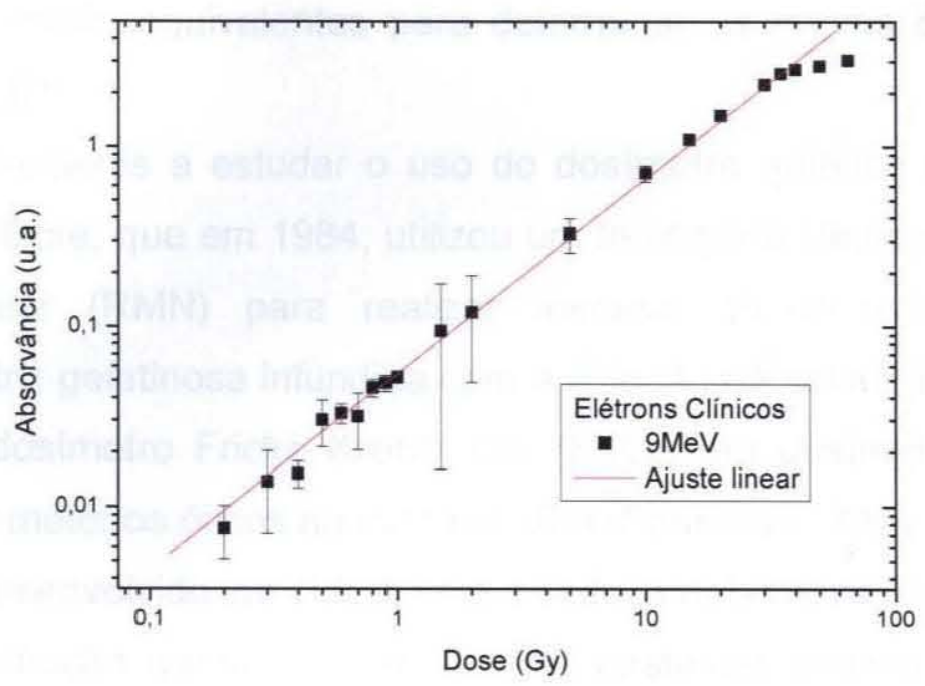

Figura 5 - Curva de dose resposta do dosímetro FXG para um feixe clínico de elétrons de $9 \mathrm{MeV}$.

A variação da absorbância acarreta uma mudança de cor na região do espectro eletromagnético visível, criando um gradiente de cores com a variação da dose absorvida no FXG (FIG.6).

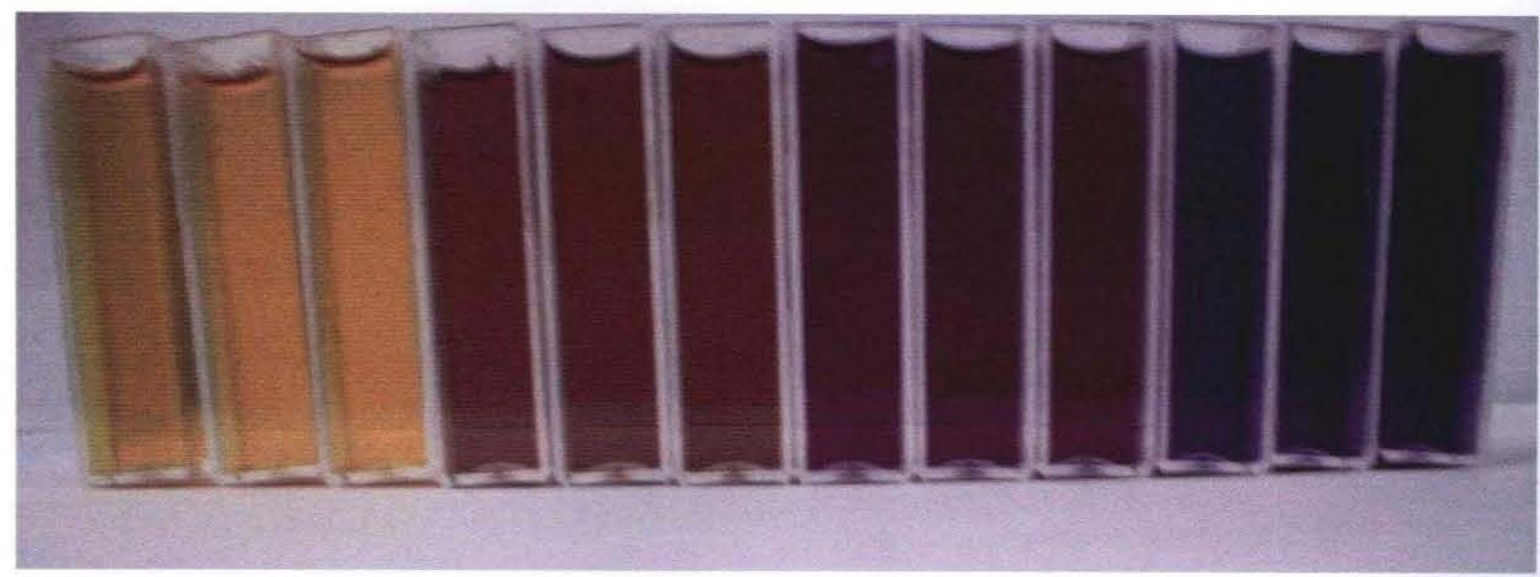

Figura 6 - Alteração de cor no dosímetro FXG - da esquerda para direita doses de 0 a $30 \mathrm{~Gy}$ em grupos de 3 cubetas.

Os dosímetros Fricke modificados são muito estudados devido às características já muito bem estabelecidas do dosímetro Fricke padrão, empregando a técnica de espectrofotometria. Com a inserção da solução Fricke padrão em uma matriz de gelatina pode-se empregar a técnica de imagem por 
ressonância magnética (IRM) e a confecção de objetos simuladores antropomórficos tecido equivalentes para determinar as curvas de isodose, em três dimensões (3D).

Um dos primeiros a estudar o uso do dosímetro químico Fricke em uma matriz de gel foi Gore, que em 1984, utilizou um tomógrafo clínico de ressonância magnética nuclear (RMN) para realizar medidas tridimensionais da dose absorvida. A matriz gelatinosa infundida com a solução de sulfato ferroso e xilenol é chamada de dosímetro Fricke Xilenol Gel (FXG), um dosímetro que permite análise tanto por métodos óticos quando por IRM (Schreiner, 2004).

O FXG desenvolvido no IPEN vem sendo amplamente estudado para a dosimetria da radiação gama, com resultados bastantes promissores devido à possibilidade de sua aplicação na dosimetria tridimensional (Cavinato, 2007; Galante, 2007). Poucos estudos têm avaliado o desempenho desse material em campos de radiação de elétrons aplicados em radioterapia (Galante, 2008) e em campos mistos gama-nêutron (Mangueira , 2008 B; Silva, 2008; Gambarini, 2000; Gambarini, 2002). 


\section{MATERIAIS E MÉTODOS}

\subsection{Sistema dosimétrico}

Neste trabalho entende-se como sistema dosimétrico não apenas o material sensível (constituído da solução FXG com as cubetas), mas também o arranjo para irradiação e leitura.

\subsubsection{Preparo, manuseio e transporte do dosímetro FXG}

O FXG foi preparado utilizando gelatina 300 Bloom e água tridestilada, à pressão e temperatura ambientes. O primeiro passo no preparo do $F X G$ é hidratar a gelatina em um béquer com $75 \%$ da água tridestilada a ser utilizada no processo. Após $10 \mathrm{~min}$ da adição da água no béquer a gelatina hidratada deve ser aquecida enquanto é misturada em um agitador magnético. Ao atingir $40^{\circ} \mathrm{C} \mathrm{o}$ aquecimento deve ser desligado mas 0 agitador deve permanecer ligado. Enquanto a solução gelatinosa atinge a temperatura de $30^{\circ} \mathrm{C}$ prepara-se a solução Fricke -modificada, com sulfato de amônio ferroso, cloreto de sódio, alaranjado de xilenol, e ácido sulfúrico com os $25 \%$ restantes da água tridestilada, nas concentrações indicadas na TAB.2. Assim que a solução gelatinosa atingir $30^{\circ} \mathrm{C}$, deve ser acrescentada à solução Fricke modificada e mantida em agitação até a completa homogeneização. Este método de preparo é descrito também por Bero 2001 e Cavinato 2007.

Após a homogeneização a solução $F X G$ é acondicionada em cubetas espectrofotométricas padrão, com volume interno de $1 \times 1 \times 4,5 \mathrm{~cm}^{3}, 1 \mathrm{~cm}$ de caminho ótico e parede acrilica de $1 \mathrm{~mm}$ de espessura, como mostra a FIG.7.

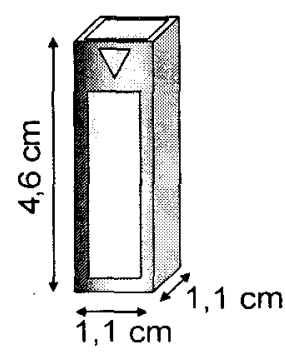

Figura 7 - Cubeta espectrofotométrica padrão (mostrando as dimensões externas). 
Tabela 2 - Composição Química do dosímetro FXG desenvolvido no IPEN

\begin{tabular}{|c|c|}
\hline Composto* $^{*}$ & $\mathrm{C}(\mathrm{mol} / \mathrm{L})$ \\
\hline Sulfato de Amônio Ferroso & 0.001 \\
\hline Cloreto de Sódio & 0.001 \\
\hline Alaranjado de Xilenol & 0.0001 \\
\hline Ácido Sulfúrico & $5.0010-02$ \\
\hline Água tri-destilada & 5,55 \\
\hline Gelatina (300 Bloom) & $10 \%$ da massa de água \\
\hline Tetraborato de Sódio** & $3,510^{-3 * * *}$ \\
\hline
\end{tabular}

* Todos os compostos são fabricados pelos laboratórios da MERCK, exceto: a Gelatina (300 Bloom) da Sigma, o Tetraborato de Sódio da Reagen, e a água tri-destilada que é obtida no laboratório de Doses Altas da Gerência de Metrologia das Radiações do IPEN.

**Adicionado à solução apenas para estudos com nêutrons térmicos. Este sal possui 19,9\% do isótopo ${ }^{10} \mathrm{~B}$

${ }^{* * *}$ Concentração para $60 \mathrm{ppm}$ de ${ }^{10} \mathrm{~B}$ no gel.

As cubetas preenchidas com o FXG devem ser mantidas refrigeradas $\left(6^{\circ} \mathrm{C}\right)$ e ao abrigo da luz por cerca de $24 \mathrm{~h}$ antes da irradiação. Para disposição no refrigerador os dosimetros foram acondicionados em caixas de isopor com divisões do tamanho de uma cubeta (FIG.8) e as caixas embaladas com papel filme. Os dosímetros foram transportados nesta embalagem até o local da irradiação, quando foram retirados e mantidos por $30 \mathrm{~min}$ à temperatura ambiente para atingir equilíbrio térmico com a sala antes da irradiação. Logo após o término das irradiações os dosimetros foram novamente embalados para retornar ao laboratório onde foi realizada a leitura. Após a leitura as cubetas retornavam à geladeira na embalagem para aguardar uma futura re-leitura ou descarte. 


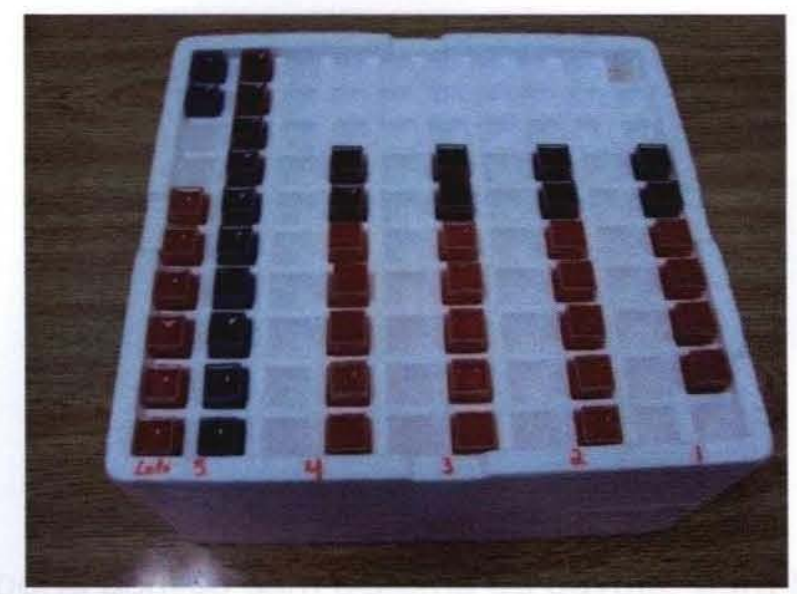

Figura 8 - Caixa de isopor com dosímetros FXG acondicionados.

\subsubsection{Objeto Simulador}

Como descrito no item 3.1.1 para irradiação em feixes de fótons e elétrons de AL clínicos o TRS-398 recomenda um objeto simulador (OS) de água. Porém, nas condições atuais de desenvolvimento, não é possível inserir o dosímetro FXG na água. Por este motivo os experimentos foram realizados com um OS constituído de placas de água sólida e um suporte de acrílico (PMMA) específico para a acomodação das cubetas espectrofotométricas.

Água sólida é o nome mais comum dado a diferentes materiais que apresentam densidade, densidade eletrônica e número atômico efetivo semelhantes aos da água.

O suporte de acrílico consiste de duas partes: um suporte em forma de "U" e duas gavetas vazadas móveis para facilitar a troca de cubetas. Este suporte foi confeccionado na oficina do IPEN com placas de acrílico (PMMA) com densidade igual a $1,190 \mathrm{~g} / \mathrm{cm}^{3}$ e número atômico efetivo 5,85 (ICRU 44, 1989).

Durante uma série de irradiações o objeto simulador é montado e fixado de forma que as placas de água sólida e o suporte em forma de "U" não se movam. As cubetas são inseridas no orifício de uma das gavetas e esta ao suporte acrílico em forma de "U" mantendo inalterado o arranjo de irradiação mesmo com a troca das gavetas, e conseqüentemente dos dosímetros. As dimensões do suporte são $30 \times 30 \times 1,8 \mathrm{~cm}^{3}$ e a abertura para inserção das cubetas $6,3 \times 4,7 \times 1,2 \mathrm{~cm}^{3}$ localizada no centro do suporte (FIG.9). 


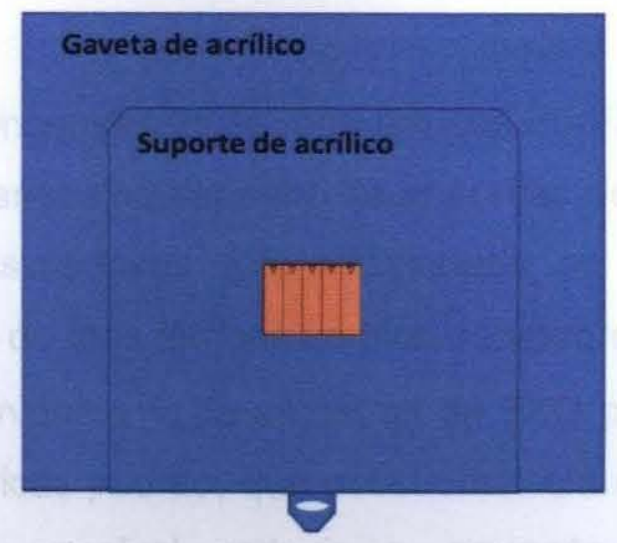

Figura 9 - Suporte acrílico com sistema de gaveta, para troca de cubetas sem alterar $\mathrm{o}$ arranjo experimental.

O sistema aqui descrito permite a adição de placas de água sólida sobre o suporte acrílico, para garantir o posicionamento do dosímetro na profundidade desejada, e abaixo do suporte, para garantir as condições de retroespalhamento ( $5 \mathrm{~cm}$ de espessura, no mínimo), como mostra FIG.10. O objeto simulador também garante uma extensão maior que $5 \mathrm{~cm}$ a partir das laterais de campo $10 \times 10 \mathrm{~cm}^{2}$ de irradiação para garantir as condições de espalhamento lateral. Todas estas são condições sugeridas pelo protocolo TRS-398.

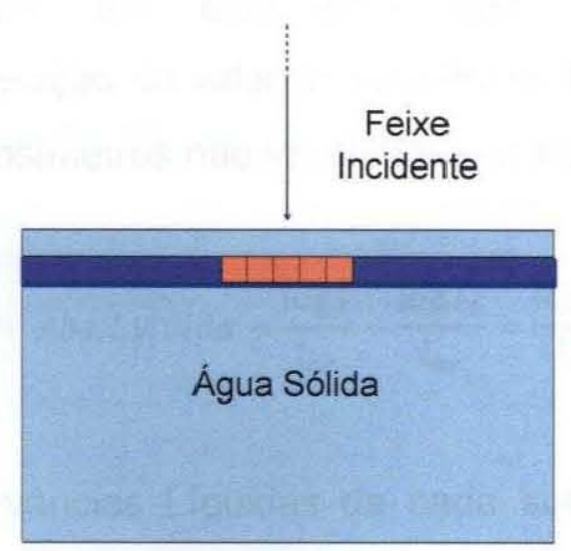

Figura 10 - Objeto simulador utilizado para o posicionamento do suporte entre as placas de água sólida.

A água sólida utilizada foi na forma de placas de $30 \times 30 \mathrm{~cm}^{2}$ em diferentes espessuras. Ela é constituída de uma mistura de poliestireno $\mathrm{C}_{8} \mathrm{H}_{8}$ com $2 \%$ dióxido de titânio resultando em um material com densidade igual a $1,045 \mathrm{~g} / \mathrm{cm}^{3}$ (Christ, 1995). O nome comercial destas placas é RW3 da marca Scanditronix. 
As alterações na concentração de íons férricos do FXG foram avaliadas de forma indireta pelas mudanças no espectro de absorção do alaranjado de Xilenol. A concentração dos íons ferrosos esta relacionada ao pico de absorção em $450 \mathrm{~nm}$ e a concentração de íons férricos ao pico de absorção em $585 \mathrm{~nm}$.

A medida da absorvância $A$ de amostras de FXG pode ser feita utilizando cubetas espectrofotométricas padrão, que possuem $1 \mathrm{~cm}$ de caminho ótico. Com este caminho ótico é possivel reduzir a equação de Beer-Lambert a (McLaughlin, 1989):

$$
A=-\log \frac{I}{I_{0}}
$$

sendo $I$ e $I_{0}$ as intensidades luminosas transmitidas através amostra e através da referência respectivamente. Nos experimentos executados com o FXG desenvolvido no IPEN a referência foi o ar ambiente do laboratório.

As leituras médias corrigidas da absorvância do FXG (Absorvância Líquida) consistem da subtração da média da leitura dos dosímetros irradiados $\left({ }^{\log \left({ }^{(} I_{a r}\right.}\right)$ ) pela média das leituras dos dosímetros não irradiados $\left(\log \left(\Gamma_{0} / I_{a r}\right)\right)$. Matematicamente esta alteração do valor de referência do ar ambiente $\left(I_{a r}\right)$ para a média das leituras dos dosímetros não irradiados $\left(\bar{I}_{0}\right)$ fica:

$$
\text { Abs. Líquida }=\frac{\log \bar{I}}{I_{a r}}-\frac{\log \bar{I}_{0}}{I_{a r}}=\frac{\log \bar{I}}{\bar{I}_{0}}
$$

Calculadas as Absorvâncias Líquidas de cada subconjunto, as curvas de dose-reposta foram levantadas e uma reta foi ajustada aos pontos experimentais no intervalo em que a resposta é linear (com o software Origin Lab 7.5). As curvas de dose resposta do FXG foram avaliadas para todas as fontes de radiação, mas as características dosimétricas foram levantadas apenas para o feixe de elétrons.

O espectro de absorção de amostras de FXG irradiadas com diferentes doses para os comprimentos de onda de $400 \mathrm{~nm}$ até $700 \mathrm{~nm}$ estão apresentados na FIG.11. Nota-se que a variação mais intensa do espectro com a dose está no comprimento de onda de $585 \mathrm{~nm}$, comprimento usual para inferência da medição 
da dose (Bero, 2001), referente à concentração dos íons $\mathrm{Fe}^{3+}$ e um segundo pico, menos intenso em $450 \mathrm{~nm}$ relacionado com a concentração dos íons $\mathrm{Fe}^{2+}$.

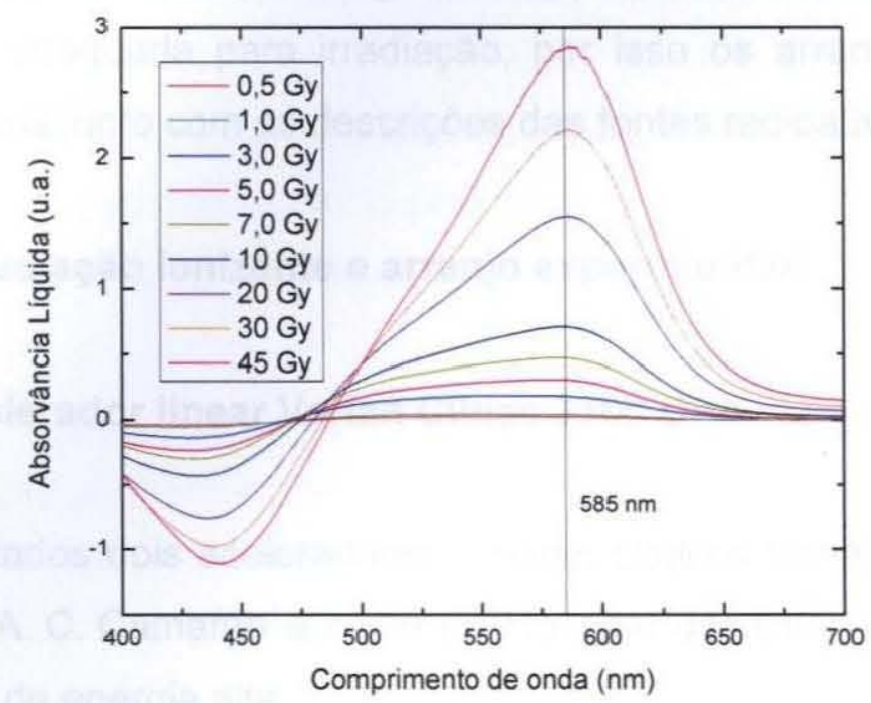

Figura 11 - Espectro de absorção do dosímetro FXG relativo ao dosímetro não irradiado, para doses de 0,5 a 45 Gy.

Estas alterações na absorvância do gel foram mensuradas com um espectrofotômetro Shimadzu UV-2101 PC, cujos parâmetros de medida estão apresentados na TAB. 3.

Tabela 3: Parâmetros de medida do Espectrofôtometro Shimadzu UV-2101 PC.

\begin{tabular}{cc}
\hline Parâmetros & \\
\hline Intervalo de comprimento de onda & $400-700 \mathrm{~nm}$ \\
Fonte de Luz & Tungstênio e Deutério \\
Largura da fenda & $2 \mathrm{~nm}$ \\
Absorvância & $-9.999-+9.999 \%$ \\
Transmitância & $-999.9-+999.9 \%$ \\
Velocidade de Varredura & 1600 (fast e intervalo de $2 \mathrm{~nm})$ \\
Precisão & $0.1 \mathrm{~nm}$
\end{tabular}

A leitura espectrofotométrica foi realizada de 1 a $3 \mathrm{~h}$ após as irradiações. Os dosímetros irradiados foram lidos antes dos não irradiados, e das menores para as maiores doses. 


\subsubsection{Arranjo para irradiação}

Cada fonte de radiação possui geometria própria e conseqüentemente uma disposição mais adequada para irradiação, por isso os arranjos experimentais serão apresentados junto com as descrições das fontes radioativas utilizadas.

\subsection{Fontes de radiação ionizante e arranjo experimental}

\subsubsection{Acelerador linear Varian Clinac 2100-C}

Foram utilizados dois aceleradores lineares clínicos Varian Clinac 2100-C, um do Hospital A. C. Camargo e outro do Hospital das Clínicas, como fonte de elétrons e fótons de energia alta.

O arranjo experimental para esta fonte de radiação consiste do objeto simulador posicionado de forma que as cubetas espectrofotométricas fiquem em uma mesma profundidade, no centro de um campo $10 \times 10 \mathrm{~cm}^{2}$. A distância foco superfície (DFS) foi de $100 \mathrm{~cm}$ e o plano central das cubetas coincide com a profundidade de dose máxima (FIG.12), ou seja, nas condições sugeridas pelo código de práticas TRS-398 exceto pela profundidade.

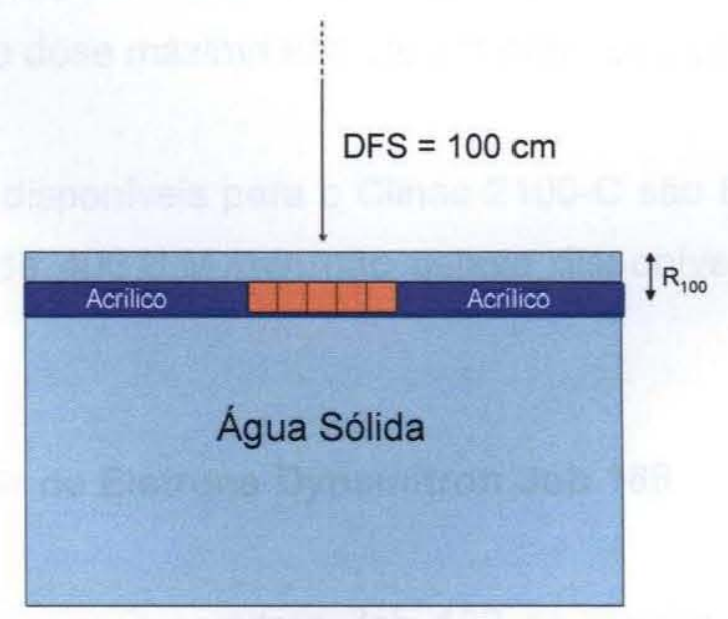

Figura 12 - Objeto simulador mostrando o arranjo experimental.

A profundidade utilizada não foi a semi-redutora $\left(R_{50}\right)$ ou a de referência $\left(\mathrm{z}_{\mathrm{ref}}\right)$ por que se pretendeu manter a maior uniformidade de dose possível dentro do dosímetro, além de que nesta profundidade uma unidade monitora (U.M.) 
equivale a $1 \mathrm{cGy}$ em um campo $10 \times 10 \mathrm{~cm}^{2}$. Como a região de máxima dose é muito extensa para elétrons de energia alta, optou-se por posicionar o centro da região de máxima dose no centro das cubetas, tanto para elétrons como para fótons.

A TAB.4 relaciona as energias nominais dos feixes de elétrons e fótons produzidos pelos aceleradores com a profundidade de dose máxima $R_{100}$ e a espessura de água sólida sobre os dosímetros.

Tabela 4 - Profundidade de dose máxima $R_{100}$, Espessura de água sólida sobre o suporte e energia nominal dos feixes gerados pelos Clinac $2100-\mathrm{C}$ para um Campo $10 \times 10 \mathrm{~cm}^{2}$.

\begin{tabular}{ccccc} 
& \multicolumn{2}{c}{ Elétrons } & \multicolumn{2}{c}{ Fótons } \\
\cline { 2 - 5 } Energia Nominal & $\mathrm{R}_{100}(\mathrm{~cm})$ & Espessura $(\mathrm{cm})$ & $\mathrm{R}_{100}(\mathrm{~cm})$ & Espessura $(\mathrm{cm})$ \\
$4 \mathrm{MeV}^{*}$ & $0,55-0,65$ & 0,0 & -- & - \\
$6 \mathrm{MeV}^{* *}$ & $1,2-1,4$ & 0,7 & 1,5 & 0,9 \\
$9 \mathrm{MeV}^{* *}$ & $1,8-2,2$ & 1,4 & -- & -- \\
$12 \mathrm{MeV}^{* *}$ & $2,5-3,1$ & 2,2 & -- & -- \\
$15 \mathrm{MeV}^{* *}$ & $2,6-3,6$ & 2,5 & 2,9 & 2,3
\end{tabular}

*Energia disponivel apenas para o acelerador do Hospital A. C. Camargo.

**Os patamares de dose máxima não variam entre os aceleradores.

As taxas de dose disponiveis para o Clinac 2100-C são 80, 160, 240, 320 e 400 U.M./min. A taxa de 400 U.M./min não estava disponivel no acelerador do Hospital das Clínicas.

\subsubsection{Acelerador de Elétrons Dynamitron Job 188}

O acelerador industrial Dynamitron Job 188 do Centro de Tecnologia das Radiações (CTR) foi utilizado como fonte de elétrons de 1,499 MeV possuindo largura de feixe de $112 \mathrm{~cm}$, taxa de dose de 1,10 kGy/s $(0,31 \mathrm{~mA})$ e velocidade de bandeja de $6,72 \mathrm{~m} / \mathrm{min}$. As bandejas são de aço inox com uma placa de madeira de $3 \mathrm{~cm}$ no fundo, sobre a qual as amostras foram colocadas. 


\subsubsection{Fonte de ${ }^{60} \mathrm{Co}$ (Gammacell)}

Como padrão de comparação da resposta do dosímetro FXG foi utilizada uma fonte de radiação gama de ${ }^{60} \mathrm{Co}$ para pesquisas do tipo Gammacell para irradiação das amostras com uma dose homogênea com fótons de 1,25 MeV. Este equipamento pertence Centro de Tecnologia das Radiações (CTR) do IPEN.

Para as irradiações com esta fonte, os dosímetros foram fixados entre cinco placas de $3 \mathrm{~mm}$ de lucite (condição de equilíbrio eletrônico), formando uma caixa sem tampa. Este arranjo foi disposto sobre um suporte cilíndrico de isopor, de modo que as cubetas ficassem posicionadas no centro do volume útil do irradiador (FIG.13), condição ideal para melhor uniformidade da dose dentro do gel (Galante, 2007). A atividade da fonte em 01/10/2008 era 105,64 TBq $(2,855 \mathrm{kCi})$ acarretando em uma taxa de dose de $2,36 \mathrm{kGy} / \mathrm{h}$ e uma dose de trânsito de 2,04 Gy.

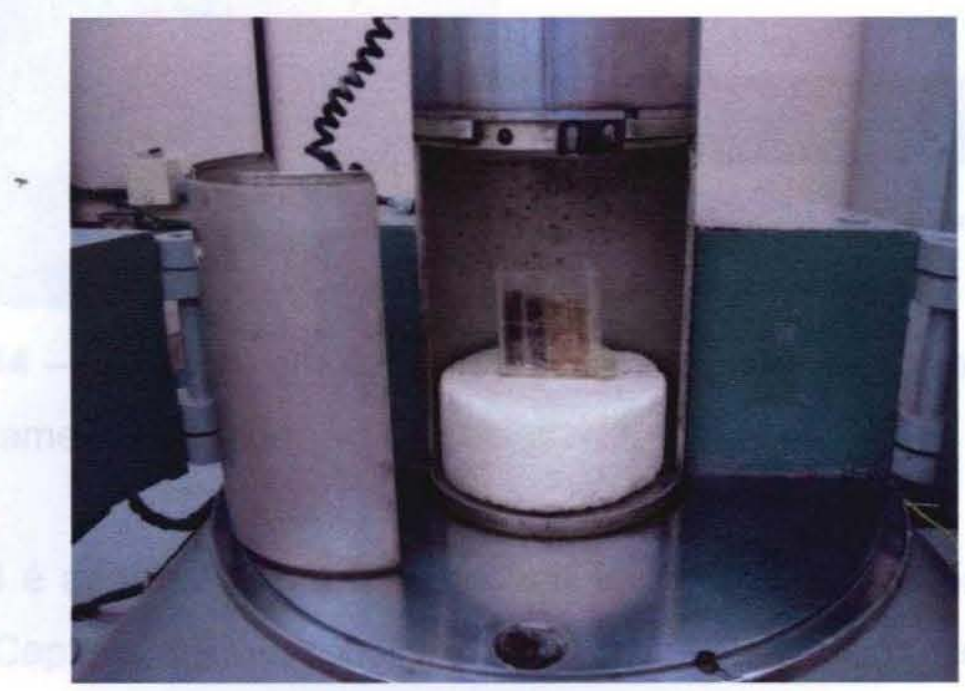

Figura 13 - Arranjo experimental para irradiação na fonte de ${ }^{60} \mathrm{Co}$ Gammacell pertencente ao CTR.

\subsubsection{Reator nuclear IEA-R1}

O dosímetro Fricke Gel foi modificado para realização de testes de dosimetria com nêutrons térmicos em campos mistos gama-nêutron pela adição de $60 \mathrm{ppm}$ de ${ }^{10} \mathrm{~B}$, tornando-o sensivel a neutrons térmicos (Mangueira, $2008 \mathrm{~A}$ ). $\mathrm{O}$ uso do FXG com a adição de Boro para aplicações voltadas para Terapia por 
Captura de Nêutrons já foi demonstrado e com o aumento do interesse em procedimentos radioterápicos mais eficientes, vem se tornando cada vez mais comum (Gambarini, 1997; Uusi-Simola, 2007).

O Reator Nuclear IEA-R1 do IPEN, através do sistema já existente no BH\#3, foi utilizado como fonte de nêutrons térmicos. $O$ suporte acrílico para irradiação de pendorfs já existente no arranjo do $\mathrm{BH} \# 3$ permite fixar os dosímetros $\mathrm{FXG}$ em diferentes posições e quantidades. A posição de irradiação do conjunto (dosímetros + suporte), chamado de amostra, esta exemplificada na FIG.14.

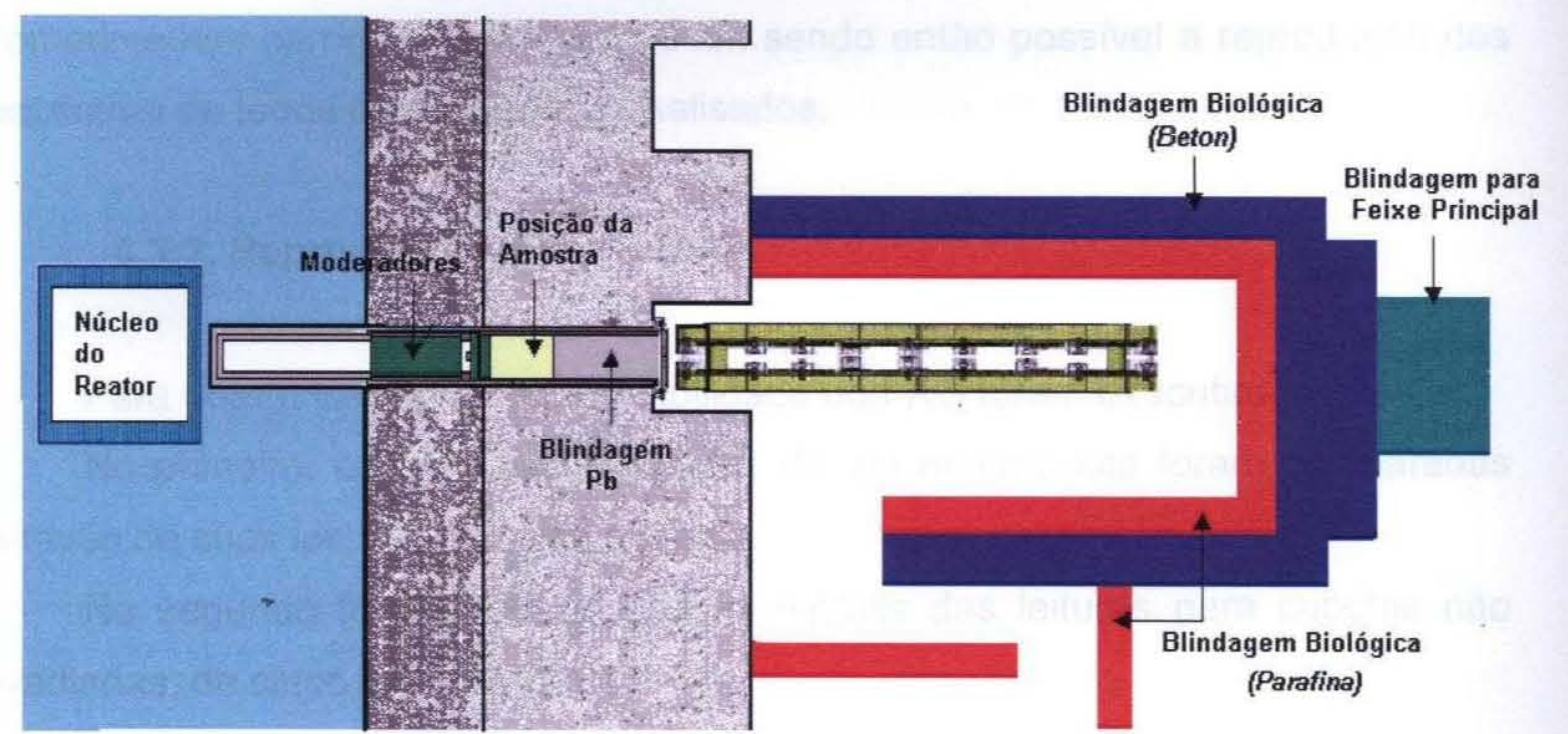

Figura 14 - Esquema em corte horizontal do BH\#3 com o suporte (amostra) completamente inserido.

O BH\#3 é adaptado para fornecer um feixe de nêutrons para pesquisa em Terapia por Captura de Nêutrons. Por isso, existe entre o núcleo do reator e o porta amostras, moderadores constituídos de materiais que não apenas "termalisam" os nêutrons, mas também blindam a radiação gama. Apesar disso, o feixe ainda é constituído por uma parcela significativa de nêutrons epitérmicos e raios gama de espectro energético grande. Durante as irradiações o reator nuclear operou a 2,5 MW gerando em uma taxa de dose de $32 \mathrm{cG} / \mathrm{min}$ de nêutrons e 8,5 cGy/min de gama, no centro do suporte de irradiação. 
4.3. Testes de desempenho do dosímetro FXG

\subsubsection{Espectro de absorção ótica do FXG irradiado com feixes clínicos de elétrons e nêutrons e feixe industrial de elétrons}

Antes do início dos testes de desempenho com o dosímetro FXG há a necessidade de verificar se o espectro de absorção do dosímetro não foi modificado pelo feixe de partículas incidente.

Todas as leituras realizadas com o espectrofotômetro foram para os comprimentos de onda de 400 a $700 \mathrm{~nm}$ sendo então possivel a reprodução dos espectros de todos os dosimetros analisados.

\subsubsection{Reprodutibilidade do FXG}

Para determinação da reprodutibilidade do FXG foram executados 2 testes:

No primeiro, cubetas não irradiadas de um mesmo lote foram comparadas através de suas leituras relativas à média.

No segundo foram comparadas as médias das leituras para cubetas não irradiadas, de cinco lotes diferentes.

\subsubsection{Curvas de dose resposta}

\subsubsection{Curvas de dose resposta para feixes de fótons e} elétrons do acelerador Varian Clinac 2100-C

O dosímetro FXG desenvolvido no IPEN possui suas curvas dose resposta já bem estabelecidas para feixes de fótons (Schreiner, 2004; Galante, 2007), assim, foram obtidas curvas comparativas de fótons e elétrons para feixes clínicos. Devido à limitação dos aceleradores, só foi possível realizar esta análise para energias de $6 \mathrm{MeV}$ e $15 \mathrm{MeV}$. 


\subsubsection{Curvas de dose resposta para acelerador Dynamitron} Job 188

Os dosímetros foram fixados sobre o fundo de madeira da bandeja de inox. O sistema de esteira leva a bandeja para dentro do irradiador, passando obrigatoriamente duas vezes pelo feixe.

Como a energia máxima dos elétrons neste acelerador é de aproximadamente $1,5 \mathrm{MeV}$, a dose depositada no dosímetro não é homogênea, sendo necessário irradiar as cubetas por dois lados opostos. Outro problema é a alta taxa de dose que não permite a deposição de menos de 0,5 kGy por volta (2 "passadas" em baixo do feixe). Assim, um dosímetro nomeado como 0,5 kGy passou duas vezes em baixo do feixe com a face ótica voltada para o irradiador e outras duas com face ótica voltada para a bandeja, recebendo a dose nominal uma vez em cada face.

\subsubsection{Curvas de dose resposta para Reator Nuclear IEA-R1}

Para a irradiação no BH\#3, o dosímetro FXG foi fixado na parte frontal do

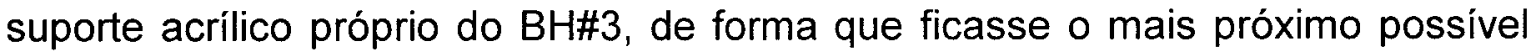
dos moderadores. Neste arranjo apenas duas cubetas eram suportadas por irradiação. A dose foi estimada pelo tempo de irradiação e pela dosimetria termoluminescente de albedo feita pelo Centro de Engenharia Nuclear (CEN).

\subsubsection{Limite inferior e superior de detecção para feixes clínicos de elétrons}

Os limites de detecção foram determinados apenas para o feixe de elétrons do acelerador clínico. O limite inferior de detecção (LID) foi determinado empregando equação 5. O limite superior de detecção (LSD) é dado como o primeiro ponto que se localiza a mais de um desvio padrão em relação à reta ajustada para doses de 1 a 30 Gy (região qualitativamente linear). O LSD não será utilizado nas regressões lineares por já exceder o limite de variação estipulado. 


$$
L I D=\left(L_{0}+3 \sigma_{\bar{D} . \sigma .0)}\right) f_{c a l}
$$

onde $L_{0}$ é a leitua para cubetas não irradiadas

$\sigma_{\overline{D .0}: 0}$ é o desvio padrão da leitura para cubetas não irradiadas

$f_{\text {cal }}$ o fator de calibração do lote.

\subsubsection{Dependência energética da resposta para feixes clínicos de elétrons}

A dependência energética foi estudada através das leituras de dosímetros irradiados com 5, 20 e 40 Gy de dose absorvida em função da energia nominal do feixe. A Taxa de dose utilizada foi de 320 U.M./min. As absorvâncias foram divididas pela média das leituras para uma mesma dose (absorvância relativa).

\subsubsection{Dependência da resposta com a taxa de dose para feixes clínicos de elétrons}

As taxas de dose utilizadas foram 80, 160, 240, 320 e 400 U.M./min. Todas as cubetas foram irradiadas com elétrons de $9 \mathrm{MeV}$ e dose de $5 \mathrm{~Gy}$. A dose de 5 Gy foi escolhida por ter apresentado a maior variação no teste de reprodutibilidade. As absorvâncias foram divididas pela média das leituras (absorvância relativa).

\subsubsection{Variação da absorvância em função do tempo (estabilidade)}

Para avaliar a variação da absorvância do dosímetro FXG em função da oxidação natural do ferro com o tempo foram feitas medições em dosimetros não irradiados durante um periodo $60 \mathrm{~h}$ e com dosímetros irradiados com doses de 1 a 30 Gy durante um periodo de $240 \mathrm{~h}$.

Também foi avaliada a influência do período pós preparação do dosímetro na curva de dose reposta. Para isto foram realizadas irradiações em alguns intervalos de tempo após o preparo da solução FXG, para um mesmo lote. Os dosimetros foram acondicionados em caixas térmicas (uma para cada grupo do 
lote), dentro de um refrigerador e mantidos nesta situação até uma hora antes da irradiação ou leitura. Devido à indisponibilidade do acelerador clínico durante longos periodos, foi possível apenas fazer irradiações com intervalos de tempo múltiplos de 24h. Assim, as análises para variações de tempo menores que um dia, foram realizadas no irradiador de ${ }^{60} \mathrm{Co}$ do tipo Gamma Cell apenas para a dose de $30 \mathrm{~Gy}$, uma vez que quanto maior a dose absorvida maior a variação na resposta.

\subsection{Sistema alternativo de leitura}

Como mostrado no item 3.5.1, as alterações químicas no FXG também alteram as propriedades óticas do dosímetro, devido à presença de alaranjado de xilenol em sua composição. Este composto modifica significativamente o espectro de absorção do dosímetro irradiado em relação ao não irradiado, principalmente no comprimento de onda de $585 \mathrm{~nm}$ (região do amarelo/laranja). Isto permite então que dispositivos óticos simples como câmeras fotográficas digitais possam ser utilizados como sistemas de leitura do FXG. Estes sistemas de leitura podem ser baseados em Dispositivos de Carga Acoplada (CCD - do inglês chargecoupled device) e são bem conhecidos e utilizados por alguns Centros de Pesquisa (Gambarini, 2004; Tarte 1997), principalmente, para dosimetria 2D de feixes radioterápicos (Minasawa, 2008).

Este teste não foi repetido e as cubetas preenchidas com FXG foram irradiadas apenas no acelerador do Hospital das Clínicas, com feixe de elétrons de $9 \mathrm{MeV}$.

As imagens dos dosimetros irradiados foram captadas logo após a leitura no espectrofotômetro. Para isto todas as cubetas foram posicionadas juntas sobre um negatoscópio e a imagem adquirida com uma câmera Sony Cyber-Shot 8 MP a $30 \mathrm{~cm}$ do negatoscópio, no modo "Easy" e sem o uso de flash, com o intuito de captar a luz que atravessa o FXG. O arquivo em formato JPG foi processado com uma rotina em MATLAB, sendo a matriz referente à cor azul eliminada e, então realizado uma média entre as matrizes referentes às cores vermelho e verde. $A$ intensidade de luz $l$ que atravessa o dosímetro foi estimada pela média de um quadrado de lado 50 pixels, no centro da cubeta a ser analisada. 
Para o sinal obtido pela câmera fotográfica foi utilizada a seguinte equação para o cálculo da leitura do FXG para uma determinada dose:

$$
L_{\cos }=-\log \left(\frac{1}{l_{0}}\right)
$$

sendo $L_{C C D}$ a leitura do FXG, I a média do sinal para cubetas irradiadas com uma determinada dose e $I_{0}$ a média do sinal das cubetas não irradiadas.

\subsection{Aplicação do dosímetro FXG em dosimetria 3D para Braquiterapia de alta taxa de dose}

Os dosímetros químicos possuem uma resolução espacial maior que as câmaras de ionização ou dosímetros do estado sólido (lbbott, 2004), como em radioterapia pretende-se depositar a maior quantidade de dose possível no tumor, poupando ao máximo os tecidos saudáveis, procuram-se cada vez mais técnicas de tratamento que permitam uma distribuição de dose absorvida com um gradiente alto nas bordas do volume alvo. Uma das técnicas que permite um planejamento com distribuições de dose nestas características é a braquiterapia de alta taxa de dose.

Dentre os tratamentos braquiterápicos mais comuns no Hospital A. C. Camargo está o de câncer de colo de útero. Nesta modalidade um aplicador, constituido por uma sonda intra-uterina e dois ovóides (FIG.15), é fixado na região a ser tratada. Após o planejamento com o software Brachyvision, o aparelho de carregamento remoto posiciona uma pequena fonte de Irídio dentro do aplicador, de forma que a contribuição na dose absorvida de cada parada da fonte ao longo do tratamento resulte nas curvas de isodose desejáveis ao tratamento.

Esta modalidade mais complexa de tratamento foi escolhida para o teste devido a uma discussão entre as aprimorandas do Hospital A. C. Camargo a respeito da influência do tamanho dos ovóides na qualidade do tratamento conforme as características da paciente.

Para este teste foi construido um simulador constituído de um pote plástico de 2 L, que foi perfurado em 3 pontos em sua lateral e preso sobre um suporte de 
isopor para fixar o aplicador braquiterápico de titânio. Foi utilizado o aplicador de titânio, pois se pretendia fazer imagens tridimenssionais por Ressonância Magnética Nuclear (RMN).

Depois de fixado o aplicador no pote, o mesmo foi preenchido com FXG e armazenado em geladeira por $24 \mathrm{~h}$.

O objeto simulador foi definido como conjunto do pote com o aplicador braquiterápico e o FXG.

Como o volume era muito grande o tempo de espera com o objeto simulador dentro da sala de irradiação para equilibrio térmico foi de $2 \mathrm{~h}$.

O objeto simulador foi posicionado sobre a mesa de tratamento, radiografado e planejado da mesma forma que uma paciente. Após planejamento o software apresenta as curvas de isodose calculadas.

Realizada a irradiação o objeto simulador foi levado à sala do tomógrafo de RMN onde aguardou por $1 \mathrm{~h}$ antes de ser posicionado para a obtenção das imagens.

Após a obtenção das imagens por RMN o objeto simulador foi desmontado de forma a retirar o pote plástico causando o menor dano possível ao FXG para a tentativa de também obter imagens por CCD.
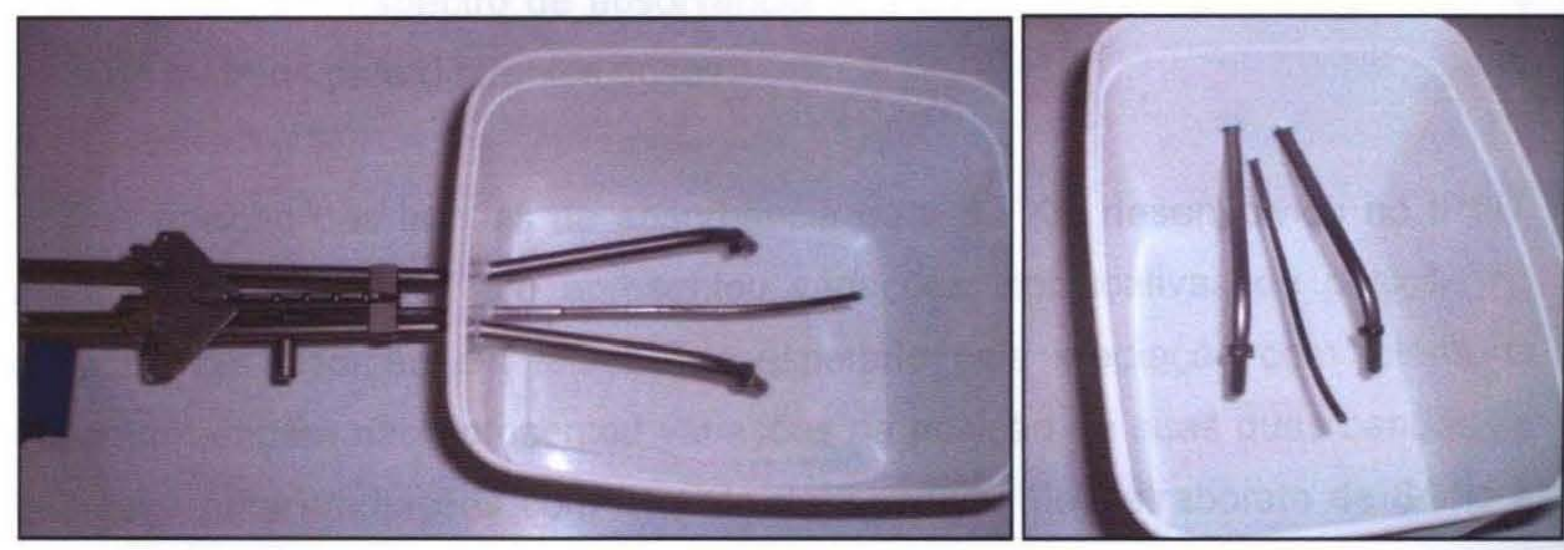

Figura 15 - Aplicador útero-vaginal para braquiterapia intra-cavitária inserido no pote sem o FXG, mostrando os dois ovóides (projetados para o fundo do pote) e a sonda intra-uterina (projetada para a abertura do pote). 


\section{RESULTADOS E DISCUSSÕES}

\subsection{Espectro de absorção ótica do FXG irradiado com feixes clínicos de} elétrons e nêutrons e feixe industrial de elétrons

A FIG.16 apresenta a absorvância líquida para cubetas irradiadas com feixes clínicos de elétrons no acelerador do $\mathrm{HC}$ com doses de 0,5 a $45 \mathrm{~Gy}$.

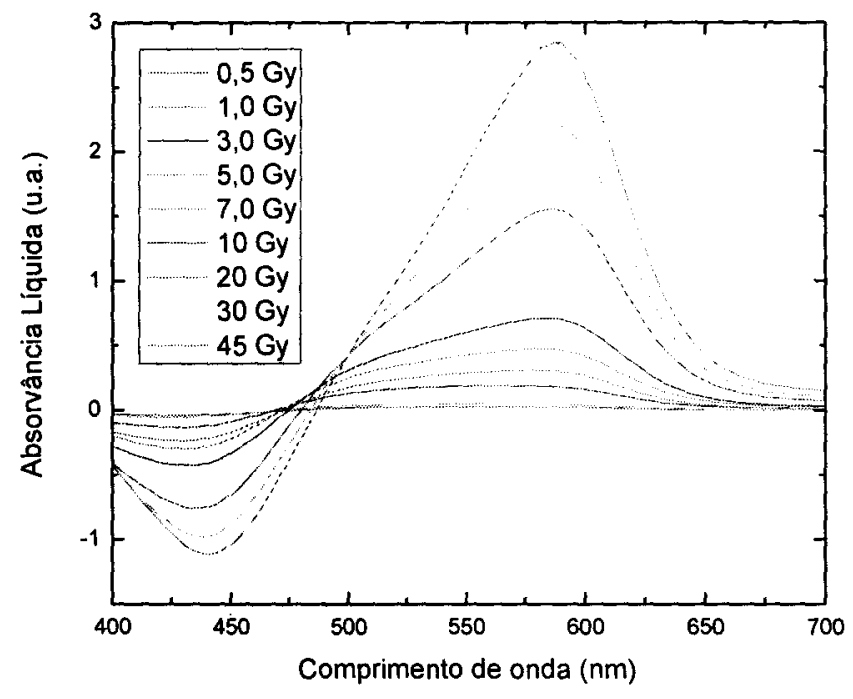

Figura 16 - Espectro de absorvância do FXG irradiado com feixes clínicos de elétrons para diferentes doses.

A posição das bandas de absorbância para o FXG desenvolvido no IPEN, irradiado com elétrons não apresentou variações significativas de posição no espectro de absorção em relação ao esperado pela irradiação com fótons. $O$ espectro também não apresentou variações na posição de suas duas bandas de interesse para irradiações com taxa de dose, adição de Tetraborato de Sódio a solução ou irradiação no feixe de nêutrons do $\mathrm{BH} 33$, sendo estes espectros omitidos por serem semelhantes ao da FIG. 16, exceto pelas intensidades. 


\subsection{Reprodutibilidade do FXG}

A FIG.17 apresenta a absorvância relativa para dosimetros não irradiados de um mesmo lote.

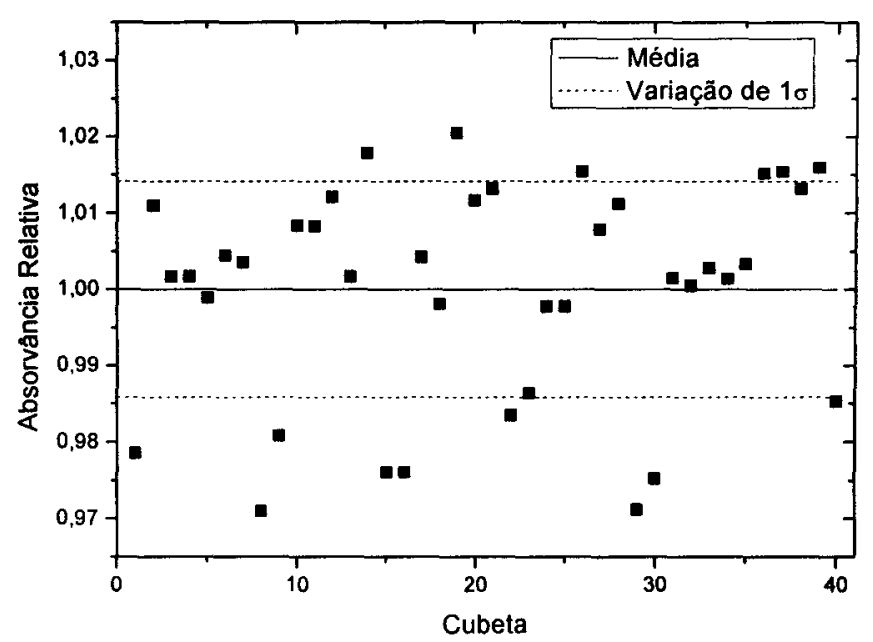

Figura 17 - Absorvância líquida relativa das cubetas não irradiadas de um mesmo lote.

De acordo como os resultados para cubetas não irradiadas de um único lote foi observado um desvio padrão de 1,4\%. Nota-se também que neste teste não houve nenhum valor que ultrapassou $3 \%$ da média. Ao longo dos experimentos foi observado que uma seleção prévia dos dosímetros, assim que são preparados, visando redução do desvio padrão do FXG não irradiado reduz as incertezas nas curvas de calibração, como é de se esperar. Nota-se que as cubetas descartadas neste pré-teste em geral apresentam sinais claros de danos, como arranhões e opacidade ou de partículas ou bolhas no gel.

A FIG.18 apresenta as absorvâncias médias relativas para 5 lotes sendo cada média obtida a partir de 40 dosímetros. 


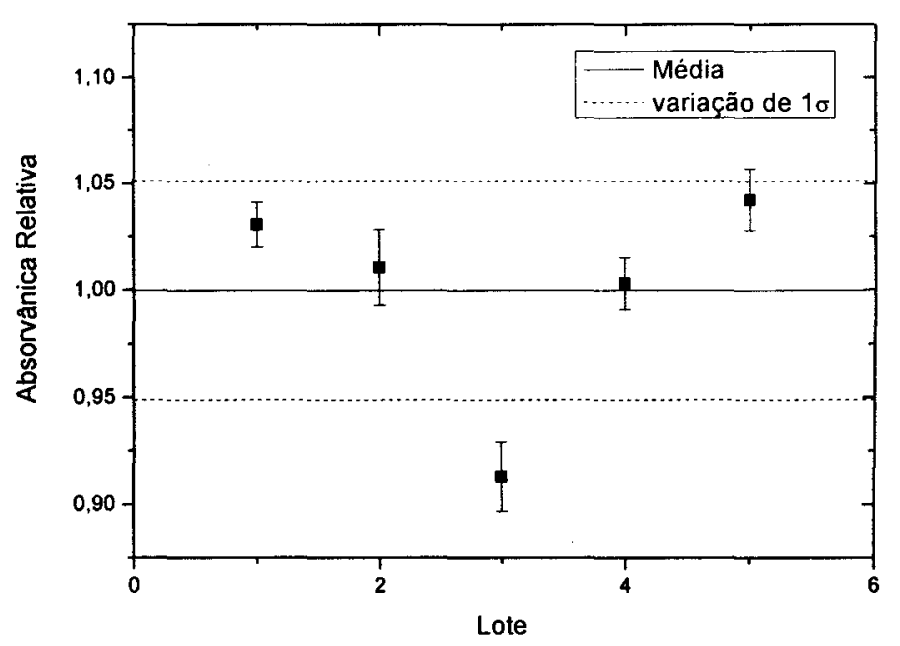

Figura 18 - Absorvância liquida relativa das cubetas não irradiadas para 5 lotes.

Ao analisar a média da absorvância dos dosímetros não irradiados de lotes diferentes, foi observado um desvio padrão de $5,1 \%$, reflexo da grande variação na intensidade do sinal que pequenas variações de concentração dos componentes dà solução. Os lotes 1,2 e 4 foram os únicos preparados com $400 \mathrm{~mL}$ ou mais, apresentando um desvio padrão de $1,4 \%$, semelhante ao do teste para lote único. Isso é esperado uma vez que volumes maiores de preparo irão possuir a concentração dos componentes mais exatas. Também durante os demais experimentos notou-se que os sinais de absorvância dos dosímetros não irradiados são mais semelhantes entre lotes produzidos com mais de $400 \mathrm{ml}$. Os outros experimentos realizados fizeram uso de grande parte das cubetas, em geral sobrando menos de 10 dosimetros não irradiados, inviabilizando a obtenção de valores quantitativos para testes de reprodutibilidade.

\subsection{Curvas de dose-resposta}

O ajuste por uma sigmóide em escala linear foi o que melhor representou as curvas de dose resposta e de variação da resposta do dosímetro com o tempo, mas por praticidade foi escolhido utilizar escala logaritmica e apenas a região das curvas na qual a função é aproximadamente uma reta. Isto está exemplificado na 
FIG.19 e os limites da linearidade da resposta do FXG serão discutidos no item 5.4 .

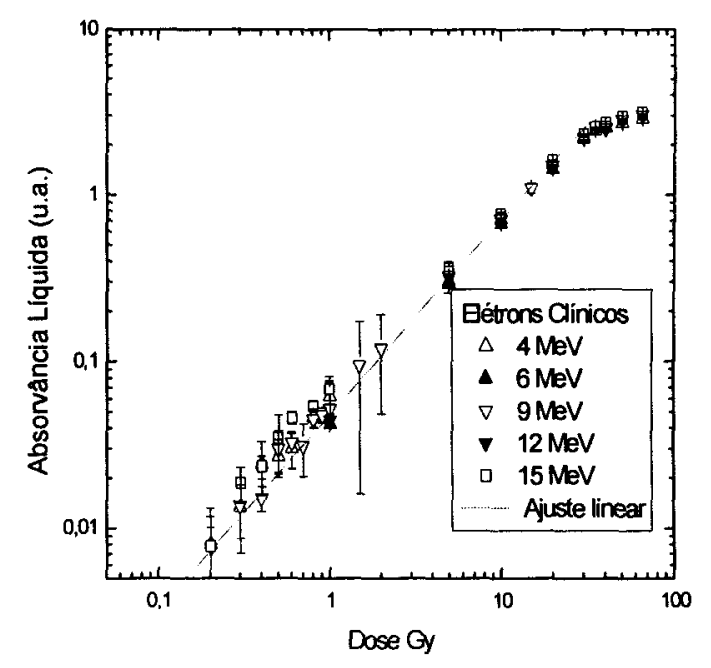

Figura 19 - Curva de dose resposta do FXG mostrando a aproximação linear qualitativa para várias energias.

\subsubsection{Curvas de dose resposta para feixes de fótons e elétrons do aceleradör Varian Clinac 2100-C}

As curvas de dose resposta para fótons e elétrons de 6 e $15 \mathrm{MeV}$ estão apresentadas na FIG.20.

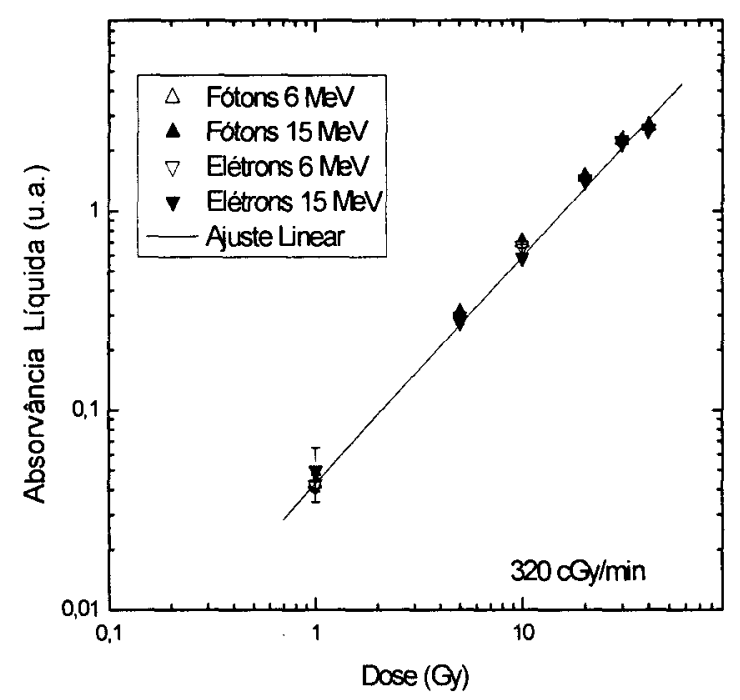

Figura 20 - Curva de dose resposta do FXG para fótons e elétrons.

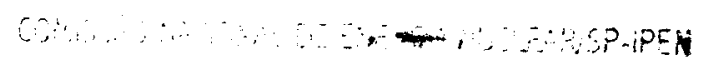


Considerando que, para fótons e elétrons de 6 e $15 \mathrm{MeV}$, a curva dose resposta foi ajustada como uma reta para leituras de doses de 1 a 40 Gy (ver item 5.4). Os coeficientes angular e linear das 4 retas são apresentados na TAB.5. Variação do sinal para uma mesma dose das quatro curvas é apresentada na TAB.6.

Tabela 5 - Coeficientes do ajuste linear* da curva dose resposta para fótons e elétrons de 6 e $15 \mathrm{MeV}$

\begin{tabular}{|c|c|c|c|}
\hline Feixe & Energia & Coeficiente Linear & Coeficiente Angular \\
\hline \multirow{2}{*}{ Elétrons } & 6 & $-0,02 \pm 0,01$ & $0,07 \pm 0,01$ \\
\cline { 2 - 4 } & 15 & $-0,02 \pm 0,01$ & $0,07 \pm 0,01$ \\
\hline \multirow{2}{*}{ Fótons } & 6 & $-0,07 \pm 0,01$ & $0,08 \pm 0,01$ \\
\cline { 2 - 4 } & 15 & $-0,01 \pm 0,01$ & $0,07 \pm 0,01$ \\
\hline
\end{tabular}

*todos $\operatorname{com} p<0,0001$

Tabela 6 - Variação porcentual para a leitura do dosimetro FXG para uma mesma dose entre as curvas de dose resposta do $F X G$ para fótons e elétrons

\begin{tabular}{|c|c|}
\hline Dose (Gy) & Variação Porcentual \\
\hline 1 & 1,75 \\
\hline 5 & 3,34 \\
\hline 10 & 5,29 \\
\hline 20 & 2,12 \\
\hline 30 & 1,93 \\
\hline 40 & 2,88 \\
\hline
\end{tabular}

Pelas TAB.5 e 6 pode-se notar que as variações no sinal são da ordem da reprodutibilidade do gel (item 5.2), e os coeficientes angulares são praticamente idênticos, logo se pode considerar que a resposta do gel é independente do tipo de feixe incidente estudado para doses de 1 a $40 \mathrm{~Gy}$. 


\subsubsection{Curvas de dose resposta para acelerador Dynamitron Job 188}

A curva de dose resposta acelerador de elétrons industrial Dynamitron Job 188 está apresentada na FIG.21.

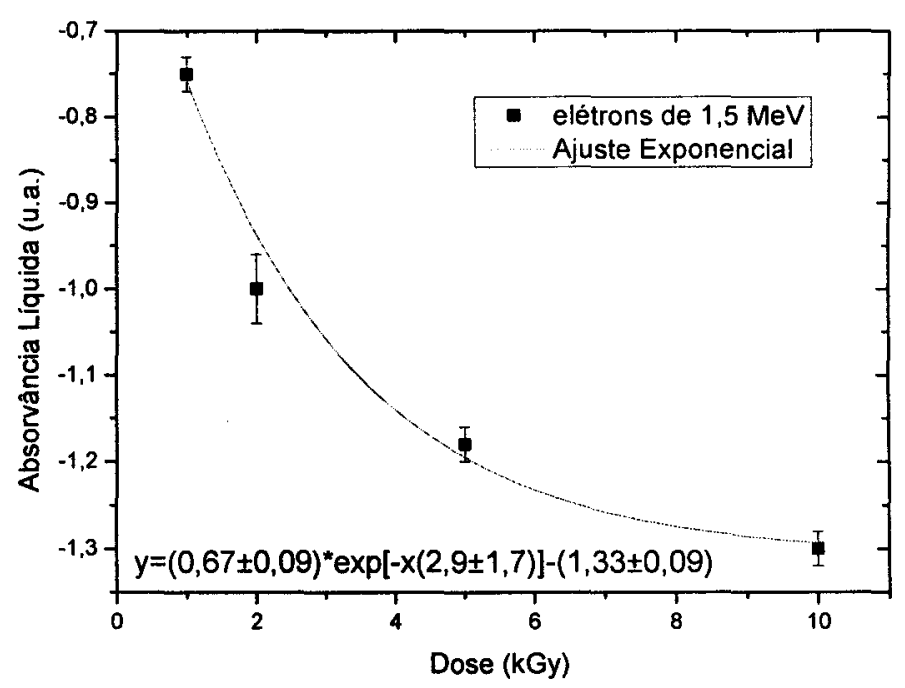

Figura 21 - Curva de dose resposta do FXG para elétrons de 1,499 MeV com larguca de feixe de $112 \mathrm{~cm}$, taxa de dose de 1,10 kGy/s $(0,31 \mathrm{~mA})$ e velocidade de bandeja de $6,72 \mathrm{~m} / \mathrm{min}$.

Neste experimento foi observado um comportamento completamente diferente em relação aos experimentos com aceleradores clínicos. Em primeiro lugar, observou-se que quanto maior a dose depositada no dosímetro mais incolor ele ficava (FIG.22), e conseqüentemente menor era a absorvância, que é indicado na FIG.21. Outro comportamento percebido foi que alguns segundos depois de sair do irradiador, para doses maiores que $5 \mathrm{kGy}$, surgiam bolhas de gás no meio da matriz de gelatina, que atrapalharam a leitura (FIG.23). Também foi observado que para estas doses a gelatina não liquefazia quando aquecida e era possivel observar um gradiente de cor dentro da cubeta, indicando a inomogeneidade de dose dentro do dosímetro, o que já esperado devido a baixa energia dos elétrons e pode ser visualmente verificado como mostrado na FIG.24. 


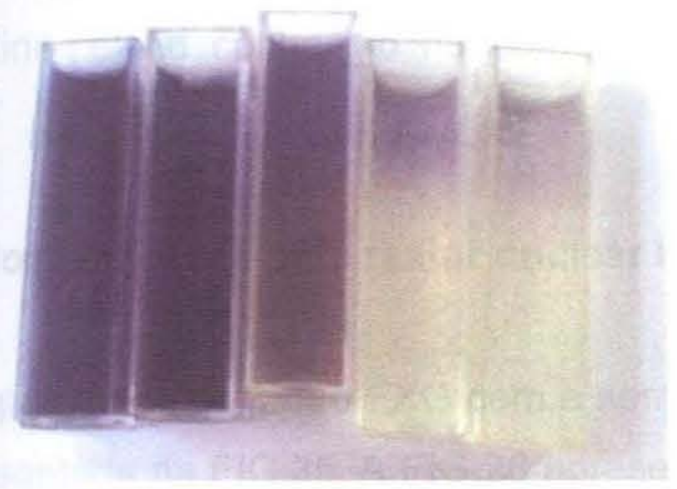

Figura 22 - Alteração de cor no dosímetro FXG devido a irradiação com feixes industriais de elétrons - da esquerda para direita doses de 1, 2, 5, $10 \mathrm{kGy}$, sendo as 2 primeiras com a mesma dose.

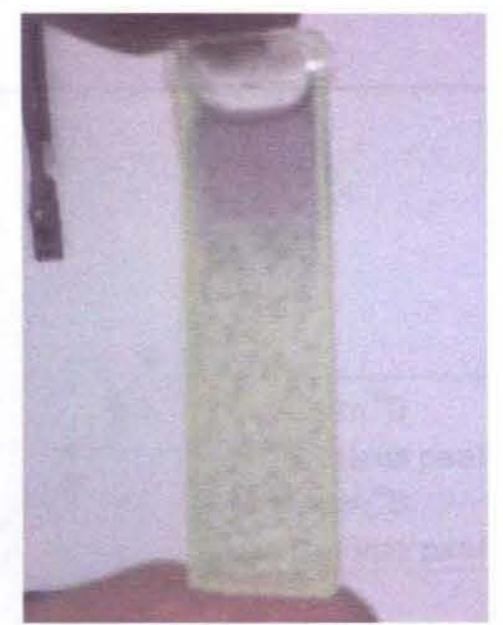

Figura 23 - Detalhe das bolhas formadas pela irradiação com feixes industriais de elétrons para doses acima de $5 \mathrm{kGy}$.

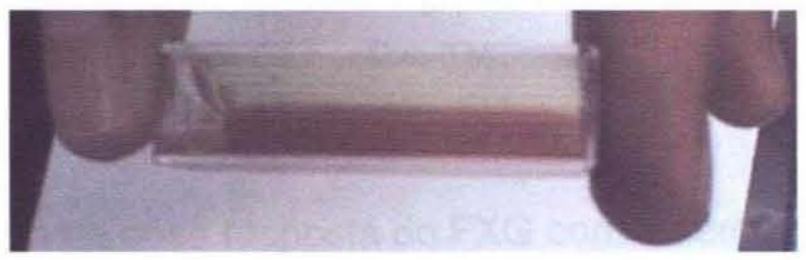

Figura 24 - Gradiente de cor dentro da cubeta indicando o gradiente de dose previsto pela energia do feixe de elétrons.

A perda de cor do dosímetro pode ser explicada pela quebra das moléculas de xilenol, uma vez que é conhecido o uso deste tipo de feixe no processamento de resíduos químicos (McLaughlin, 1989; lliev, 2004). A formação de bolhas de 
gás pode ser gerada pela liberação de gás hidrogênio, oxigênio e outros, durante a polimerização da gelatina, efeito conhecido na confecção de membranas e cápsulas de remédios.

\subsubsection{Curvas de dose resposta para reator nuclear IEA-R1}

A curva de dose resposta do dosímetro FXG com e sem adição de ${ }^{10} \mathrm{~B}$ para irradiação no ${ }^{60} \mathrm{Co}$ é apresentada na FIG.25. A FIG.26 apresenta a curva de dose resposta do dosímetro $F X G$ com Boro para o feixe misto gama/nêutron. O gráfico da FIG.27 foi obtido a partir da subtração das curvas de dose resposta para o dosimetro FXG com ${ }^{10} \mathrm{~B}$ da FIG.25 pela FIG.26, levando em consideração que contribuição da dose gama para o feixe misto é de apenas $25 \%$ da dose total.

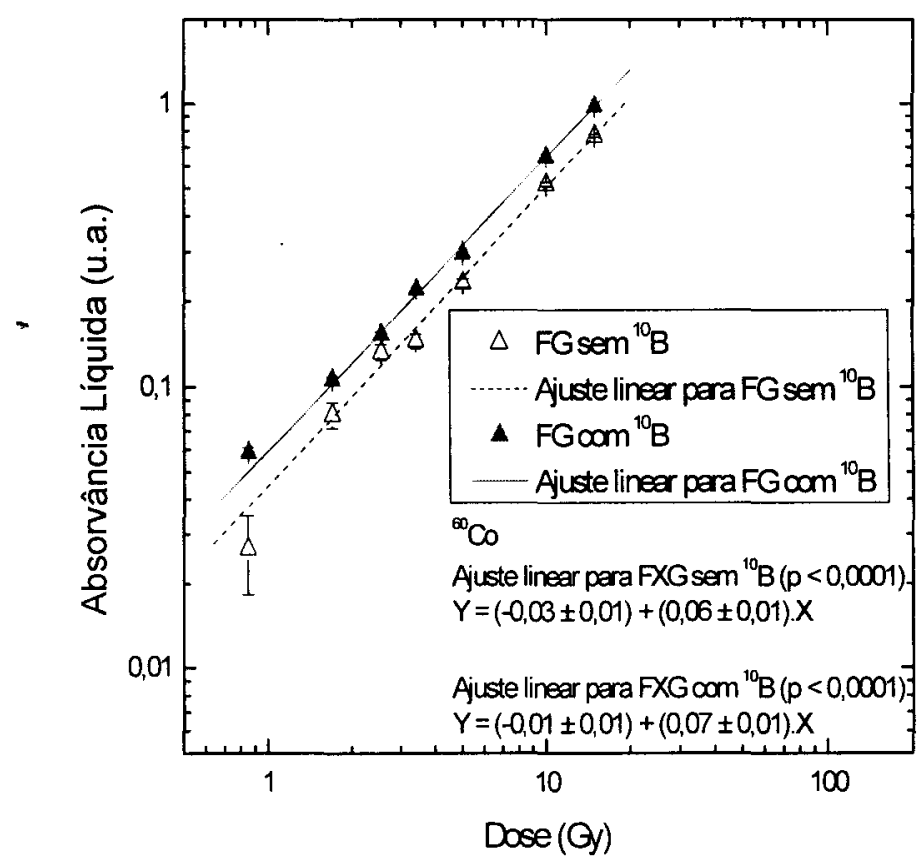

Figura 25 - Curva de dose resposta do FXG com e sem adição de ${ }^{10} \mathrm{~B}$ para ${ }^{60} \mathrm{Co}$. 


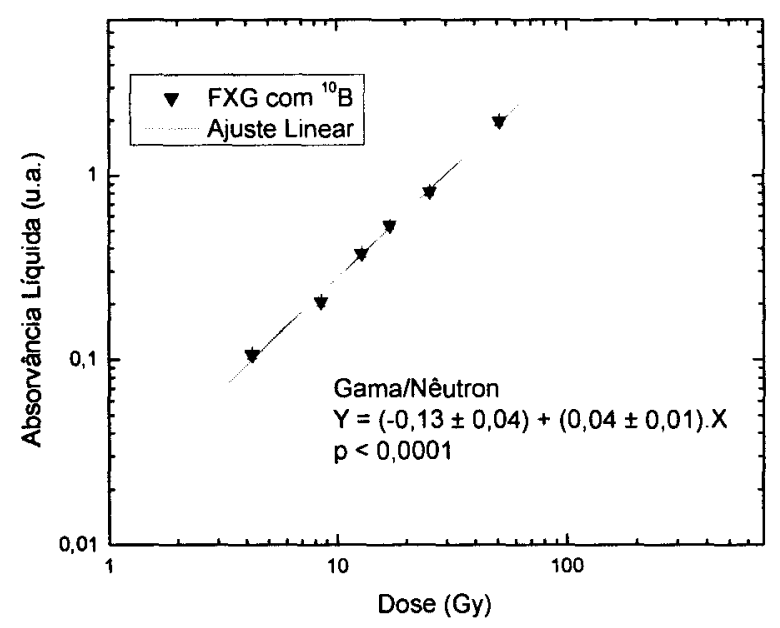

Figura 26 - Curva de dose resposta do FXG com adição de ${ }^{10} \mathrm{~B}$ para o feixe misto gamma/nêutron.

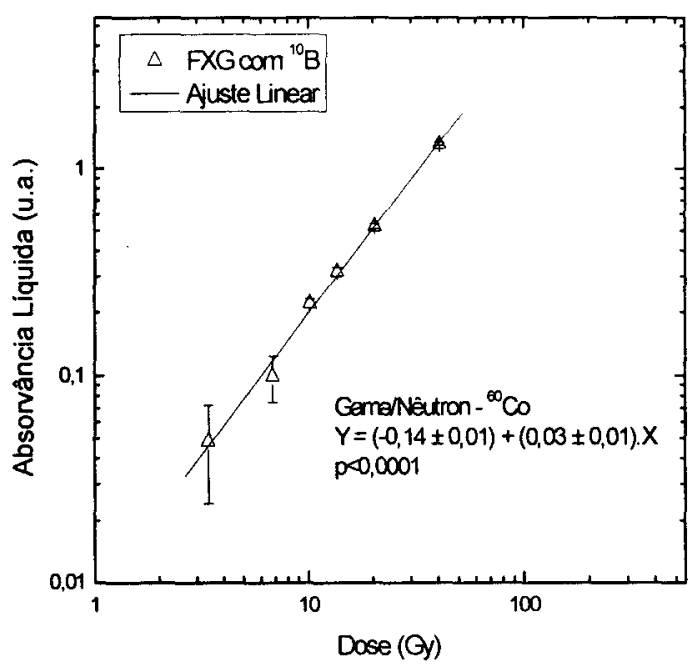

Figura 27 - Curva de dose resposta do FXG com adição de ${ }^{10} \mathrm{~B}$ para nêutrons.

Pela FIG.25 nota-se que o coeficiente angular para as duas curvas são praticamente idênticos e o sinal para o dosimetro $F X G$ com adição de ${ }^{10} \mathrm{~B}$ mais intenso. Por isso as irradiações realizadas no $\mathrm{BH} \# 3$ foram realizadas apenas para o FXG com adição de ${ }^{10} \mathrm{~B}$. Na FIG.26 é apresentada a curva de calibração para o dosímetro $F X G$ com adição de ${ }^{10} \mathrm{~B}$ para o feixe misto gama/nêutron apresentando um comportamento linear até 50 Gy. No gráfico da FIG.27 é possivel visualizar o comportamento linear da resposta do dosímetro FXG para um feixe de nêutrons corroborando o uso do FXG na dosimetria dos nêutrons do BH\#3. 


\subsection{Limite inferior e superior de detecção do FXG para feixes clínicos de elétrons}

A FIG.28 apresenta as curvas de dose-resposta para feixes clínicos de elétrons de 4, 9 e $15 \mathrm{MeV}$ de energia nominal com doses de 0,2 a $65 \mathrm{~Gy}$.

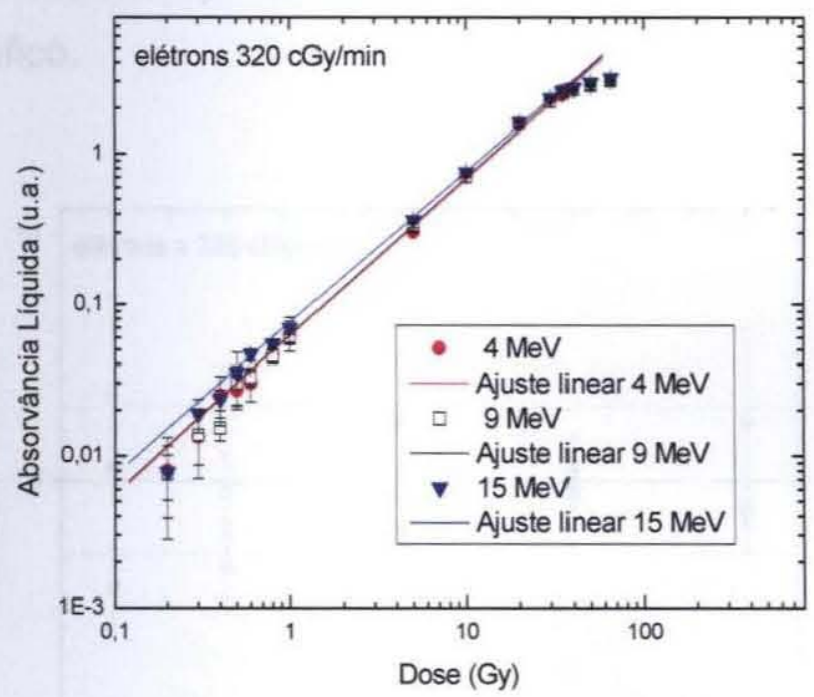

Figura 28 - Curva de dose resposta do FXG para determinação do LID e do LSD para feixes padrão de elétrons.

A TAB.7 mostra os coeficientes angulares, o LID e o LSD obtidos para as curvas da FIG. 28.

Tabela 7 - Coeficiente Angular, LID e LSD para feixes clínicos de elétrons em função da energia nominal.

\begin{tabular}{|c|c|c|c|}
\hline Energia (MeV) & Coeficiente Angular & LID (Gy) & LSD (Gy) \\
\hline 4 & $0,04 \pm 0,09$ & 0,17 & 40 \\
\hline 9 & $0,03 \pm 0,08$ & 0,08 & 40 \\
\hline 15 & $0,06 \pm 0,08$ & 0,14 & 40 \\
\hline
\end{tabular}

Maximizando as incertezas devido a reprodutibilidade do FXG, tem-se que o intervalo útil do sistema dosimétrico FXG desenvolvido no IPEN, para feixes de elétrons de 4 a $15 \mathrm{MeV}$, está entre 0,2 e 40 Gy. 


\subsection{Dependência energética da resposta do dosímetro FXG para feixes clínicos de elétrons}

A FIG.29 apresenta absorvância líquida relativa pelas médias das leituras para uma determinada dose em função da energia nominal do feixe para doses absorvidas de 5, 20 e 40 Gy. As outras doses foram omitidas para facilitar a visualização do gráfico.

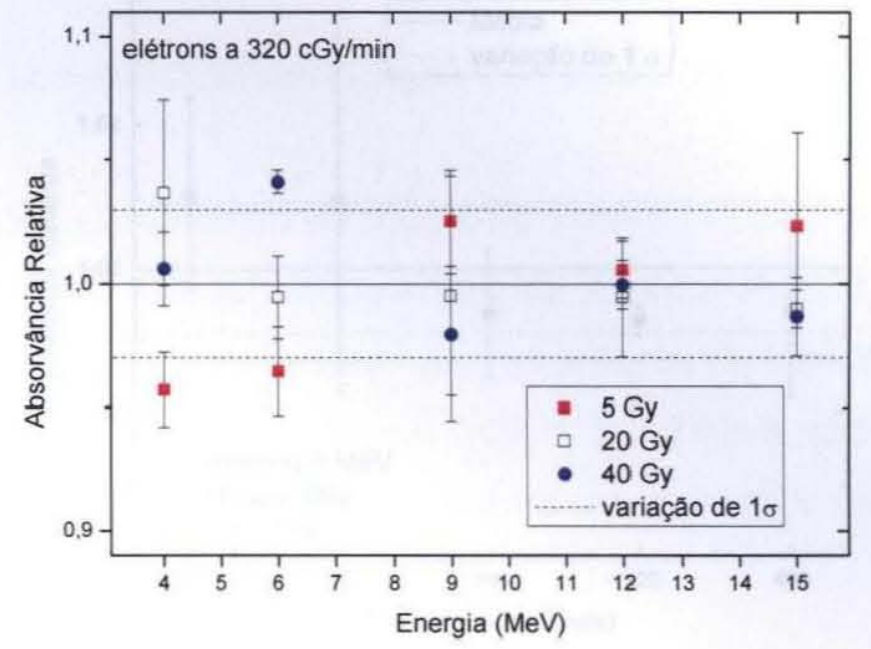

Figura 29 - Absorvância líquida relativa para doses absorvidas de 5, 20 e 40 Gy em função da energia nominal do feixe.

Pela FIG.29 observa-se que as variações na leitura foram menores que $5 \%$. O desvio padrão de todas as leituras foi de $3 \%$. Este comportamento se manteve ao longo da curva de 1 a 40 Gy, logo, podemos considerar que a resposta do gel é independente da energia do feixe padrão de elétrons para energias de 4 a $15 \mathrm{MeV}$. 


\subsection{Dependência da resposta do dosímetro FXG com a taxa de dose para} feixes clínicos de elétrons

A FIG.30 apresenta a absorvância líquida relativa para um mesmo lote do dosímetro FXG e a FIG.31 apresenta as mesmas informações, exceto que a média foi realizada com 5 lotes diferentes.

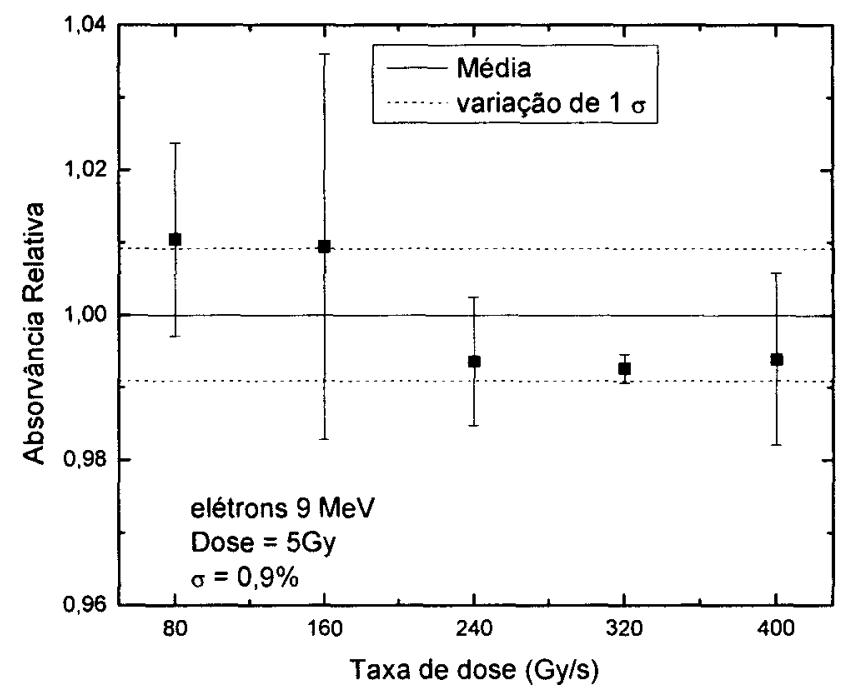

Figura 30 - Absorvância líquida relativa para um único lote de FXG em função da taxa de dose com campo padrão de elétrons

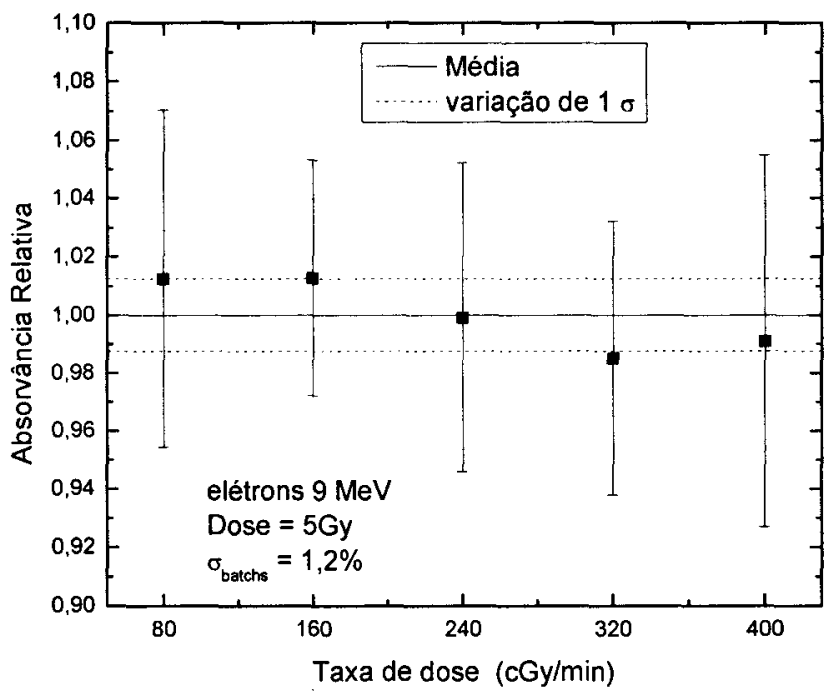

Figura 31 - Absorvância líquida relativa para 5 lotes de FXG em função da taxa de dose com campo padrão de elétrons. 
A absorvância das amostras de um mesmo lote não apresentam uma dependência significante com a taxa de dose, considerando a imprecisão nas medidas e a reprodutibilidade do gel. Pode-se observar que, para a média de cinco lotes, também não há dependência significante com a taxa de dose, considerando a imprecisão nas medidas e a reprodutibilidade do dosímetro. Com isto podemos afirmar que o sistema dosimétrico estudado é independente da taxa de dose para taxas de 80 a 400 cGy/min e dose absorvida de 5 Gy.

\subsection{Variação da absorvância em função do tempo (estabilidade)}

A FIG.32 mostra a variação da média do sinal de dosímetros não irradiados, para um único lote de $F X G$, em um intervalo de 240h. A FIG.33 apresenta curvas de dose resposta para elétrons, sendo que, as leituras no mesmo conjunto, foram realizadas 6 vezes em um intervalo de 240 h. Na TAB. 8 são apresentados os coeficientes das regressões lineares dos dados apresentados na FIG.33.

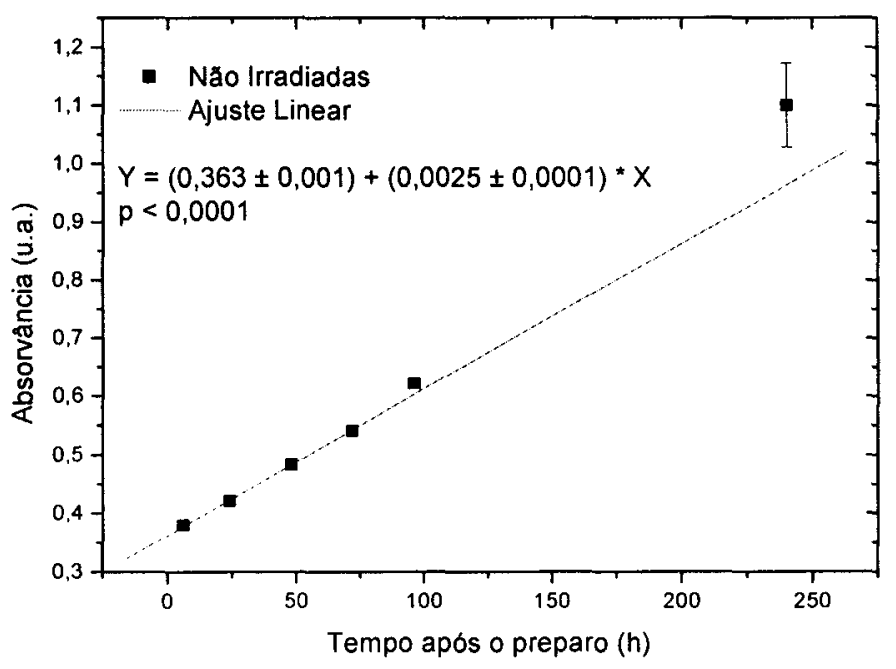

Figura 32 - Variação da média do sinal de dosímetros não irradiados, para um único lote de FXG. 


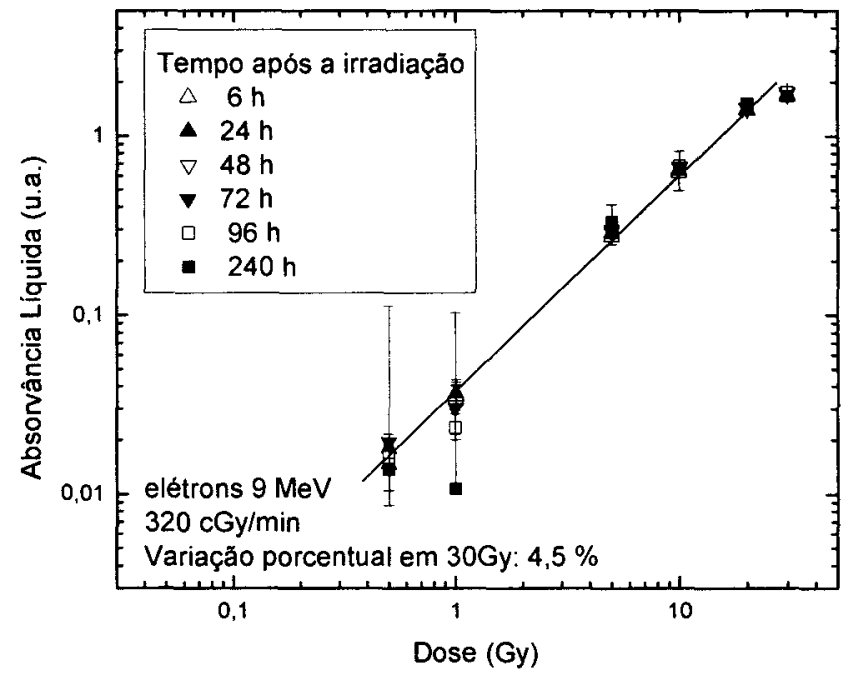

Figura 33 - Curvas de dose reposta de dosímetros FXG (sobrepostas) que foram mensuradas em diferentes tempos após a irradiação.

Pode-se observar pela FIG.32 que o dosímetro FXG não irradiado sofre oxidação natural mesmo mantido na geladeira. No entanto, esta variação no sinal não traz influências significativas às curvas de calibração, como pode ser observado na FIG.33 e TAB.8 que mostram a variação da absorvância líquida e coeficientes das regressões lineares não possuem alterações significativas no tempo.

Tabela 8 - Coeficientes do ajuste linear da curva de dose resposta do FXG para irradiações com elétrons mensuradas em diferentes tempos após a irradiação.

\begin{tabular}{ccc}
\hline Tempo $(\mathrm{h})$ Coeficiente Linear & Coeficiente Angular \\
\hline 6 & $-0,02 \pm 0,01$ & $0,06 \pm 0,01$ \\
24 & $-0,01 \pm 0,01$ & $0,06 \pm 0,01$ \\
48 & $-0,01 \pm 0,01$ & $0,06 \pm 0,01$ \\
72 & $-0,02 \pm 0,01$ & $0,07 \pm 0,01$ \\
96 & $0,01 \pm 0,01$ & $0,06 \pm 0,01$ \\
240 & $0,04 \pm 0,01$ & $0,06 \pm 0,01$ \\
\hline
\end{tabular}

*todos $\operatorname{com} p<0,0002$ 
A FIG.34 apresenta as curvas de dose resposta para um lote de dosímetros FXG que foi irradiado com elétrons em diferentes tempos após o preparo. Este experimento foi repetido para uma dose absorvida de $30 \mathrm{~Gy}$ na fonte GammaCell em intervalos de tempo menores entre as irradiações e os resultados estão na FIG.35. Os parâmetros dos ajustes lineares da FIG.34 estão apresentados na TAB.9.

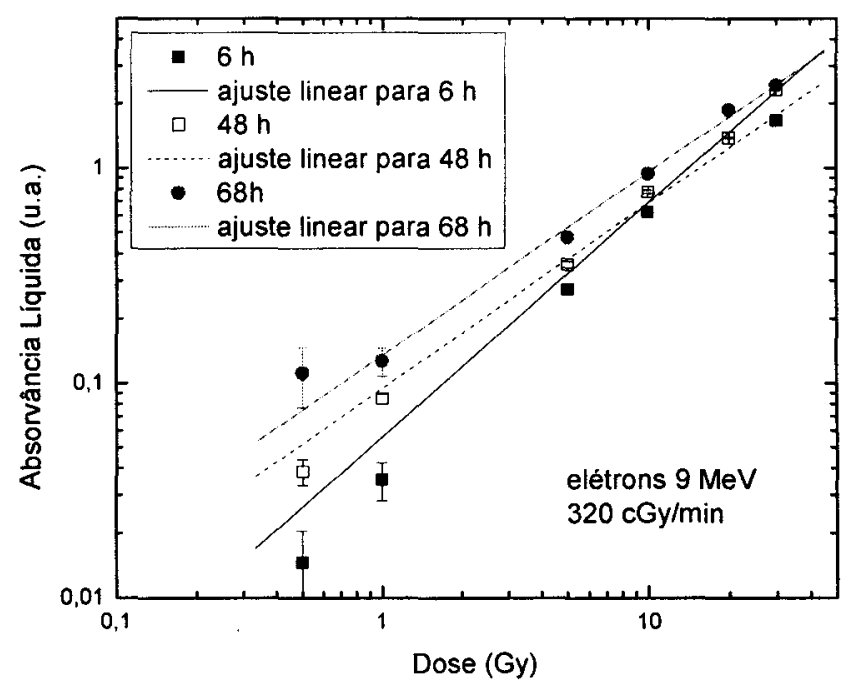

Figura 34 - Curvas de dose reposta de dosimetros FXG irradiados em diferentes tempos após o preparo.

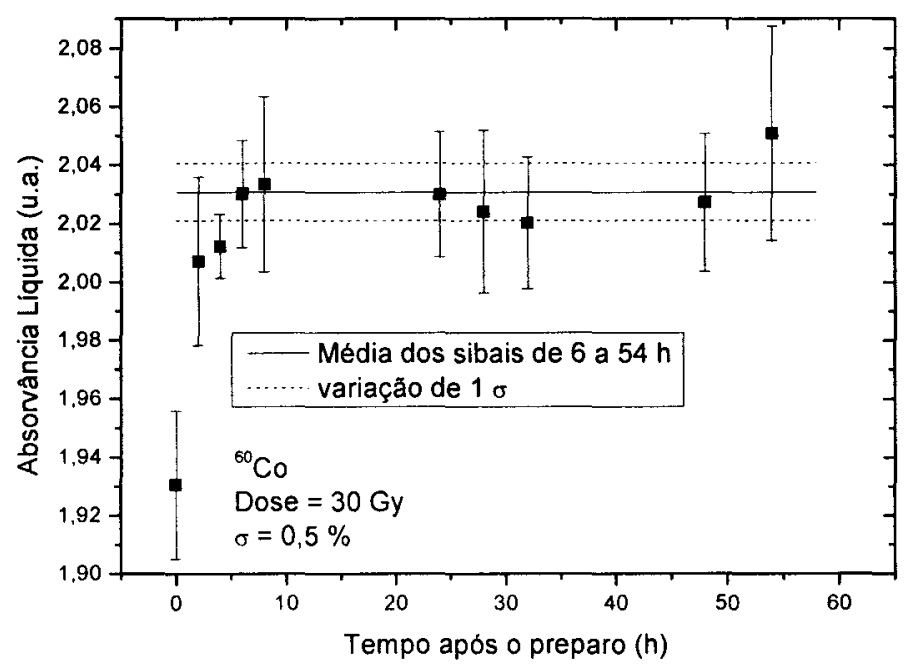

Figura 35 - Dependência da resposta do dosímetro FXG, irradiado com ${ }^{60} \mathrm{Co}$, em função do tempo após o preparo. 
Tabela 9 - Coeficientes do ajuste linear* da curva de dose resposta do FXG para irradiações com elétrons em diferentes tempos após o preparo

\begin{tabular}{ccc}
\hline Tempo (h) Coeficiente Linear & Coeficiente Angular \\
\hline 6 & $0,02 \pm 0,01$ & $0,06 \pm 0,01$ \\
48 & $-0,01 \pm 0,01$ & $0,08 \pm 0,01$ \\
68 & $0,10 \pm 0,01$ & $0,08 \pm 0,01$ \\
\hline
\end{tabular}

*todos $\operatorname{com} p<0,0002$

Dos resultados obtidos para irradiações com elétrons em diferentes tempos após o preparo, pode ser concluido que o coeficiente angular sofre alterações entre 6 e $48 \mathrm{~h}$ após o preparo, enquanto que o coeficiente linear se altera a partir de $48 \mathrm{~h}$. Como se espera o maior coeficiente angular possivel, para uma melhor sensibilidade e um valor de leitura nulo no ponto de $0 \mathrm{~Gy}$, concluí-se que o tempo ideal entre o preparo e a irradiação está entre 6 e 48h.

Analisando o experimento com a fonte de ${ }^{60} \mathrm{Co}$ observa-se que a partir de $10 \mathrm{~h}$ após o preparo não há mais variação significativa na resposta do dosimetro irradiado com $30 \mathrm{~Gy}$. Assim opta-se por adotar o período de $24 \mathrm{~h}$ entre o preparo e a irradiação como o ideal, pois uma imprecisão de até $12 \mathrm{~h}$ no horário de início da irradiação não acarretará em alterações na resposta do mesmo.

\subsection{Sistema alternativo de leitura}

A FIG.36 é a imagem fotográfica que alimentou a rotina computacional de análise de sinal, acrescida de uma escala para dosimetro FXG, relacionando cor e dose. Nesta imagem há uma matriz de cubetas, sendo que as quatro primeiras linhas são de dosimetros Gel de Alanina feitos por Cléber F. Silva e as quatro últimas de FXG. Apenas as informações referentes aos dosimetros FXG foram utilizadas neste trabalho. 


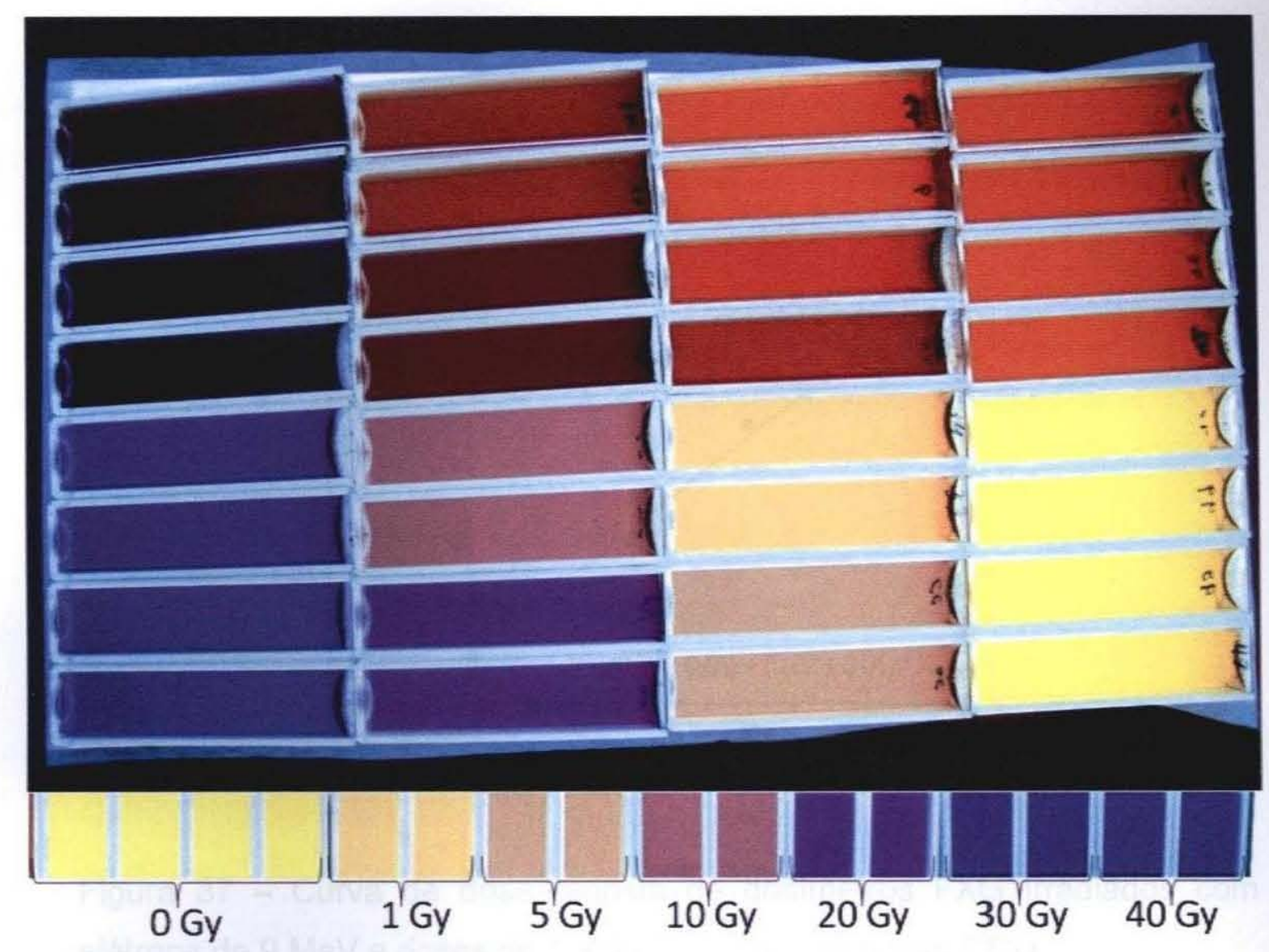

Figura 36 - Imagem fotográfica do dosímetro FXG e Alanina Gel utilizada para análise em rotina computacional, acrescida de uma barra de cores para FXG.

Com os dados obtidos da rotina computacional foram elaborados os gráficos contidos na FIG.37 e FIG.38 sendo que nesta ultima também foram utilizados dados espectrofotométricos. A FIG.37 é a curva de dose resposta do dosímetro FXG para a leitura CCD e a FIG.38 a comparação entre as intensidades das leituras com espectrofotômetro e com CCD, para as doses de 1, $5,10,20,30$ e 40 Gy. 


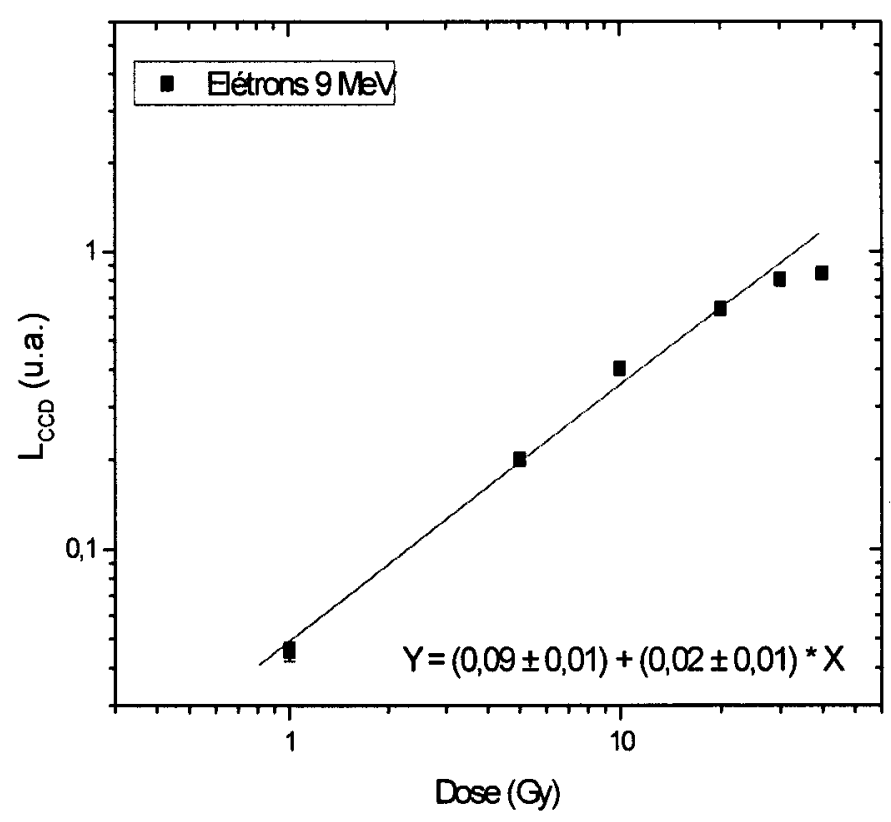

Figura 37 - Curva de dose reposta de dosímetros FXG irradiados com elétrons de $9 \mathrm{MeV}$ e doses de 1 a 40 Gy para leitura com CCD.

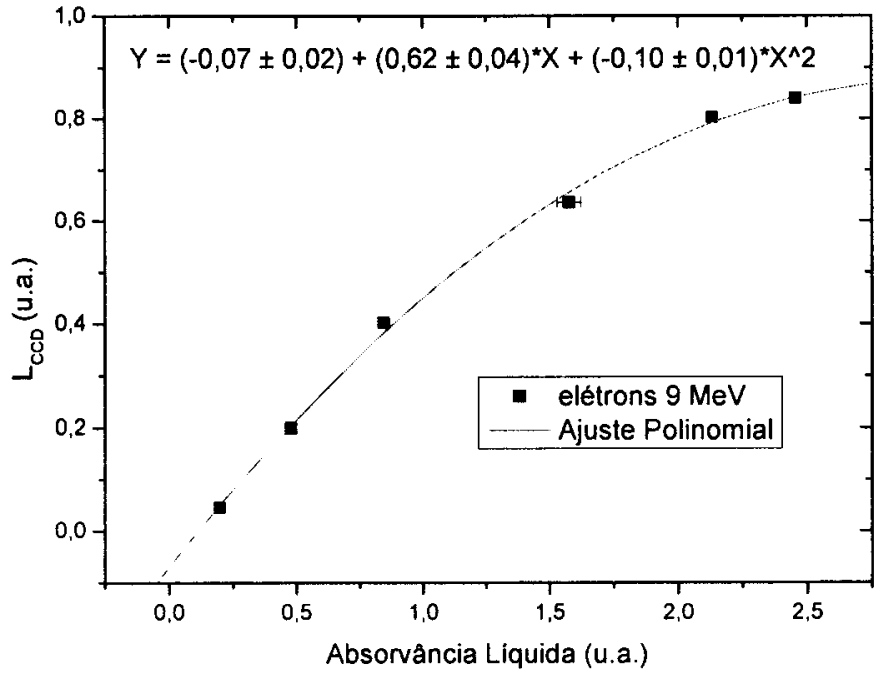

Figura 38 - Comparação entre as intensidades das leituras do dosimetro FXG para os dois sistemas de leitura. As doses analisadas foram 1, 5, 10, 20,30 e 40 Gy apresentadas no gráfico em ordem crescente de sinal.

Pela FIG.37 pode-se notar uma tendência de saturação do sinal a partir da dose de 30 Gy e um comportamento linear da leitura CCD com a dose. 
Em comparação com a intensidade de sinal do espectrofotômetro (FIG.38) pode-se afirmar que a saturação do sistema de leitura por CCD é com doses menores do que com o espectrofotômetro e que as intensidades das leituras também são maiores no sistema espectrofotométrico, como já era esperado (Minasawa, 2008).

\subsection{Aplicação do dosímetro FXG em dosimetria 3D para Braquiterapia de alta taxa de dose}

As curvas de isodose calculadas pelo software Brachyvision para o objeto simulador estão apresentadas na FIG.39.

A imagem obtida por CCD, do objeto simulador desmontado colocado em frente a um negatoscópio está apresentada na FIG.40.

Comparando a FIG.39 com a FIG.40 pode-se notar que a região mais escura em torno dos aplicadores na FIG.40 é muito semelhante ao contorno das isodoses calculadas apresentadas na FIG.39. Isto ficou ainda mais evidente quando o FXG foi fatiado em cortes axiais de aproximadamente $2 \mathrm{~cm}$ para a retirada do aplicador braquiterápico. A imagem destes cortes pode ser observada na FIG.41 e na FIG.42. 


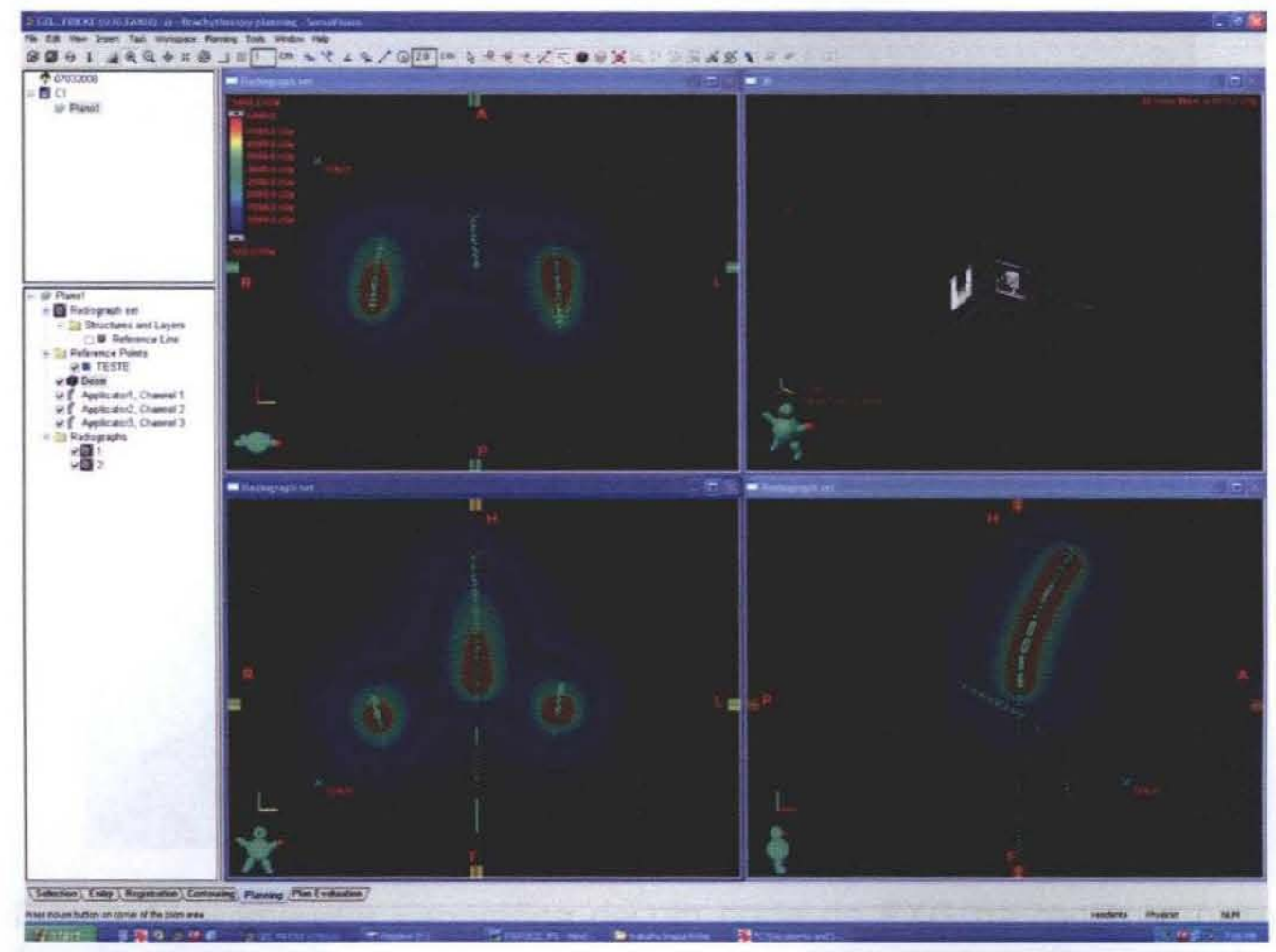

Figura 39 - Curvas de isosode geradas pelo software Brachyvision a partir de duas radiografias ortogonais do objeto simulador e da determinação das posições e tempo das paradas da fonte.

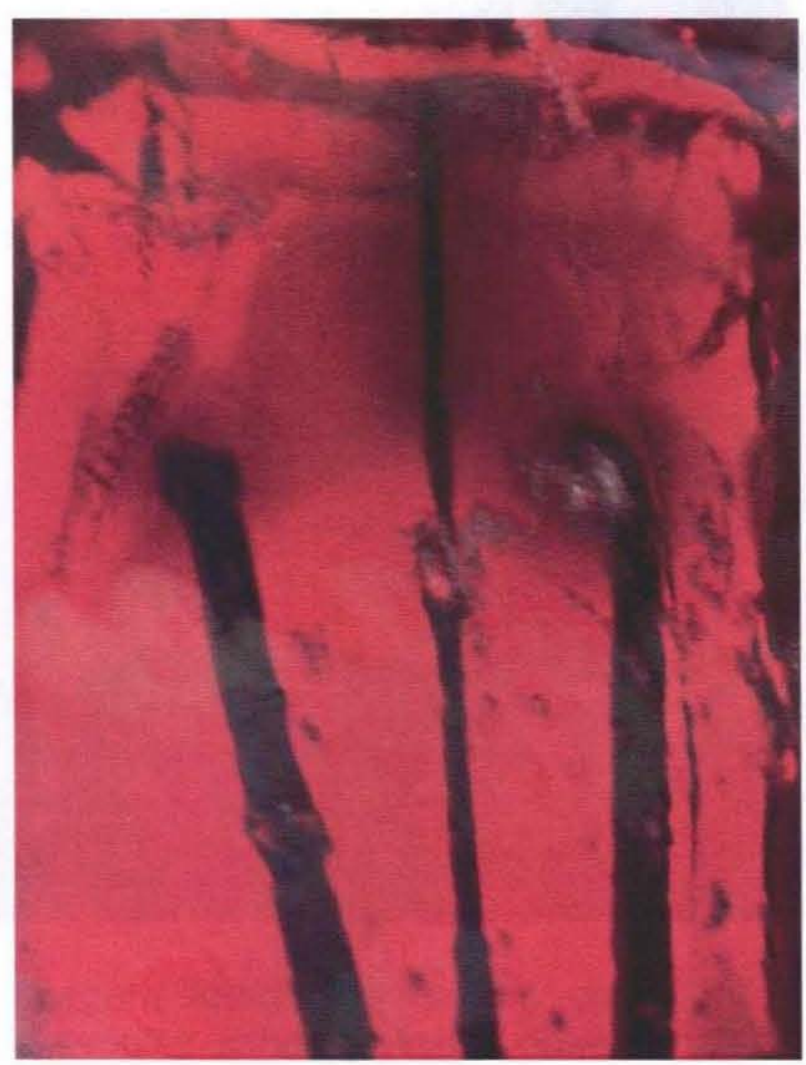

Figura 40 - Imagem fotográfica do objeto simulador desmontado (sem o pote plástico) após ser posicionado em frente a um negatoscópio. 


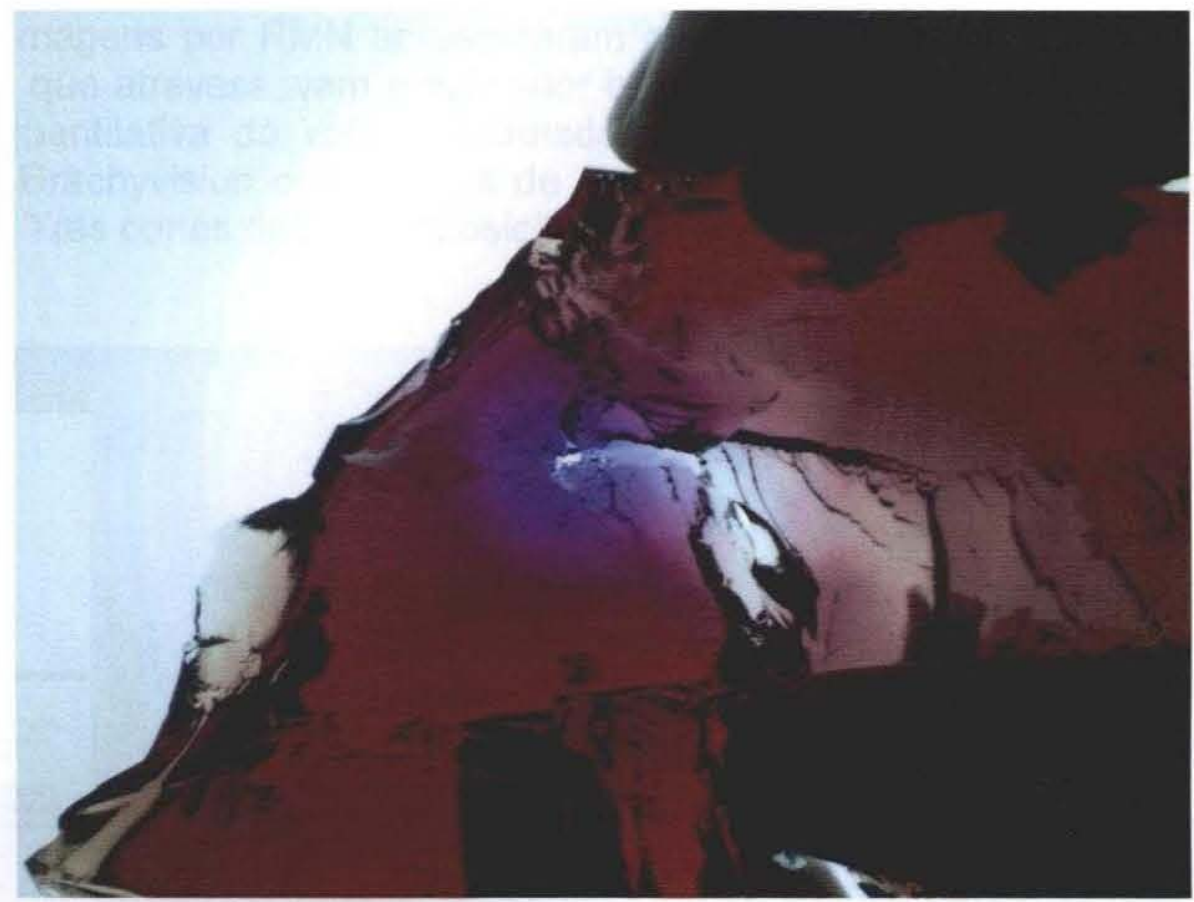

Figura 41 - Imagem fotográfica de um corte do FXG na região próxima ao fim da sonda intra-uterina sendo possível observar o orifício gerado pela retirada da sonda e também o gradiente de cor no gel gerado pela irradiação.

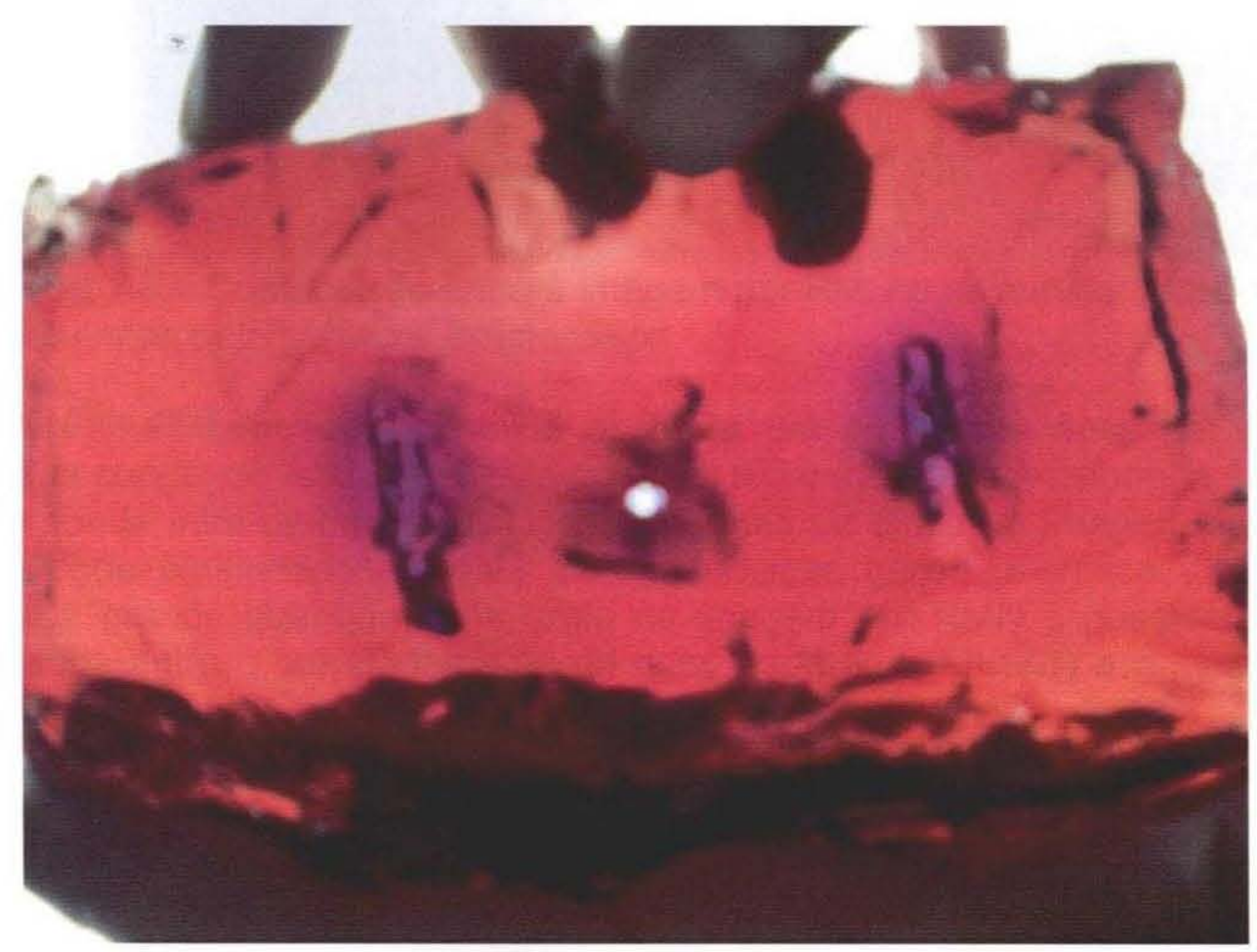

Figura 42 - Imagem fotográfica de um corte do FXG na região que compreende os ovódies sendo possivel observar os três orifícios gerados pela retirada do aplicador e também o gradiente de cor no gel gerado pela irradiação. 
As imagens por RMN apresentaram muitos artefatos de imagem em todos os cortes que atravessavam o aplicador braquiterápico, impossibilitando qualquer análise quantitativa do volume irradiado. Estas imagens foram carregadas no software Brachyvision e as curvas de isodose calculadas foram sobrepostas às imagens. Três cortes desta composição estão apresentados na FIG.43.

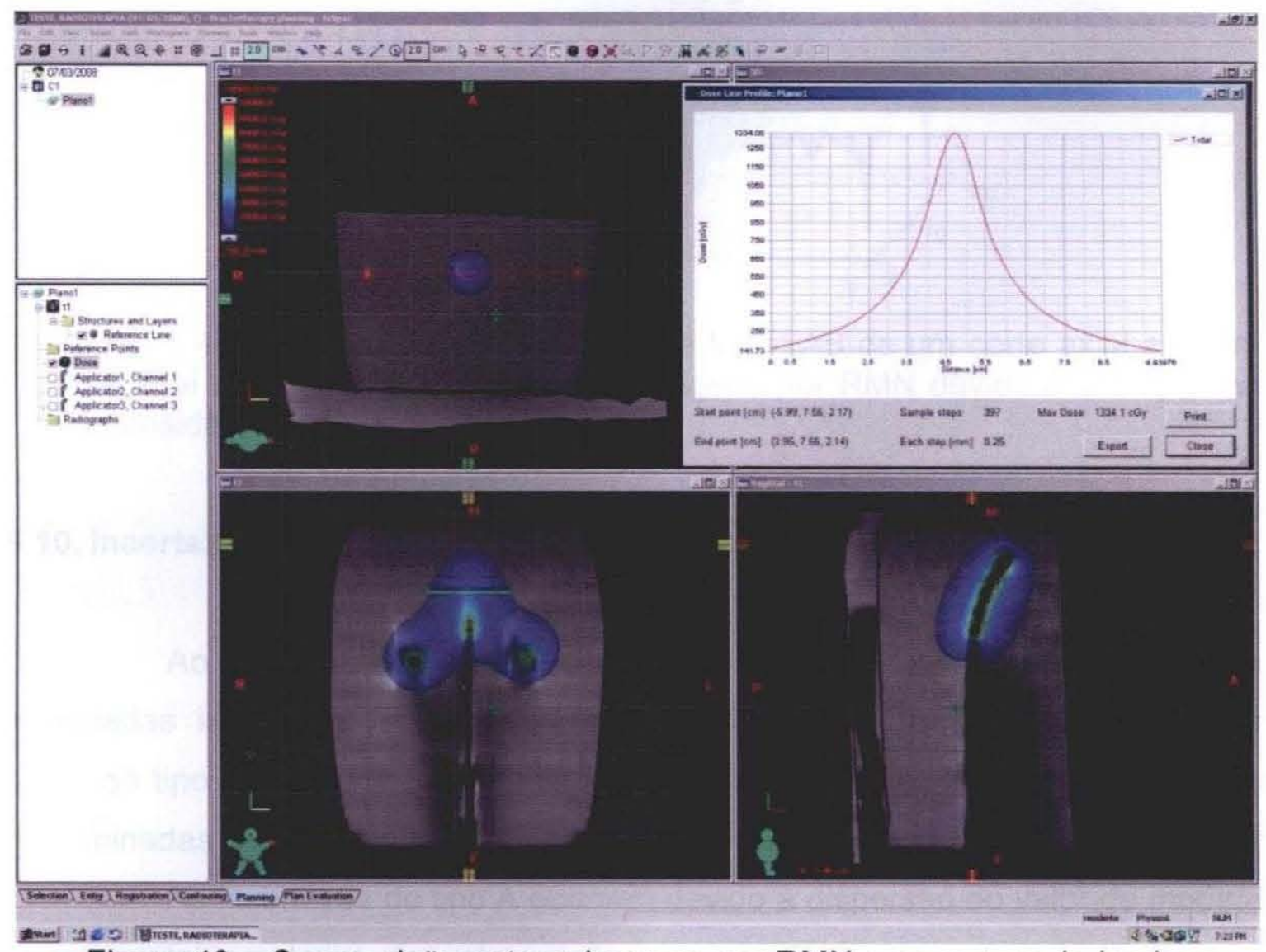

Figura 43 - Composição entre a imagem por RMN e as curvas de isodose calculadas pelo software Brachyvision.

Na FIG.43 também é possível observar um gráfico de dose por posição obtido das curvas de isodose calculadas para um corte unidimensional a $1 \mathrm{~mm}$ do final da sonda intra-uterina. A avaliação dos tons de cinza da imagem por RMN, em um corte bidimensional nesta mesma posição gerou o gráfico da FIG.44. Apesar da grande quantidade de ruído na imagem por RMN é possível notar a semelhança entre o comportamento da dose esperada (FIG.43) e o sinal obtido por RMN (FIG.44). 


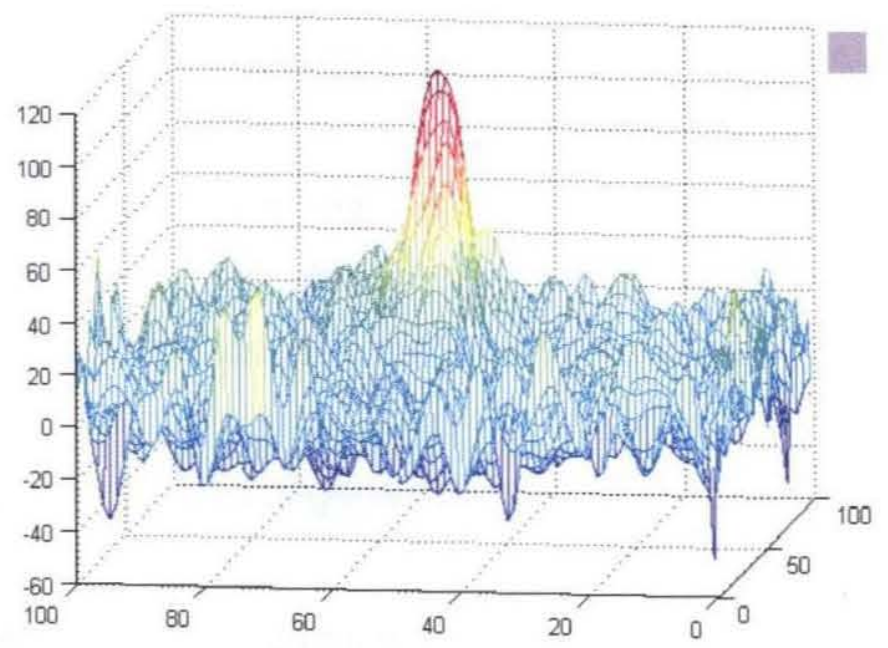

Figura 44 - Gráfico gerado no software MATLAB de um corte axial a $1 \mathrm{~mm}$ do final da sonda intra-uterina nas imagens por RMN devido a variação na intensidade do valor dos voxels.

\subsection{Incertezas nas medidas}

Ao tentar estimar o valor verdadeiro de uma medida experimental são associadas incertezas às medidas. Estas incertezas podem ser classificadas como do tipo $\mathrm{A}$, determinadas ou estimadas por método estatístico, e do tipo $\mathrm{B}$, determinadas ou estimadas por outros métodos (não-estatísticos).

As incertezas do tipo $\mathrm{A}$ ocorrem devido à dispersão do valor da medida experimental em torno do valor verdadeiro, ou seja, de caráter aleatório. As incertezas do tipo B são incertezas originadas de erros instrumentais, ambientais e observacionais que podem ser inferidas pelo experimentador, mas não podem ser matematicamente estabelecidas. A incerteza total das medidas é dada pela equação 9 (Vuolo, 1996).

$$
\sigma_{\text {Total }}^{2}=\sigma_{A}^{2}+\sigma_{B}^{2}
$$

Onde:

$\sigma_{\text {Total }}:$ Incerteza total;

$\sigma_{A}$ : Valor associado à incerteza tipo A;

$\sigma_{B}$ : Valor associado à incerteza tipo B. 
Pode-se supor que as origens das incertezas do tipo A são:

- Dispersão do valor da medida de Absorvância realizado no espectrofotômetro: é dado pelo desvio padrão de cada medida cuja ordem grandeza é equivalente a reprodutibilidade intra-lote do gel.

Pode-se supor que as origens das incertezas do tipo B são:

- Concentração dos reagentes na solução: estas variações acarretam apenas em erros sistemáticos na solução, pois a balança utilizada tem uma precisão de $\pm 0,0001$ (da ordem do empuxo do ar nos reagentes) e a vidraria utilizada é de alta precisão o que acarreta em pequenas alterações no rendimento químico da solução, não influenciando significantemente na resposta do gel (Galante, 2006).

- Tempo de estocagem do gel no refrigerador: para tempos entre $10 \mathrm{e}$ $50 \mathrm{~h}$, a variação da resposta do gel é da ordem da reprodutibilidade do gel, portanto esta incẽrteza pode ser desprezada.

- Tempo de translado (da retirada do refrigerador até a sala de irradiação) e tempo entre a irradiação e leitura das amostras: estas variações sistemáticas na resposta são devido a oxidação natural dos ions férricos presentes na solução FXG e que segundo os testes de estabilidade podem ser negligenciados para o intervalo de tempo estudado desde que seja observada a absorvância líquida do dosímetro;

- Leitura Espectrofotométrica: o espectrofotômetro utilizado possui uma precisão na leitura da absorvância de $\pm 0,0001$, valor muito menor que a reprodutibilidade intra-lote sendo esta incerteza desconsiderada;

- Dose Absorvida nas irradiações com ${ }^{60} \mathrm{Co}$ na GammaCell: é garantido, pelo CTR, uma homogeneidade de dose melhor que $2 \%$ dentro da cubeta e uma imprecisão de $\pm 1,7 \%$ no valor da dose, portanto estes são erros sistemáticos que podem ser negligenciados neste irradiador.

- Dose Absorvida nas irradiações nos aceleradores lineares: a precisão na dose absorvida na região de máxima dose é de 0,01 Gy e o gradiente 
de dose dentro da cubeta pode ser desconsiderado devido as características das curvas de PDP. Estas características também garantem que uma variação de até $2 \mathrm{~mm}$ na profundidade de irradiação não acarreta em uma variação estatística significativa no valor da dose absorvida (informações obtidas por comunicação interpessoal com os aprimorandos e físicos dos hospitais e pela observação das curvas de PDP dos aceleradores, estas curvas são de autoria dos físicos dos hospitais e sigilosas, e não puderam ser apresentadas neste trabalho);

- Dose Absorvida nas irradiações no $\mathrm{BH \# 3} \mathrm{do} \mathrm{reator} \mathrm{de} \mathrm{pesquisa} \mathrm{do}$ IEA-R1 do IPEN: neste irradiador há grandes imprecisões no tempo de inserção e retirada das amostras, devido as limitações físicas dos equipamentos, assim como na taxa de fluência dos nêutrons que apresenta uma pequena variação entre os ciclos de funcionamento do reator apesar da constância na potência (comunicação interpessoal com o prof. Dr. Paulo R. P. Coelho). Estas influências não foram consideradas por que a dose absorvida no FXG foi estimada por dosimetria LiF Albedo realizada pelo Centro de Engenharia Nuclear/IPEN e que apresenta imprecisão de menor que $10 \%$. 


\section{CONCLUSÕES}

- O espectro de absorção do dosímetro FXG irradiado com feixes clínicos e industriais de elétrons e com feixe clínico de nêutrons não apresentou variação na posição das bandas de absorvância em relação ao espectro de absorção do dosímetro irradiado com fótons.

- A reprodutibilidade do FXG intra e inter-lotes foram $1,4 \%$ e $5,1 \%$ respectivamente, podendo ser melhorada com a fabricação de volumes maiores e seleção dos dosímetros a serem irradiados.

- As características avaliadas para o dosímetro FXG desenvolvido no IPEN e seu desempenho permitem afirmar que seu uso em feixes clínicos de elétrons é tão satisfatório quanto para feixes clínicos de fótons, ou seja, apresenta linearidade no mesmo intervalo de dose e não apresenta variação na leitura em função do tipo de feixe incidente.

- A curva de dose reposta para um feixe industrial de elétrons apresentou um comportamento exponencial decrescente para doses entre 0,5 e $10 \mathrm{kGy}$.

- Foi possível comprovar a viabilidade na determinação na dose absorvida no feixe misto gama-nêutron do $\mathrm{BH} 3$ do reator nuclear IEA-R1.

- O sistema dosimétrico com a adição de ${ }^{10} \mathrm{~B}$ apresentou linearidade na curva de dose resposta para o feixe misto gama/nêutron para doses de até 50 Gy e com a subtração da dose gama a curva permaneceu linear, corroborando seu uso na dosimetria do feixe de nêutrons do $\mathrm{BH} \# 3$.

- A curva de dose resposta do sistema dosimétrico apresenta comportamento linear dentro dos limites de detecção, sendo que o LID foi estabelecido como 0,2 Gy e o LSD como 40 Gy, para energias de feixes clinicos de elétrons entre 4 e $15 \mathrm{MeV}$.

- A resposta do sistema dosimétrico não apresentou dependência quanto a energia (de 4 a $15 \mathrm{MeV}$ ) ou taxa de dose (de 80 a 400 cGy/min) do feixe clínico de elétrons. Também não foram encontradas diferenças significativas entre a reposta para feixe clínicos de elétrons ou fótons com energias de 6 ou $15 \mathrm{MeV}$.

- Os testes de estabilidade permitiram observar que os valores de absorvância líquida e conseqüentemente as curvas de dose resposta não 
apresentam variação significativa no periodo observado, apesar do sinal de absorvância aumentar com o tempo.

- Foi possível observar que a intensidade de resposta do FXG muda conforme o intervalo de tempo entre a fabricação e a irradiação para uma mesma dose, podendo ser estabelecido o período de $24 \mathrm{~h}$ como tempo ótimo entre a fabricação e a irradiação.

- O sistema de leitura baseado em CCD apresentou resposta linear com a dose no intervalo observado. As características inferiores da análise espectrofotométrica em relação a CCE (sensibilidade e saturação) não impedem nem desmotivam sua aplicação, pois o custo, a facilidade e a velocidade de obtenção dos valores do sinal são melhores no método CCD.

- O teste para aplicação do dosímetro FXG em dosimetria 3D para Braquiterapia de alta taxa de dose apresentou resultados que indicam a viabilidade de sua aplicação na dosimetria $3 D$ de tratamentos radioterápicos que apresentam distribuições com alto gradiente de dose como a braquiterapia, radioterapia conformacional, radioterapia $3 \mathrm{D}$ e radiocirurgia.

- A maior fonte de incertezas está associada ao desvio padrão das medições que está relacionado à reprodutibilidade do dosímetro.

Assim os resultados obtidos foram considerados suficientes para corroborar o uso do gel em simuladores para construção de curvas de isodose de feixes clínicos de elétrons. Também se pode utilizar o FXG desenvolvido no IPEN para avaliar a distribuição de dose 3D de campos radioterápicos mistos de fótons e elétrons uma vez que não foi observada variações na curva de dose resposta entre os dois feixes, além de indicar o seu uso na dosimetria 3D de feixes para Terapia por Captura de Nêutrons. 


\section{REFERÊNCIAS BIBLIOGRÁFICAS}

ATTIX, F. H. Introduction to radiological physics and radiation dosimetry. London.: John Willey \& Sons, 1986.

BALDOCK, C. Historical overview of the development of gel dosimetry: a personal perspective. Journal of Physysics, v. 56, p. 14-22, 2006.

BARTH, R. F.; CODERRE, J. A.; VICENTE, M. G. H.; BLUE, T. E. Boron Neutron Capture Therapy of Cancer: Current Status and Future Prospects. Clinical Cancer Research, v. 11, p. 3987-4002, 2005.

BERO, M.A.; GILBOY, W.B.; GLOVER, P.M. Radiochromic gel dosemeter for three-dimensional dosimetry. Radiation Physics and Chemistry, v. 61, p. 433-435, 2001.

BURN, K. W.; COLLI, V.; CURZIO, G.; D'ERRICO, F.; GAMBARINI, G.; ROSI, G.; SCOLARI, L. Characterisation of the TAPIRO BNCT epithermal facility. Radiation Protection Dosimetry, v. 110, p. 645-649, 2004.

CALCINA, C. S. G.; OLIVEIRA, L. N.; ALMEIDA, C. E.; ALMEIDA, A. Dosimetric parameters for small field sizes using Fricke xylenol gel, thermoluminescent and film dosimeters, and an ionization chamber. Physics in Medicine and Biology, v. 52, p. 1431-1439, 2007.

CAMERON, J. R; SUNTHARALINGAM, N; KENNEY, G. N. Thermoluminescent dosimetry. Madison, 1968.

CÁRDENAS, J. P. N.; MADI FILHO, T.; CAMPOS, L. L. Preliminary results of a dosimetric system to be applied in microdosimetry as a support instrument in operational routines in nuclear medicine and radiotherapy. In: 12th INTERNATIONAL CONGRESS OF THE INTERNATIONAL RADIATION PROTECTION ASSOCIATION, October 12-24, 2008, Buenos Aires. Proceedings... Buenos Aires: IRPA-12, 2008. 1 CD-ROM.

CAVINATO, C. C.; CAMPOS, L. L. Study of the stability, reproducibility and dose rate dependence of the fricke gel dosimeter developed at IPEN. In: INTERNATION NUCLEAR ATLATIC CONFERENCE 2007, Sept. 30 - Oct. 5, 2007, Santos. Proceedings... Santos, INAC 2007, 2007.

CHRIST, G. White polystyrene as a substitute for water in high energy photon dosimetry. Medical Physics, v. 22, p. 2097-2100, 1995. 
COMISSÃO NACIONAL DE ENERGIA NUCLEAR. Requisitos de

Radioproteção e Segurança para Serviços de Radioterapia. Rio de Janeiro:

CNEN, 1990. (CNEN-NE-3.06).

DAY, M. J. Radiation dosimetry using nuclear magnetic resonance: an

introductory review. Physics in Medicine and Biology, v. 35, p. 1605-1609, 1990.

DEWILTON, M.S. High power, high reliability, electron accelerators for industrial processing. Radiation Physics and Chemistry, v. 25, p. 643-

646,1985.EISBERG, R.; RESNICK. Fisica Quântica. Editora Campus, ed. 9, 1994.

FRICKE, H.; MORSE, S. The chemical action of Roentgen rays on dilute ferrosulphate solutions as a measure of dose. American Journal of

Roentgenology, Radium Therapy, and Nuclear Medicine, v. 18, p. 430-432, 1927.

GALANTE, A. M. S. ; CAMPOS, L. L. . Dose-Response Curves of Fricke Gel Dosimeter for Different Compounds Concentrations. In: XI CONGRESSO BRASILEIRO DE FÍSICA MÉDICA, 2006, Ribeirão Preto. Anais... XI Congresso Brasileiro de Física Médica, 2006.

GALANTE, A. M. S.; CAMPOS, L. L. Investigations of the Fricke Gel (FXG) Dosimeter Developed at IPEN Irradiated with ${ }^{60}$ Co Gamma Rays. In: INTERNATIONAL NUCLEAR ATLANTIC CONFERENCE 2007.

Sept. 30 - Oct 5, 2007, Santos. Proceedings... Santos, INAC 2007, 2007.

GALANTE, A. M. S., CAMPOS, L. L. Chemical dosimeters development at IPEN for the radiation process quality control. In: Aidan N. Camilleri. (Org.).

Radiation Physics Research Progress. Nova York: Nova Science Publishers, Inc, 2008 , v. 10 , p. $355-384$.

GAMBARINI, G.; BIRATTARI, C.; MONTI, D.; FUMAGALLI, M. L.; VAI, A.; SALVADORI, P.; FACCHIELLI, L.; SICHIROLLO, A. E. Fricke-infused agarose gel phantoms for NMR dosimetry in boron neutron capture therapy and proton therapy. Radiation Protection Dosimetry, v. 70, p. 571-575, 1997.

GAMBARINI, G.; AGOSTEO, S.; MARCHESI, P.; NAVA, E.; PALAZZI, P.; PECCI, A.; ROSI, G.; TINTI, R. Discrimination of various contributions to the absorbed dose in BNCT: Fricke-gel imaging and intercomparison with other experimental results. Applied Radiation and Isotopes, v. 53, p. 765-772, 2000.

GAMBARINI, G.; BIRATTARI, C.; COLOMBI, C.; PIROLA, L.; ROSI, G. Fricke Gel Dosimetry in Boron Neutron Capture Therapy. Radiation Protection Dosimetry v. 101, p. 419-422, 2002. 
GAMBARINI, G.; BIRATTARI, C.; Mariani, M.; Marchesini, R.; Pirola, L.; Prestini, P.; Sella, M.; Tomatis, S. Study of light transmittance from layers of Fricke-xylenol-orange-gel dosimeters. Nuclear Instruments and Methods in Physics Research Section B, v. 213, p. 321-324, 2004.

GAUER ,T.; ENGEL, K.; SOKOLL, J.; GROHMANN, C.; CREMERS, F. Planning Study for Funnel Breast Patients: Comparison between Tomotherapy and Electron IMRT using an Add-on Electron MLC. International Journal of Radiation Oncology Biology Physics, v. 72, p. S515 - S516, 2008.

GORE, J. C.; YANG, Y. S.; SCHULZ, R. I. Measurement of Irradiation Dose distribution by Nuclear Magnetic Resonance (NMR) Imaging. Physical Medical and Biology, v. 29, p. 1189-1197, 1984.

HUMPHRIES JR., S. Principles of Charged Particle Acceleration, Ed. John Wiley and sons, 1999.

IBBOTT, G. S. Applications of Gel Dosimetry. Journal of Physics: Conference Series 3, p. 58-77, 2004. doi:10.1088/1742-6596/3/1/007

ILIEV, V.; TOMOVA, D.; BILYARSKA, L.; PETROV, L. Photooxidation of xylenol orange in the presence of palladium-modified $\mathrm{TiO}_{2}$ catalysts. Catalysis

Communications, v. 5, p. 759-763, 2004.

INSTITUTO NACIONAL DE CÂNCER. Curso: Elétron na Radioterapia Rio de Janeiro, INCA, 2008. 1 CD-ROM.

INTERNATIONAL ATOMIC ENERGY AGENCY. Absorbed Dose Determination in External Beam Radiotherapy. An International Code of Practice for Dosimetry Based on Standards of Absorbed Dose to Water, Vienna, Apr. 2000. (TRS-398)

INTERNATIONAL COMMISSION ON RADIATION UNITS AND MEASUREMENTS. Tissue Substitutes in Radiation Dosimetry and Measurement, Bethesda, 1989. (ICRU 44)

JOHNS, H. E.; CUNNINGHAM, J. R. The physics of radiology. 4.ed. Springfield: Charles C Thomas, 1986.

KARZMARK, C. J.; NUNAN, C. S.; TANABE, E. Medical Electron Accelerators. New York: McGraw-Hill, 1993.

KHAN , F. M. Physics of radiation therapy. 2 ed. Baltimore: Williams \& Wilkins, 1994. 
KLEVENHAGEN, S. C. Physics and dosimetry of therapy electron beams. Madison, Wis.: Medical Physics Pub., 1993.

KNOLL, G. F. Radiation detection and measurement. 2. ed, New York: Wiley \& Sons, 1989.

MACDOUGALL, N. D.; PITCHFORD, W. G.; SMITH, M. A. A systematic review of the precision and accuracy of dose measurements in photon radiotherapy using polymer and Fricke MRI gel dosimetry. Physics in Medicine and Biology, v. 47, p. R107-R121, 2002.

MANGUEIRA, T. F.; SILVA, C. F.; COELHO, P. R. P.; CAMPOS, L. L. Gamma/Neutron Dose Evaluation Using Fricke Gel and Alanine Gel Dosimeters to be Applied in Boron Neutron Capture Therapy. In: 7th International Topical Meeting on Industrial Radiation and Radioisotope Measuremente Application, June 22-27, 2008, Praga. Proceedings... Praga: IRRMA 7th, 2007.

MANGUEIRA, T. F.; CAMPOS, L. L. Dose rate response analyses of FXG using spectrophotometric and MRI techniques. In: 12th International Congress of the International Radiation Protection Association, Ovtober 19-24, 2008, Buenos Aires. Proceedings... Buenos Aires: IRPA-12, 2008. 1 CD-ROM

MARYANSKI, M. J.; GORE, J. C.; KENNAN, R.; SCHULZ, R. J. NMR relaxation enhancement in gels polymerized and crosslinked by ionizing radiation: a new approach to 3D dosimetry by MRI. Magnetic Resonance Imaging, v. 11, p. 253-258, 1993.

MCLAUGHLIN, W. L.; BOYD, A. W.; CHADWICK, K. H.; MCDOLNALD, J. C.; MILLER, A. Dosimetry for radiation processing. London: Taylor \& Francis, 1989.

METCALFE, P.; KRON, T.; HOBAN, $P$. The physics of radiotherapy $X$-rays and electrons. Madison, Wl: Medical Physics, 2007.

MINASAWA, R. A.; SANTOS, L. E. R.; PARADA, M. A.;

DAGHASTANLI, K. R. P.; CIANCAGLINI, P.; DE ALMEIDA, A. Digital Image Analysis to Standardize a Photometric Method in Colorimetric Quantification. Instrumentation Science \& Technology, v. 36, p. 97-104, 2008.

NELMS, B. Positive change: Proton Therapy at the University of Florida. The decimal point, Florida, volume 2, issue 7, 2008.

SCHREINER,L .J. Review of Fricke gel dosimeters. Journal of Physics, v. 3, p. 9-21, 2004. 
SILVA, C.F.; CAMPOS, L.L. Stability and influence of dose rate in the signal response of alanine gel dosimeter. In: 16th INTERNATIONAL CONFERENCE ON DEFECTS IN INSULATING MATERIALS, August 24-29, 2008, Aracaju, SE. Proceedings... Aracaju: ICDIM-16, 2008.

TARTE, B. J.; JARDINE, P. A.; VAN DOORN, T.; NITSCHKE, K. N.; POULSEN, M. G. Development of a CCD array imaging system for measurement of dose distributions in doped agarose gels. Medical Physics, v. 24, p. $1521-1525,1997$.

TAUHATA, L, SALATI, I. P. A.,DI PRINZIO, R., DI PRINZIO, A. R. RADIOPROTEÇÃO E DOSIMETRIA: FUNDAMENTOS. $6^{\mathrm{a}}$ rev. RIO DE JANEIRO: IRD/CNEN, 2006.

UUSI-SIMOLA, J.; HEIKKINEN, S.; KOTILUOTO, P.; SERÉN, T.; SEPPÄLÄ, T.; AUTERINEN, I.; SAVOLAINEN, S. MAGIC polymer gel for dosimetric verification in boron neutron capture therapy. Journal of Applied Clinical Medical Physics. v. 8, p. 114-23, 2007.

VUOLO, J. H. Fundamentos da Teoria dos Erros. 2.ed. São Paulo: Edgar Blücher, 1996. 